\title{
Enantiomere Naturstoffe: Vorkommen und Biogenese
}

Jennifer M. Finefield, David H. Sherman, Martin Kreitman und Robert M. Williams*

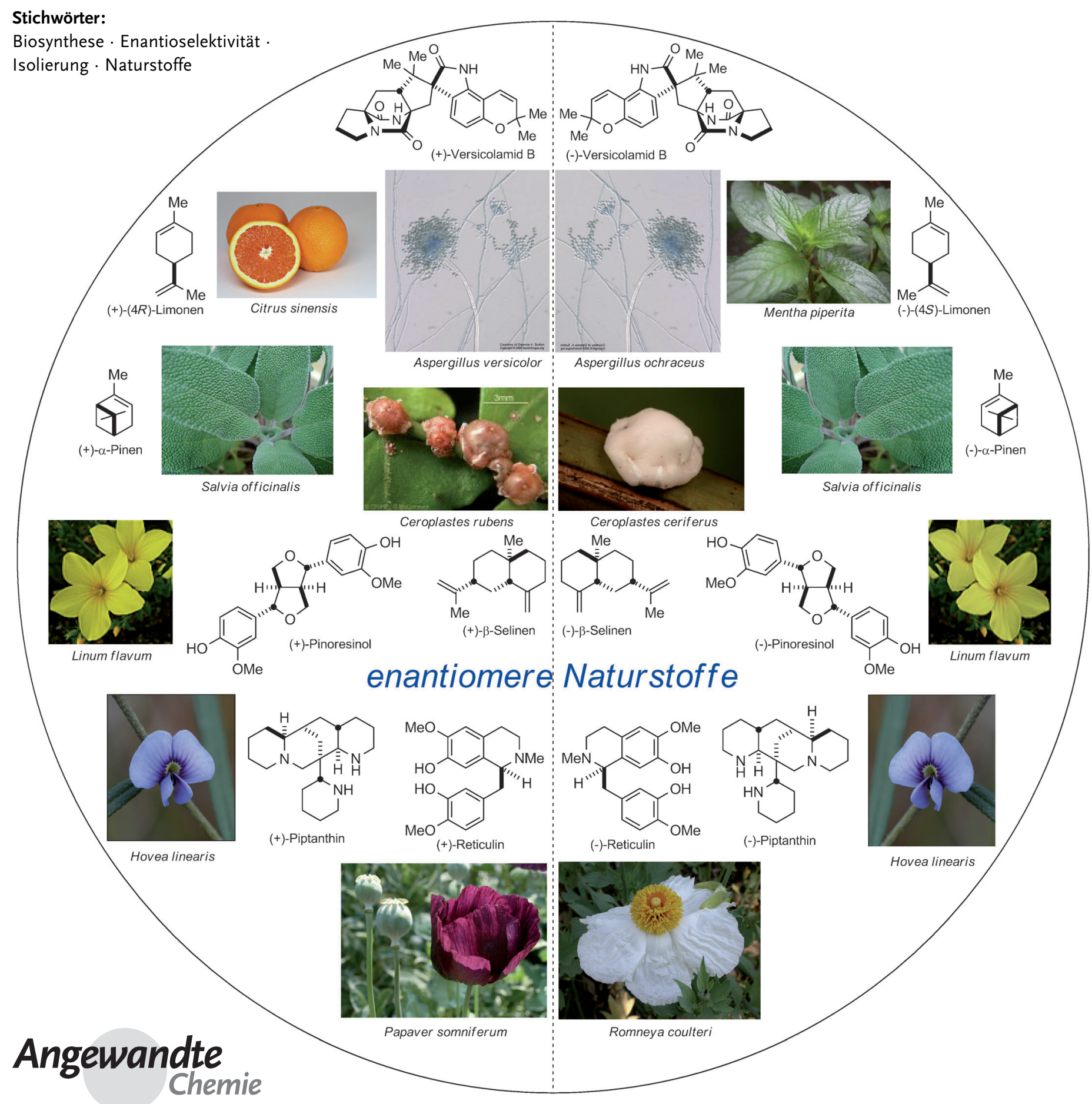


$I_{n}$ Form synthetisiert - manchmal entstehen aber auch beide Enantiomere. Solche enantiomeren Naturstoffe können von einer Art oder von verschiedenen Gattungen und/oder Arten gebildet werden. Intensive Forschungen wurden über viele Jahre durchgeführt, um die Biogenese natürlich vorkommender Enantiomere zu verstehen, doch viele faszinierende Rätsel und stereochemische Anomalien sind nach wie vor ungelöst.

\section{Einleitung}

Land- und Meerespflanzen, Tiere, Pilze, Bakterien und andere Organismen synthetisieren eine Vielzahl von Sekundärmetaboliten, die üblicherweise als „Naturstoffe“ bezeichnet werden. ${ }^{[1]}$ Während die Produktion von Metaboliten des Primärstoffwechsels, die dazu dienen, die Lebensvorgänge aufrecht zu erhalten, unabdingbar ist, können Organismen im Allgemeinen ohne die Synthese von Sekundärmetaboliten überleben. Allerdings unterstützen diese Metaboliten oft Reproduktions- und/oder Verteidigungsprozesse der Produzenten. $^{[2,3]}$ Aus medizinischer Sicht bieten die Naturstoffe eine reiche Quelle bioaktiver Substanzen, darunter auch solche mit Wirkungen gegen Tumoren, Bakterien, Insekten, Würmer, Nematoden oder mit immunsuppressiven Eigenschaften. Naturstoffe werden vielfach als Ausgangspunkte für die Suche nach und die Entwicklung von synthetischen und halbsynthetischen Wirkstoffen genutzt. ${ }^{[4,5]}$

In der weit überwiegenden Zahl der Fälle werden chirale Naturstoffe in der Natur in enantiomerenreiner Form hergestellt, d.h., im Produzenten entsteht nur ein Enantiomer. ${ }^{[1,6]}$ So wird in der Natur nur das biologisch aktive (-)Isomer von Morphin synthetisiert, und zwar spezifisch durch die Schlafmohn-Pflanze Papaver somniferum. ${ }^{[7]}$ Andererseits ist die Produktion und Isolierung enantiomerer Metaboliten bekannt, ist aber selten, wenn man sie in Relation zur weiten Verbreitung von Sekundärmetaboliten setzt. Diese Enantiomerenpaare können von verschiedenen Gattungen oder Arten gebildet werden, sodass das eine Enantiomer aus einer Art oder Gattung und das zweite Enantiomer aus einer anderen Art oder Gattung isoliert werden kann. Manchmal lassen sich auch auch beide Enantiomere aus einer einzigen Art, entweder als Racemat oder mit einem Enantiomerenüberschuss, isolieren. ${ }^{[6 a]}$

Seit über 75 Jahren bemühen sich Organiker und Biologen, die Biosynthesewege bioaktiver Naturstoffe aufzuklären. ${ }^{[2,4]}$ Die Biogenese enantiomerer Metaboliten ist im Allgemeinen aber noch schlecht verstanden. Dies liegt zum Teil daran, dass in vielen Fällen ein Enantiomer in der Natur gegenüber seinem Gegenstück dominiert, wie dies bei (-)-Nicotin und in vielen anderen Fällen gegeben ist, ${ }^{[8]}$ in denen das andere natürliche Enantiomer vielleicht erst Jahre oder Jahrzehnte später gefunden wird. Als Folge davon ist die Biosynthese des vorherrschenden und manchmal aktiveren Enantiomers gut untersucht, während die Biosynthese seines weniger verbreiteten Gegenstücks unbekannt bleibt.

\section{Aus dem Inhalt}

\begin{tabular}{lr}
\hline 1. Einleitung & 4887 \\
\hline 2. Terpene & 4887 \\
\hline \begin{tabular}{l} 
3. Phenylpropanoide \\
\hline 4. Polyketide
\end{tabular} & 4894 \\
\hline $\begin{array}{l}\text { 5. Alkaloide } \\
\text { G. Zusammenfassung und } \\
\text { Ausblick }\end{array}$ & 4900 \\
\hline
\end{tabular}

Mit diesem Aufsatz soll ein Überblick über das Vorkommen gut bekannter Sekundärmetaboliten, von denen beide Enantiomere in der Natur vorkommen, gegeben werden; wenn möglich, soll diskutiert werden, wie die seltenen Enantiomere gebildet werden. Wegen der unüberschaubaren Zahl bekannter Sekundärmetaboliten und der oft übersehenen Berichte über die optische Rotation oder die Circulardichroismus(CD)-Spektren von ähnlichen Substanzen aus unterschiedlichen Quellen wurden nicht alle enantiomeren Naturstoffe identifiziert. Außerdem sind trotz Jahrzehnte währender Forschung noch nicht alle Biosynthesewege zur Bildung enantiomerer Naturstoffe vollständig aufgeklärt; daher werden sich die biogenetischen Diskussionen auf solche Metaboliten konzentrieren, an denen bedeutsame und relevante Biosyntheseforschung betrieben wurde. Dieser Aufsatz ist nach Verbindungsklassen gegliedert, die auf den wichtigsten Biosynthesewegen beruhen: Terpene (Isoprene), Phenylpropanoide (Shikimisäure), Polyketide (Acetate) und Alkaloide (Aminosäuren). In vielen Fällen greift diese Einteilung allerdings zu kurz, weil viele Naturstoffe gemischten biosynthetischen Ursprungs sind (z.B. Terpenalkaloide oder gemischte Metaboliten aus Polyketid und nichtribosomalem Peptid).
[*] J. M. Finefield, Prof. Dr. R. M. Williams

Department of Chemistry, Colorado State University Fort Collins, CO 80523 (USA)

Prof. Dr. D. H. Sherman

Life Sciences Institute and Departments of Medicinal Chemistry, Microbiology \& Immunology, and Chemistry, University of Michigan Ann Arbor, MI 48109 (USA)

Prof. Dr. M. Kreitman

Department of Ecology and Evolution, University of Chicago 1101 East 57th Street, Chicago, IL 60637 (USA)

Prof. Dr. R. M. Williams

The University of Colorado Cancer Center

Aurora, CO 80045 (USA)

E-Mail:rmw@lamar.colostate.edu

Homepage: http://rwindigol.chm.colostate.edu/ 


\section{Terpene}

Terpene sind eine große Gruppe strukturell sehr unterschiedlicher Naturstoffe mit weit über 30000 Einzelverbindungen. ${ }^{[9,10]}$ Sie werden typischerweise aus einer großen Zahl von Pflanzenarten isoliert und zeigen umfangreiche biologische Aktivitäten, von Lockstoffen für bestäubende Insekten und chemischen Abwehrstoffen für Pflanzen bis zu ätherischen Ölen und Chemotherapeutika für medizinische Anwendungen. ${ }^{[10]}$ Alle Terpenoide entstehen durch wiederholte Kopf-Schwanz-Kondensation von $\mathrm{C}_{5}$-Isopreneinheiten und werden anhand der Zahl dieser Isoprenoideinheiten weiter in Familien unterteilt. Die Monoterpene $\left(\mathrm{C}_{10}\right)$ entsprechen dem kleinsten Strukturtyp, gefolgt von den Sesquiterpenen $\left(\mathrm{C}_{15}\right)$, den Diterpenen $\left(\mathrm{C}_{20}\right)$, den Sesterterpenen $\left(\mathrm{C}_{25}\right)$, den Triterpenen $\left(\mathrm{C}_{30}\right)$, den Tetraterpenen $\left(\mathrm{C}_{40}\right)$ und den Polyterpenen $\left(>\mathrm{C}_{40}\right)$.

Enantiomere Terpenoide kommen relativ häufig vor. Sie sind allgemein aber auf die Familien der Monoterpene, Sesquiterpene und in seltenen Fällen Diterpene beschränkt. Bislang sind (+)- und (-)-Wistarin die einzigen Beispiele für enantiomere Sesterterpene (Abbildung 1); ihre Biosynthese muss noch aufgeklärt werden. ${ }^{[11]}$ Es wurden umfangreiche Forschungen zur Aufklärung der Biosynthese enantiomerer Monoterpene durchgeführt, und während die Biosynthese der Sesquiterpene und Diterpene inzwischen verstanden wird, gibt es doch noch eine Reihe offener Fragen zur Bildung der enantiomeren Gegenstücke aus dieser Gruppe von Sekundärmetaboliten.
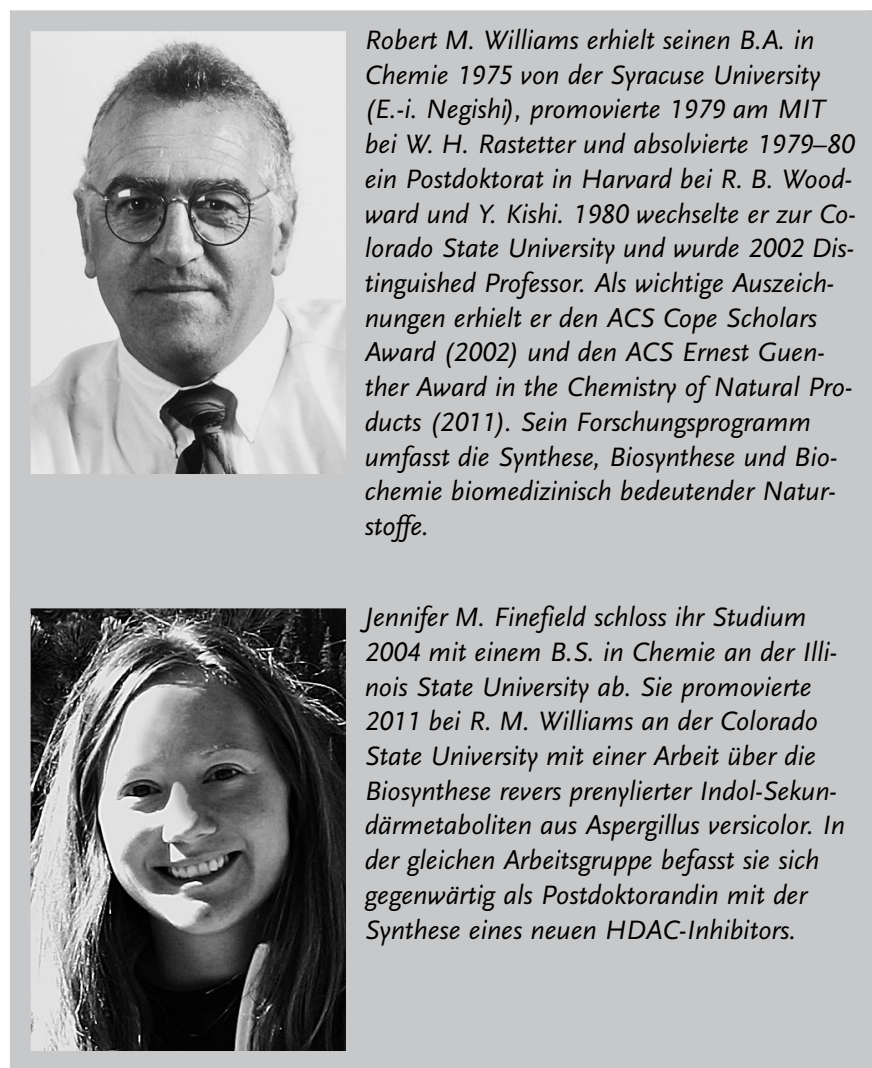

Jennifer M. Finefield schloss ihr Studium 2004 mit einem B.S. in Chemie an der Illinois State University ab. Sie promovierte 2011 bei R. M. Williams an der Colorado State University mit einer Arbeit über die Biosynthese revers prenylierter Indol-Sekundärmetaboliten aus Aspergillus versicolor. In der gleichen Arbeitsgruppe befasst sie sich gegenwärtig als Postdoktorandin mit der Synthese eines neuen HDAC-Inhibitors.

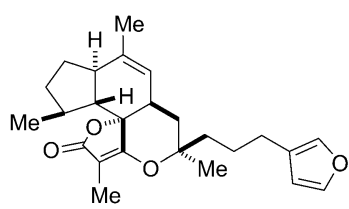

$(+)$-Wistarin

isoliert aus: Ircinia wistarii

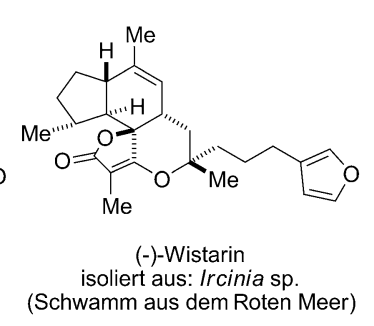

Abbildung 1. (+)- und (-)-Wistarin, die einzigen bekannten enantiomeren Sesterterpene.

\subsection{Monoterpene}

Verbindungen aus der Familie der $\mathrm{C}_{10}$-Monoterpene werden meist aus höheren Pflanzen isoliert, wo sie Duft- und Aromakomponenten vieler ätherischer Öle von Kräutern, Gewürzen, Zitrusfrüchten und Coniferen sind. ${ }^{[12]}$ Die Biosynthese von Monoterpenen wurde sorgfältig mithilfe von Isotopenstudien mit Enzympräparationen und durch Isolierung der cDNAs der Monoterpensynthasen untersucht, ${ }^{[13]}$ noch sind aber nicht alle Biosynthesewege, die zu Monoterpenen führen, völlig klar.

Über die Jahre wurde spezielles Augenmerk auf den stereochemischen Verlauf und Mechanismus der Cyclisierungsreaktionen gelegt. ${ }^{[10,14,13 a, 15]}$ Umfangreiche Forschungen haben ergeben, dass Monoterpensynthasen für die Bildung acyclischer, monocyclischer und bicyclischer Monoterpene verantwortlich sind und dass jede Synthase ein ganzes Spektrum von Produkten am gleichen aktiven Zentrum bilden

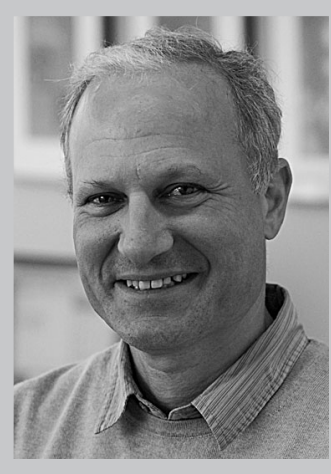

David H. Sherman erhielt 1978 seinen B.A von der UC Santa Cruz, promovierte 1981 und war Postdoktorand in Yale (1981-82) sowie am MIT (1982-84) bei H. Eisen. Jetz ist er Hans W. Vahlteich-Professor für medizinische Chemie, Professor für Chemie und Professor für Mikrobiologie und Immunologie an der University of Michigan. Er wurde u. a. mit dem ACS Cope Scholar Award (2009) und dem SI Charles Thom Award ausgezeichnet. Sein Interesse gilt der molekulargenetischen, biochemischen und bioorganischen chemischen Untersuchung mikrobieller Naturstoffbiosynthesen.

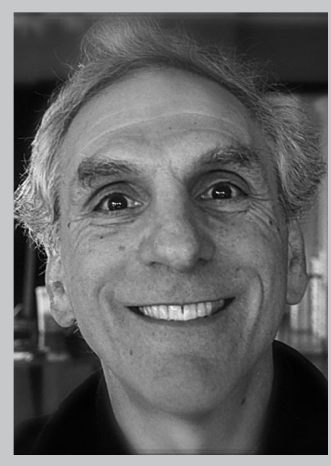

Martin Kreitman erhielt einen B.S. in Biologie 1975 von der Stony Brook University versity of Florida. Er promovierte 1983 in of Chicago. Zu seinen wichtigsten Auszeichnungen gehören das MacArthur Fellows Program 1991 und die Ernennung zum Fellow of the American Academy of Arts and Science im Jahr 2010. Sein zentrales Forschungsinteresse gilt den evolutionären Kräften, die die molekulare Variation und Evolubei G. Stork an der University of Columbia und den M.S. in Zoologie 1977 von der UniPopulationsgenetik in Harvard bei R. Lewontin und ist derzeit Professor an der University tion beherrschen. 
kann. Weil beide Monoterpen-Enantiomere in der gleichen Art häufig gleichzeitig auftreten, kam die Frage nach ihrer Biosynthese auf. Durch die Isolierung und Charakterisierung zahlreicher Cyclasen aus Salvia-, Mentha-, Tanacetum-, Foeniculum-, Pinus-, und Citrus-Arten einschließlich der (+)-Limonensynthase aus Mentha piperita (Pfefferminze), der (-)-Limonensynthase aus Carum carvi L. (Kümmel) und der (+)- und (-)- $\alpha$-Pinensynthasen aus Salvia officinalis (Salbei) konnte nachgewiesen werden, dass die MonoterpenEnantiomere unabhängig auf stereochemisch verschiedenen Stoffwechselwegen entstehen. Nicht alle Monoterpensynthasen sind jedoch streng stereospezifisch, wie man an der (-)-Limonensynthase aus Kümmelsamen sehen kann (siehe Abschnitt 2.1.1)..$^{[10,13 a]}$

Anhand der umfangreichen Arbeiten über Monoterpene ließ sich ein weithin akzeptierter Mechanismus für die Monoterpencyclisierung aufstellen (Schema 1). ${ }^{[10,13 a]}$ Zunächst bindet Geranyldiphosphat (GPP) stereoselektiv im aktiven Zentrum als rechts- oder linkshändiges helicales Konformer. GPP wird ionisiert und isomerisiert zum $(3 R)$ - oder zum $(3 S)$ Linalyldiphosphat (LPP). Eine zweite Ionisierung des enzymgebundenen $(3 R)$ - oder $(3 S)$-LPP leitet die C6-C1-Cyclisierung zum $\alpha$-Terpinylkation in der $(4 R)$ - oder $(4 S)$-Form ein. Von diesem universellen monocyclischen Zwischenprodukt aus können die zahlreichen Monoterpenstrukturen über vielfältige Mechanismen (weitere elektrophile Cyclisierung, Hydridverschiebungen oder Wagner-Meerwein-Umlagerungen) aufgebaut werden; die Reaktionssequenz wird schließlich durch eine Deprotonierung oder eine nucleophile Abfangreaktion beendet.

Wie in Tabelle $1 \mathrm{zu}$ sehen, werden viele chirale Monoterpene in beiden enantiomeren Formen gebildet und das oft von der gleichen Pflanzenart. Außerdem zeigen viele der enantiomeren Monoterpene eine spezifische biologische Aktivität, wobei jedes Enantiomer oft klar unterscheidbare biologische Eigenschaften aufweist. Die Aufklärung der Synthese enantiomerer Monoterpene wurde durch die Isolierung und Charakterisierung verschiedener Monoterpensynthasen weit vorangebracht. Im Folgenden werden drei gut untersuchte Biosynthesen von enantiomeren Monoterpenen (Limonen, Carvon und $\alpha$-Pinen) vorgestellt, für die verschiedene stereospezifische Enzyme identifiziert wurden, die die Cyclisie-

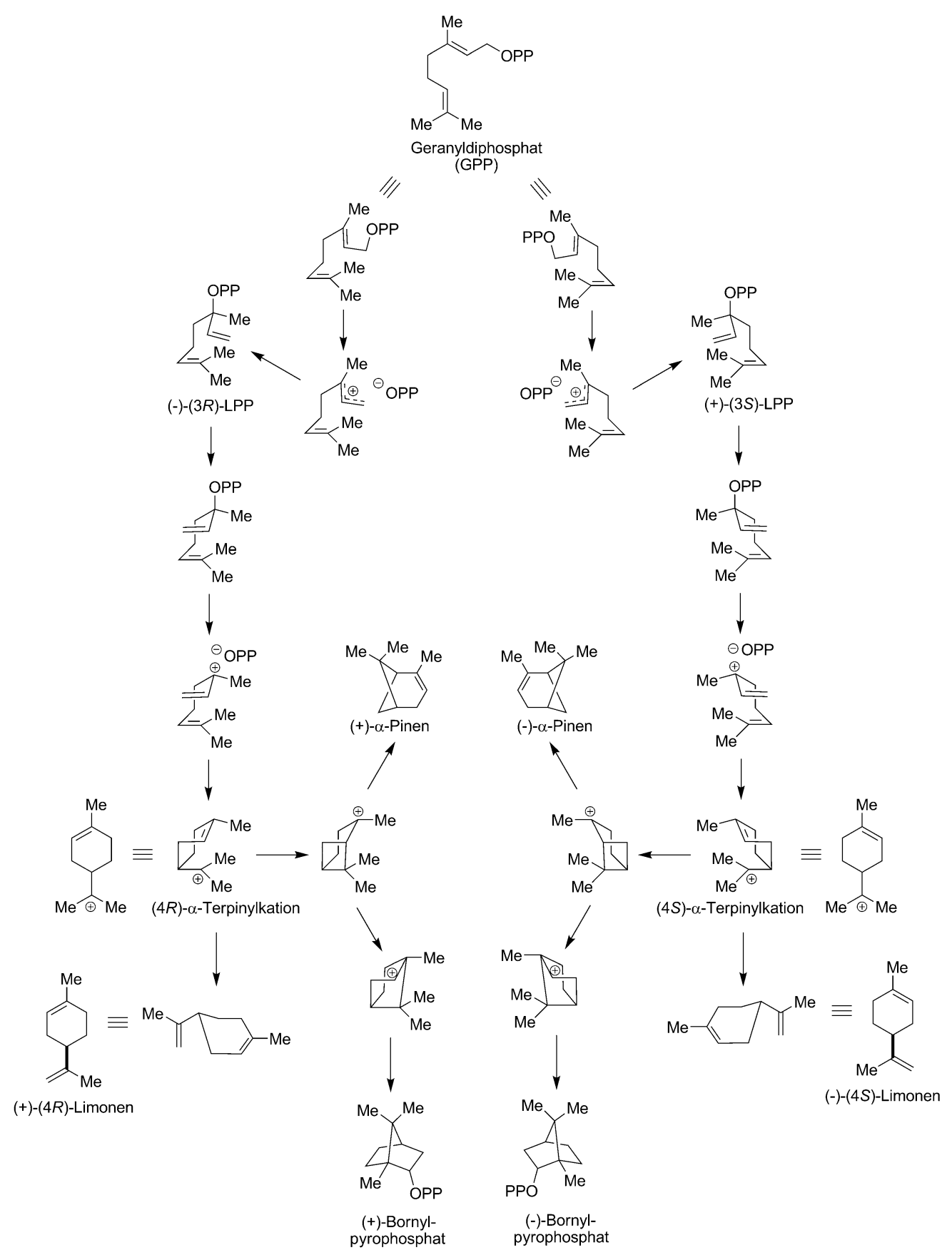

Schema 1. Enantiomere Biogenese ausgewählter Monoterpene. ${ }^{[15 a]}$ 
Tabelle 1: Vorkommen und biologische Aktivität enantiomerer Monoterpene.

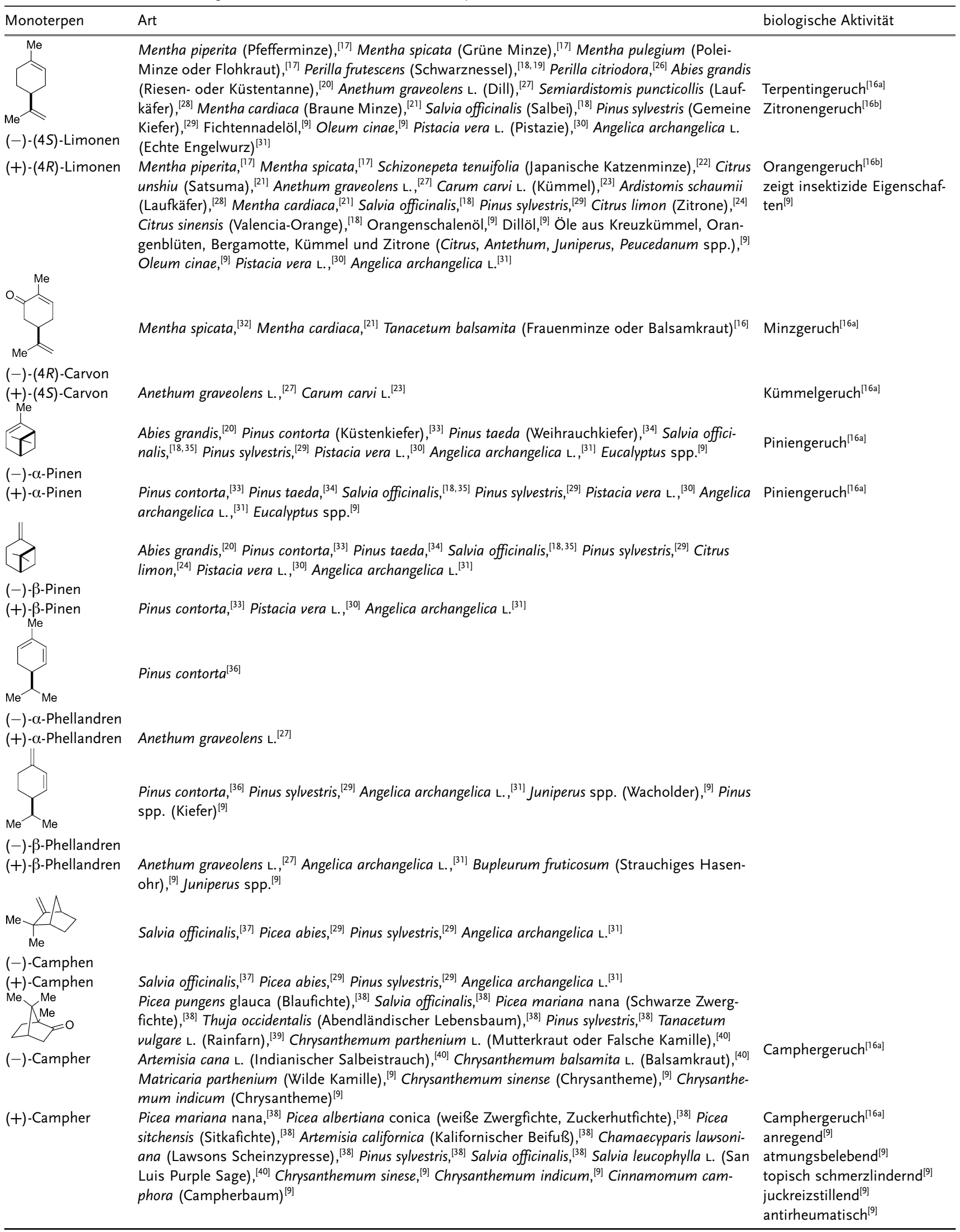


Tabelle 1: (Fortsetzung)

\begin{tabular}{|c|c|c|}
\hline Monoterpen & Art & biologische Aktivität \\
\hline $\begin{array}{l}\mathrm{Me} \\
\mathrm{Me} \\
\mathrm{M}_{\mathrm{OH}}\end{array}$ & $\begin{array}{l}\text { Thuja orientalis (Chinesischer Lebensbaum), }{ }^{[38]} \text { Thuja standishii (Japanischer Lebensbaum), }{ }^{[38]} \\
\text { Pinus sylvestris }{ }^{[29]}\end{array}$ & $\begin{array}{l}\text { Camphergeruch mit Holzno- } \\
\text { te }^{[16 b]}\end{array}$ \\
\hline $\begin{array}{l}(-) \text {-Borneol } \\
(+) \text {-Borneol }\end{array}$ & Picea sitchensis, ${ }^{[38]}$ Chamaecyparis lawsoniana, ${ }^{[38]}$ Pinus sylvestris, ${ }^{[29]}$ Salvia officinalis ${ }^{[38]}$ & $\begin{array}{l}\text { Camphergeruch mit erdig- } \\
\text { pfeffriger Note }\end{array}$ \\
\hline $\begin{array}{l}\text { Me } \\
(-) \text {-Sabinen } \\
(+) \text {-Sabinen }\end{array}$ & $\begin{array}{l}\text { Pinus sylvestris, }{ }^{[29]} \text { Angelica archangelica } \text { L. }^{[31]} \\
\text { Pinus sylvestris, }{ }^{[29]} \text { Salvia officinalis, }{ }^{[4]]} \text { Angelica archangelica } \text { L. }^{[31]}\end{array}$ & \\
\hline
\end{tabular}

rung von GPP zu den entsprechenden Monoterpenolefinen entgegengesetzter Konfigurationen katalysieren.

\subsubsection{Limonen und Carvon}

Limonen ist ein weit verbreitetes cyclisches Monoterpen und eine gemeinsame Vorstufe der Naturstoff-Familie der $p$ Menthole und des bekannten Monoterpens Carvon. Limonen und Carvon sind aus Sicht ihrer biologischen Aktivität insofern einzigartig, als jedes Enantiomer anders riecht. Das wohl bekannteste Beispiel dafür ist, dass (+)-Carvon nach Kümmel riecht und das Enantiomer nach Grüner Minze. ${ }^{[16 a]}$

Die beiden Limonen-Enantiomere, die in der Natur vorkommen, werden je nach Art entweder als einzelne Verbindung oder als Enantiomerengemisch synthetisiert. Limonen leitet sich von GPP ab, und aus zellfreien Extrakten und Enzympräparationen aus verschiedenen Arten wurden zwei unterschiedliche Limonencyclasen (-synthasen) identifiziert. $^{[4,15 \mathrm{~d}, 17-24]}$ In Schema 2 ist gezeigt, wie bei der Umsetzung

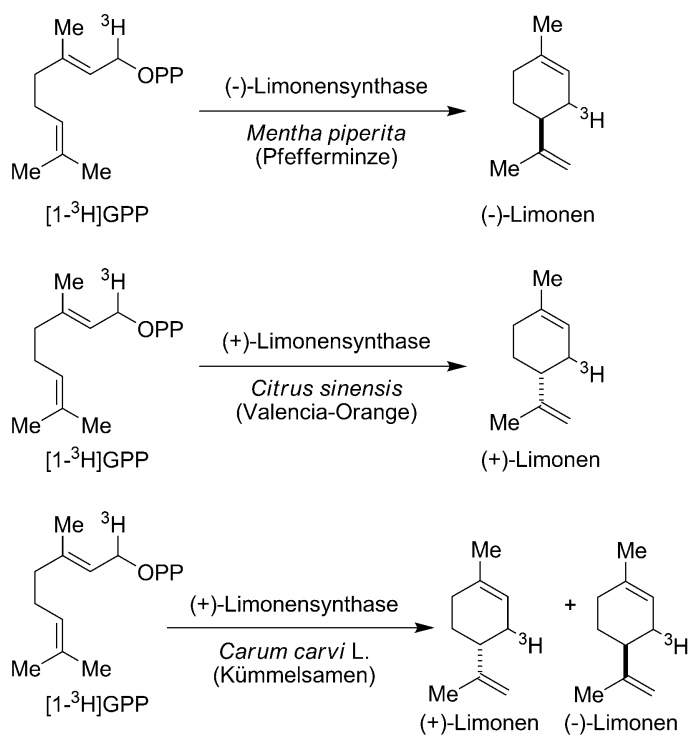

$98: 2$

Schema 2. Enantioselektive Biogenese von Limonen. von tritiummarkiertem GPP durch Limonensynthase aus Mentha piperita (Pfefferminze) und Mentha spicata (Grüne Minze) (-)-[ $\left.{ }^{3} \mathrm{H}\right]$ Limonen entsteht. ${ }^{[17]}$ Andererseits erhält man durch die Umsetzung von tritiummarkiertem GPP mit einer Präparation der löslichen Limonencyclase aus Citrus sinensis (Valencia-Orange) enantiomerenreines (+)-Limonen. ${ }^{[18]}$ Wenn auf vergleichbare Art tritiummarkiertes GPP durch eine Limonensynthase aus Carum carvi L. (Kümmelsamen) umgesetzt wird, fällt ein Gemisch von (+)- und (-)Limonen von 98:2 an, was darauf schließen lässt, dass das Enzym aus Kümmelsamen die Bildung von (+)-Limonen

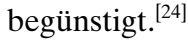

Carvon ist ebenfalls ein cyclisches Monoterpen, von dem beide Enantiomere isoliert wurden. Durch Studien zum Einbau von Vorstufenverbindungen und durch Enzympräparationen konnte Limonen als Biosynthesevorstufe von Carvon bestätigt werden. ${ }^{[17 a, 23,25]}$ Zwei Serien enantioselektiver Enzyme für die Umwandlung von (+)- oder (-)-Limonen zu (+)- bzw. (-)-Carvon wurden isoliert und charakterisiert. Wie in Schema 3 gezeigt, wurden die (-)-Limonen-6-hydroxylase und die (-)-trans-Carveoldehydrogenase in Mentha spicata (Grüne Minze) gefunden, die die enantioselektive Umwandlung von (-)-Limonen in (-)-trans-Carveol und anschließend in (-)-trans-Carvon katalysieren. ${ }^{[25]}$ Während diese Enzyme hoch stereospezifisch sind, sind die entsprechenden enantiomeren Enzyme aus Carum carvi $\mathrm{L}$. nicht vollständig stereo- oder substratspezifisch. Beide LimonenEnantiomere sind Substrate für die (+)-Limonen-6-hydroxylase, und wenn $(+)$-Limonen allein mit dem Enzym umgesetzt wurde, entstanden nur $97 \%$ des erwarteten $(+)$-transCarveols. Die restlichen $3 \%$ waren eine Mischung aus (-)trans- und (-)-cis-Carveol. Carveoldehydrogenase zeigt eine moderate Substratspezifität, ersichtlich aus der Umwandlung von nicht nur (+)-trans-Carveol zu (+)-Carvon, sondern auch von (-)-cis-Carveol zu (-)-Carvon.

\subsubsection{Pinen}

$\alpha$ - und $\beta$-Pinen sind verbreitete bicyclische Monoterpene und Hauptbestandteile des ätherischen Öls von Salvia officinalis (Gemeiner Salbei). ${ }^{[18,35]}$ Beide Enantiomere von $\alpha$ Pinen sind Naturstoffe und können gemeinsam vorkommen, 

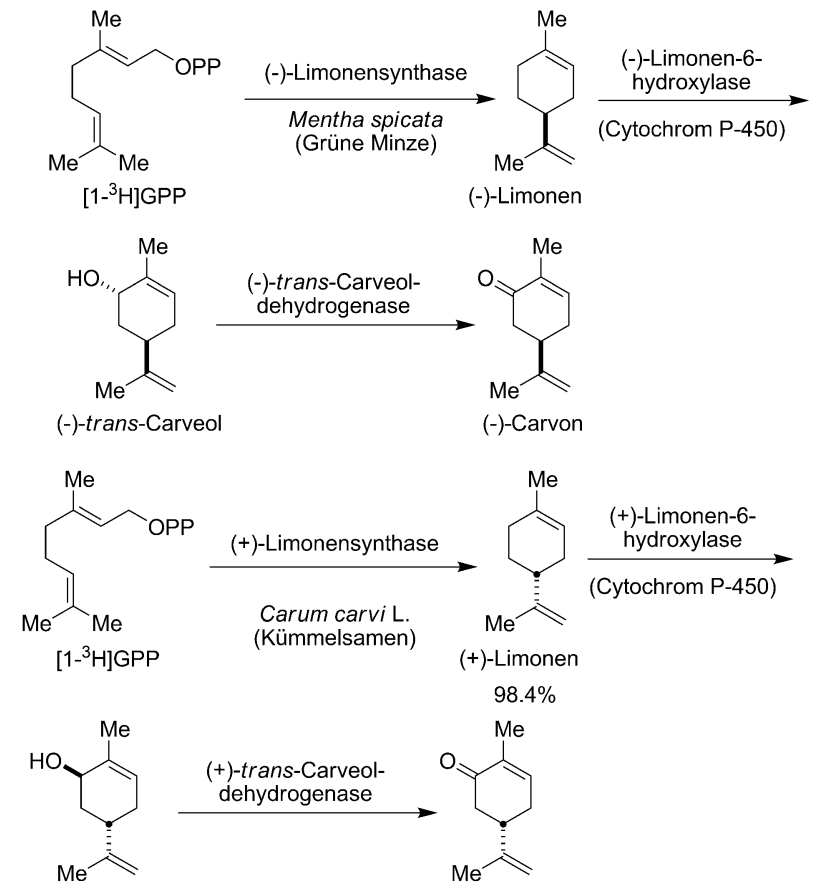

(+)-trans-Carveol (+)-Carvon

$97 \%$

$2.5 \%=(-)$-trans

$0.5 \%=(-)-c i s$

Schema 3. Enantiomere Biosynthese von Carvon.

wobei jedes der beiden Enantiomere überwiegen kann. Im Unterschied dazu wird $\beta$-Pinen fast ausschließlich als enantiomerenreine (-)-Isoform isoliert. Auch das $(+)-\beta$-Pinen wurde gefunden, allerdings selten. ${ }^{[30,31,33]}$ Biosyntheseuntersuchungen von Croteau und Gambliel in den 1980er Jahren zeigten, dass in Salvia officinalis zwei enantiomere Pinencyclasen nebeneinander vorkommen, die (+)-Pinencyclase (Cyclase I) und die (-)-Pinencyclase (Cyclase II). ${ }^{[42]}$ Wenn $\left[{ }^{3} \mathrm{H}\right] \mathrm{GPP}$ mit jeder Cyclase getrennt umgesetzt wurde, entstanden die jeweils entsprechenden $\alpha$-Pinen-Enantiomere (Schema 4). Außerdem wurde bei der Reaktion mit Cyclase II auch (-)- $\beta$-Pinen gebildet, während $(+)-\beta$-Pinen bei keiner der Cyclasereaktionen nachgewiesen werden konnte. Bei diesen Reaktionen wurden auch geringe Anteile von (+)und (-)-Camphen und Limonen als Gemische mit einem Enantiomerenüberschuss von $80 \%$ (+)-Camphen und $55 \%$ (-)-Limonen gebildet. ${ }^{[35,42,43]}$

\subsection{Sesquiterpene}

Die Sesquiterpene sind eine Gruppe aus vielfältigen acyclischen und cyclischen $\mathrm{C}_{15}$-Terpenen, die aus zahlreichen Pflanzen-, Pilz-, Bakterien-, Insekten- und marinen Arten isoliert werden können. Wie die Monoterpene finden sich auch die Sesquiterpene oft in ätherischen Ölen wie Vetiveröl und Cubeböl und haben reichhaltige pharmakologische Wirkungen. ${ }^{[44,45]}$ Leider wird in den meisten Fällen nicht die optische Drehung der Sesquiterpene mitgeteilt, und so bleibt eine entscheidende Information zur biologischen Aktivität unbekannt.

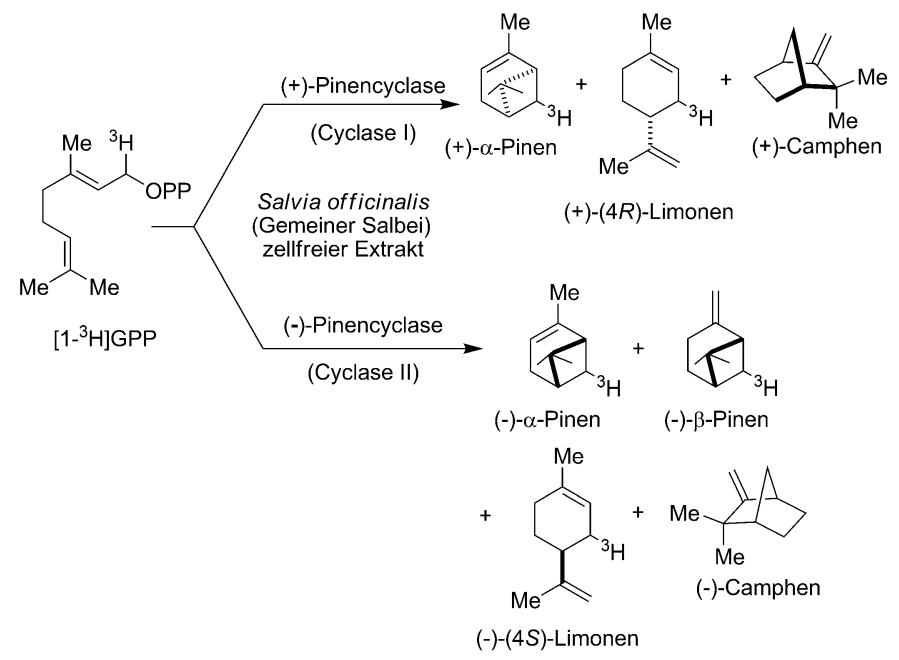

Schema 4. Enantioselektive Pinencyclasen.

Während der letzten zwanzig Jahre sind zahlreiche Sesquiterpensynthasen isoliert und charakterisiert worden, darunter die zur Synthese von 5-Epiaristolochen, ${ }^{[46]}$ Epiubenol, ${ }^{[47]}$ Pentalen, ${ }^{[48]}$ Germacren $C,{ }^{[49]} \gamma$-Humulen ${ }^{[49]}$ und $\delta$-Selinen, ${ }^{[50]}$ und die Reaktionsmechanismen dieser Enzyme wurden ebenso untersucht: $;^{[11,45,51]}$ dennoch gelang es meist nicht, die Biosynthese von enantiomeren Sesquiterpenen aufzuklären. Vor Kurzem isolierten und charakterisierten König et al. zwei enantioselektive Germacren-D-Synthasen aus Solidago canadensis (Goldrute).$^{[4,45]}$ Das Vorkommen dieser beiden Cyclasen in S. canadensis hilft, die Bildung der beiden Germacren-D-Enantiomere in dieser Art zu erklären und stützt auch die Möglichkeit, dass die Biosynthesewege anderer enantiomerer Sesquiterpene auf mehrere enantioselektive Enzyme in unterschiedlichen Arten der gleichen Gattung zurückgehen.

Die meisten Sesquiterpene sind chiral, und einige werden in beiden enantiomeren Formen gebildet. ${ }^{[44]}$ Im Allgemeinen werden enantiomere Sesquiterpene von unterschiedlichen Arten der gleichen Gattung produziert (Tabelle 2); es gibt jedoch wichtige Ausnahmen, wie das Vorkommen beider Enantiomere von Germacren D in Solidago canadensis und S. altissima. ${ }^{[45,52]}$ Ein anderes einzigartiges Beispiel ist die Isolierung der beiden Furodysinin-Enantiomere aus dem Hornschwamm Dysidea herbaceae. Die (+)-Isoform wurde aus $D$. herbaceae isoliert, den man vor Australien gesammelt hatte ${ }^{[53]}$ während die (-)-Form von der gleichen Art produziert wird, die allerdings vor den Fidschi-Inseln gesammelt wurde. ${ }^{[54]}$ Ebenfalls beobachtet wurde, dass aus terrestrischen und marinen Quellen manchmal die entgegengesetzten Sesquiterpenisomere isoliert wurden. Ein Beispiel dafür ist die Isolierung verschiedener Sesquiterpene aus der Weichkoralle Sinularia mayi. Sieben der wichtigsten Metaboliten, die aus S. mayi isoliert wurden, waren die enantiomeren Gegenstücke zu den verbreiteteren Formen aus terrestrischen Quellen. ${ }^{[55]}$ Dies ist sehr wahrscheinlich eine allgemeine Erscheinung, doch wird die stereochemische Untersuchung mariner Sesquiterpene oft vernachlässigt. ${ }^{[56]}$ 
Tabelle 2: Enantiomere Sesquiterpene.

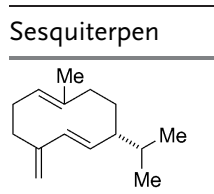

(+)-Germacren D

(-)-Germacren D

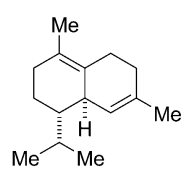

(+)- $\delta$-Cadinen

(-)- $\delta$-Cadinen<smiles>CC1=CC2(C)C(C(C)C)CCC(C)(O)C2(O)CC1</smiles>

(+)-Epicubenol

(-)-Epicubenol

$\mathrm{Me}$<smiles>CC1=CC23C=C(C)[N+]=C2CCC(C(C)O)C3CC1</smiles>

(+)-ठ-Amorphen

$(-)$ - $\delta$-Amorphen<smiles>Cc1ccc2c(c1)C(C(C)C)CCC2C</smiles>

(+)-Cadina-3,5-dien

(-)-Cadina-3,5-dien

$\mathrm{Me}$

$C_{M e}$

(+)-Calamenen (trans)

$(-)$-Calamenen (trans) Leptospermum scoparium, ${ }^{[70]}$ Piper cubeba (Kubebenpfeffer $)^{[70]}$

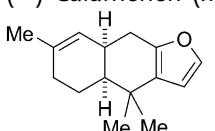

Dysidea sp. (mariner Schwamm), ${ }^{[72]}$ Dysidea herbaceae (mariner Schwamm, Australien) ${ }^{[53]}$

$(+)$-Furodysinin

(-)-Furodysinin<smiles>CC1(C)CCCC2(C)C1CCC1(C)Oc3ccc(O)cc3CC12C</smiles>

Ceroplastes rubens (rote Schildlaus), ${ }^{[57]}$ Dendropanax trifidus M. ${ }^{[58]}$ Sinularia mayi (Weichkoralle), ${ }^{[55]}$ Preissia quadrata (Lebermoos), ${ }^{[59]}$ Solidago altissima (Goldrute), ${ }^{[52]}$ Solidago canadensis (kanadische Goldrute), ${ }^{[60]}$ Podocarpus spicatus (Steineibe), ${ }^{[6]]}$ Zingiber officinale (Ingwer) ${ }^{[60]}$

Ceroplastes ceriferus (Wachsschildlaus), ${ }^{[57]}$ Solidago altissima ${ }^{[52]}$ Solidago canadensis, ${ }^{[60]}$ Pogostemon cablin (Patschulikraut), ${ }^{[60,62]}$ Pseudotsuga japonica (Japanische Douglasie), ${ }^{[9]}$ Araucaria bidwillii (Queensland-Araukarie), ${ }^{[63]}$ Vitis vinifera (Weinrebe) ${ }^{[60]}$ Populus trichocarpa $\mathrm{x}$ deltoides (Kalifornische Pappel) ${ }^{[60]}$

Araucaria bidwillii, ${ }^{[63]}$ Carum carvi L. ${ }^{[64]}$ Gossypium arboreum (Baumwollstrauch), ${ }^{[60]}$ Gossypium hirsutum (Hochland-Baumwolle), ${ }^{[60]}$ Mentha piperata ${ }^{[9]}$

Ceroplastes ceriferus, ${ }^{[57]}$ Sinularia mayi ${ }^{[55]}$ Araucaria araucana (Affenschwanzbaum), ${ }^{[63]}$ Araucaria bid-

Streptomyces sp. LL-B7, ${ }^{[66]}$ Heteroscyphus planus, ${ }^{[65]}$ Scapania undulata (Lebermoos), ${ }^{[64]}$ Juniperus rigida (Igel-Wacholder), ${ }^{[67]}$ Streptomyces sp. B-7 ${ }^{[68]}$

Cubeböl, ${ }^{[69]}$ Juniperus rigida, ${ }^{[67]}$ Cedrus atlantica (Atlaszeder) ${ }^{[9]}$

Leptospermum scoparium (Südseemyrte) ${ }^{[70]}$

Vetiveria zizanioides (L. Nash ex Small) (Vetiveröl) ${ }^{[1]}$

Conocephalum conicum (Kegelkopfmoos) ${ }^{[70]}$

Leptospermum scoparium, ${ }^{[70]}$ Kubebenpfefferö| ${ }^{[70]}$

Ceroplastes ceriferus, ${ }^{[57]}$ Conocephalum conicum ${ }^{[70]}$ willii, ${ }^{[63]}$ Carum carvi L. ${ }^{[64]}$ Heteroscyphus planus ${ }^{[65]}$ schnecke) ${ }^{[74]}$

fraßhemmend, ${ }^{[74]}$ fischtoxisch ${ }^{[74]}$

(+)-Chromazonarol

(-)-Chromazonarol 
Tabelle 2: (Fortsetzung)

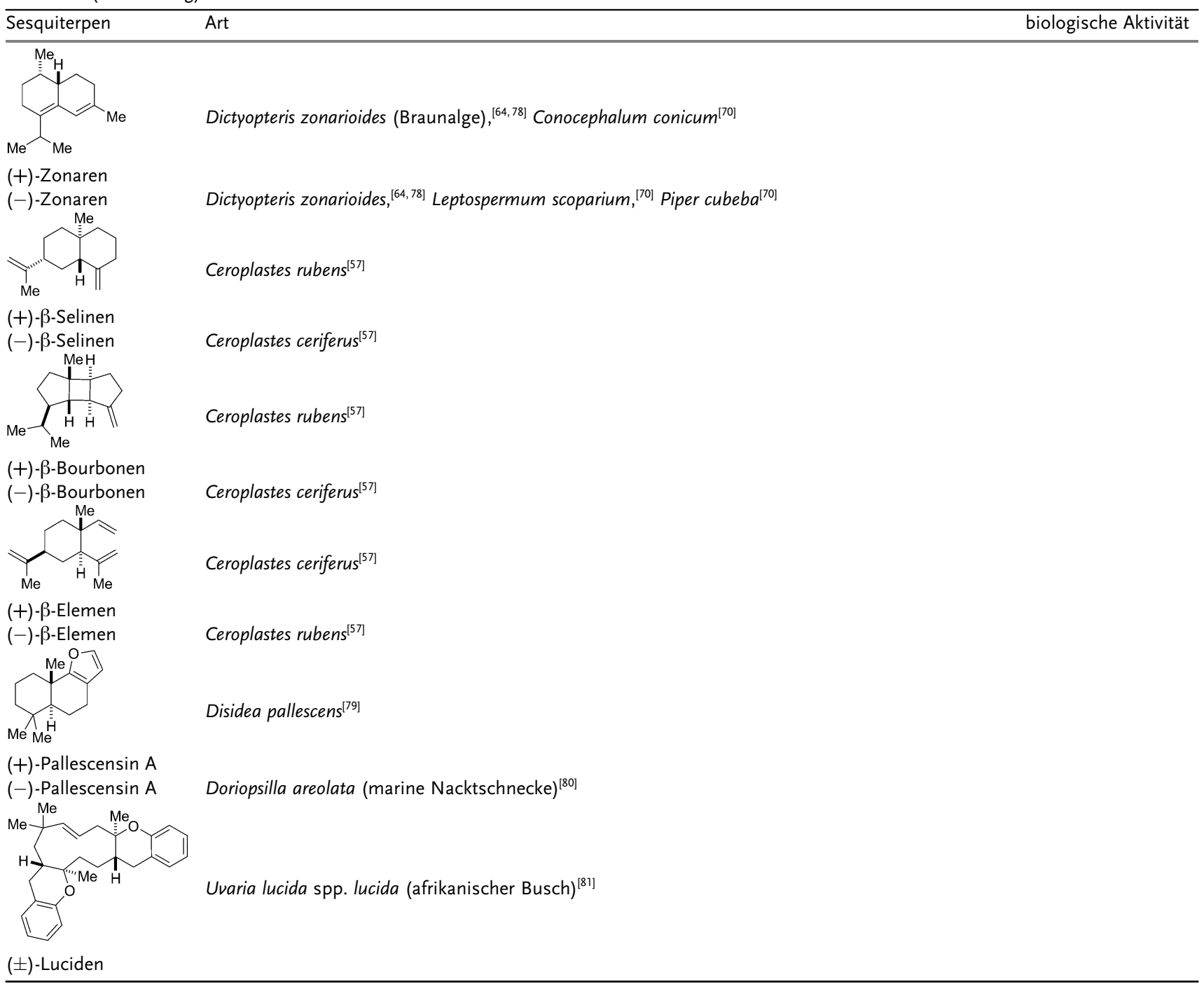

\subsection{Diterpene}

Diterpene kommen in vielen Pflanzen und Pilzen und dort im Allgemeinen in Harzen und ätherischen Ölen vor. Die strukturell vielfältige Familie der Diterpene enthält ein $\mathrm{C}_{20^{-}}$ Gerüst, das durch die Kondensation von drei Äquivalenten Isopentenylpyrophosphat (IPP) mit Dimethylallylpyrophosphat (DMAPP) zur acyclischen Geranylgeranyldiphosphat(GGPP)-Vorstufe entsteht. ${ }^{[10]}$

Ähnlich den Monoterpenen und Sesquiterpenen wurden ebenfalls enantiomere Diterpene isoliert, auch wenn sie relativ selten vorkommen (Tabelle 3). Die Bildung beider Enantiomere verschiedener Diterpene kann innerhalb derselben Art oder - häufiger - in verschiedenen Arten derselben Gattung vorkommen. Leider wurden keine Untersuchungen über die Biosynthese enantiomerer Diterpene veröffentlicht. Außerdem wurden keine biologischen Aktivitäten individueller enantiomerer Diterpene gefunden. Wie im Fall der Sesquiterpene wird auch bei der Isolierung der Diterpene die optische Drehung allgemein nicht bestimmt, und daher fehlen Informationen über das Vorkommen und die biologische Aktivität enantiomerer Diterpene.

\section{Phenylpropanoide}

Phenylpropanoide kommen in vielen Pflanzenarten vor und haben wichtige Funktionen bei Verteidigung, Strukturund Pigmentbildung sowie Vermehrung. ${ }^{[85]}$ Die Phenylpropanoide entstehen über den Shikimisäureweg und umfassen eine sehr große Zahl von Sekundärmetaboliten, die aus LPhenylalanin und/oder L-Tyrosin synthetisiert werden. ${ }^{[3]} \mathrm{Li}$ gnine, Lignane, Flavonoide, Cumarine, Chinone, Stilbene, Catechin, Aurone und Neoflavonoide sind nur einige der vielen Typen von Phenylpropanoiden, die durch die enzymatische Umwandlung von Phenylalanin zum Schlüsselintermediat $p$-Cumaroyl-CoA $(\mathrm{CoA}=$ Coenzym $\mathrm{A})$ über den allgemeinen Phenylpropanoidsyntheseweg gebildet werden. ${ }^{[86]}$ 
Tabelle 3: Diterpene.

Pacrydium intermedium (Bergkiefer), ${ }^{[82]}$
Araucaria araucana ${ }^{[63]}$

$(+)$-16-Kauren

(-)-16-Kauren

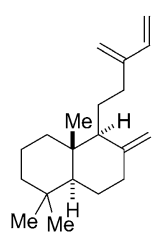

Dacrydium intermedium T. KIRK, ${ }^{[82]}$ Araucaria bidwillii, ${ }^{[63]}$ Araucaria araucana, ${ }^{[63]}$ Araucaria heterophylla ${ }^{[63]}$

Dacrydium intermedium, ${ }^{[82]}$ Araucaria bidwillii, ${ }^{[63]}$ Araucaria heterophylla $a^{[63]}$

\section{(+)-Sclaren}

(-)-Sclaren
Ein intensiv untersuchter Lignantyp sind die frühen $9\left(9^{\prime}\right)$ oxygenierten Lignane (Pinoresinol, Lariciresinol, Secoisolariciresinol und Matairesinol). Diese kommen entweder als enantiomerenreine Verbindungen oder als Enantiomerengemische mit unterschiedlichem Enantiomerenverhältnis vor. ${ }^{[91]}$ Aus Tabelle 4 lassen sich verschiedene Trends bezüglich dieser natürlich vorkommenden Lignane ableiten: Furofuran und Furanlignane sind noch nie in enantiomerenreiner Form isoliert worden, während alle mit HPLC an chiraler Phase analysierten Dibenzylbutyrolactonlignane optisch rein waren. Außerdem hängt es von der Pflanzenart ab, welches Enantiomer der Furofuran-, Furan- und Dibenzylbutanlignane vorherrscht. ${ }^{[91]}$ Auch die optische Drehung der enantiomerenreinen Dibenzylbutyrolactonlignane schwankt zwischen den verschiedenen Pflanzenarten. ${ }^{\text {[92] }}$

Wie alle Phenylpropanoide entstehen die Lignane über den Zimtsäureweg. Die Biosynthese von 9(9')-oxygenierten Lignanen ist einer der am intensivsten untersuchten Lignanstoffwechselwege. Die ersten fünf Schritte wurden ausführlich erforscht, und die meisten Enzyme für die Transformation und Erzeugung der Enantiomerenvielfalt in diesen Lignantypen wurden isoliert und charakterisiert. Inzwischen sind mehrere enantioselektive, Lignan produzierende Enzyme isoliert und charakterisiert worden. Wie in Schema 5 gezeigt, werden die $9\left(9^{\prime}\right)$-oxygenierten Lignane durch enantioselektive Dimerisierung von zwei Coniferylalkoholresten durch eine Oxidase in Gegenwart eines dirigierenden Proteins $\mathrm{zu}$ Pinoresinol mit einem Überschuss an einem Enantiomer gebildet. Das Protein hilft bei der Kontrolle der Stereospezifität bei der bimolekularen Phenoxyradikalkupplung der beiden Coniferylalkoholeinheiten. ${ }^{[92]}$ Als nächstes wird Pinoresinol stereoselektiv zu Lariciresinol reduziert, das anschließend durch die Pinoresinol/Lariciresinolreduktase wiederum stereospezifisch reduziert wird. Zwei Isoformen dieses Enzyms wurden isoliert und weisen entgegengesetzte Enantioselektivität auf (Schema 6).

$(+)$-Pinoresinol/ $(+)$-Lariciresinolreduktase wurde aus Forsythia intermedia und Thuja plicata isoliert, während man (-)-Pinoresinol/(-)-Lariciresinolreduktase in Thuja plicata fand. ${ }^{[94,95]}$ Mit Einbaustudien wurde bestimmt, dass die $(+)$-Pinoresinol/(+)-Lariciresinolreduktasen $(+)$-Pinoresinol in $(-)$-Secoisolariciresinol umsetzen und dass die entgegen-

\subsection{Lignane}

Lignane sind Phenylpropanoid-Dimere, die durch die zentralen C8-Kohlenstoffatome der beiden Phenylpropaneinheiten verbunden sind. Sie sind eine häufig vorkommende Klasse der Phenylpropanoide. ${ }^{[87,88]}$ Lignane lassen sich aus einer Vielzahl von Pflanzenarten, besonders aus Bäumen, isolieren, und man vermutet, dass sie helfen, die Kernfäule in Bäumen zu verhindern. ${ }^{[88]}$ Sie zeigen auch eine breite Palette biologischer Aktivitäten, wie Antitumor-, antimitotische und antivirale Eigenschaften. ${ }^{\left[{ }^{[9]}\right.}$ Einige der Lignane, die früh im Biosyntheseweg gebildet werden, fungieren auch als Leitstrukturen bei der Entwicklung neuer Wirkstoffe für die Tumortherapie, so wie der bekannte, vom Podophyllotoxin abgeleitete, halbsynthetische Wirkstoff Etoposid. ${ }^{[89,90]}$

Lignane können als Enantiomerenmischungen in verschiedenen Verhältnissen vorkommen, je nach Pflanzenart.

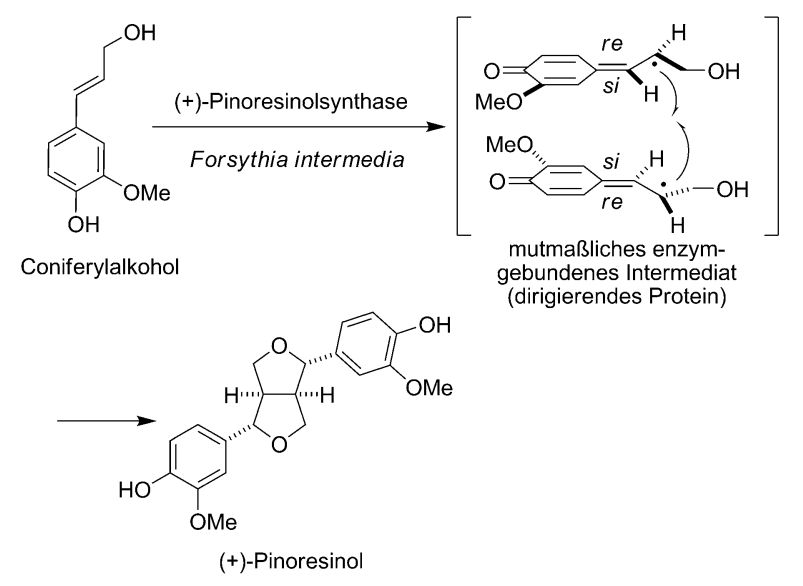

Schema 5. Enantioselektive Biosynthese von (+)-Pinoresinol. 


\section{Angewandte}

Tabelle 4: Enantiomere Lignane.

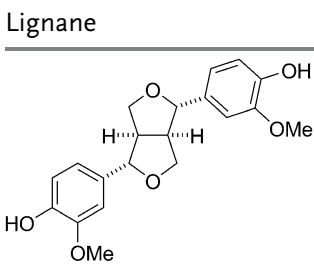

(+)-Pinoresinol

(-)-Pinoresinol<smiles>COc1cc([C@@H]2OC[C@H]3[C@H]2CO[C@H]3c2cc(OC)c(O)c(OC)c2)cc(OC)c1O</smiles>

(+)-Syringaresinol

(-)-Syringaresinol<smiles>c1cc2c(cc1[C@H]1OC[C@@H]3[C@@H](c4ccc5c(c4)OCO5)OC[C@H]13)OCO2</smiles>

(+)-Sesamin

(-)-Sesamin<smiles>COc1cc(C[C@H]2CO[C@H](c3ccc(O)c(OC)c3)[C@H]2CO)ccc1O</smiles>

$(+)$-Lariciresinol

$(-)$-Lariciresinol<smiles>COc1cc(CC(CO)C(CO)Cc2ccc(O)c(OC)c2)ccc1O</smiles>

(+)-Secoisolariciresino

(-)-Secoisolariciresinol<smiles>COc1cc(C[C@@H]2COC(=O)C2Cc2ccc(OC)c(OC)c2)ccc1O</smiles>

Wikstroemia elliptica, ${ }^{[92]}$ Daphne tangutica, ${ }^{[92]}$ Passerina vulgaris, ${ }^{[92]}$ Dirca occ identalis (Western Leatherwood, Strauch aus der Seidelbast-Familie) ${ }^{[93]}$

Forsythia koreana (koreanische Forsythie, $82 \%$ ee), ${ }^{[91]}$ Linum flavum var. compactum (Zwerg-Leinsamen, $65 \%$ ee) ${ }^{[91]}$ Larix leptolepis (Japanische Lärche, $92 \%$ ee), ${ }^{[91,92]}$ Wikstroemia viridiflora, ${ }^{[92]}$ Stellera chamaejasme (Tibetische Seidelbastart), ${ }^{[92]}$ Forsythia suspensa (Asiatische Forsythie), ${ }^{[92]}$ Forsythia spp. ${ }^{[92]}$ Fraxinus spp. ${ }^{[92]}$ Helianthus annuus (Sonnenblume) ${ }^{[98]}$

Wikstroemia sikokiana (laubabwerfender Strauch, 74\% ee), ${ }^{[91]}$ Daphne odora (Seidelbast, $95 \%$ ee), ${ }^{[91]}$ Daphne genkwa (92\% ee), ${ }^{[91]}$ Daphne tangutica, ${ }^{[92]}$ Zanthoxylum ailanthoides (Japanische Eschenart), ${ }^{\left[{ }^{92]}\right.}$ Zanthoxylum kellermanii, ${ }^{[92]}$ Senecio scandens (Greiskraut) ${ }^{[99]}$

Daphne tangutica, ${ }^{[92]}$ Zanthoxylum acanthopodium, ${ }^{[92]}$ Daphne genkwa ${ }^{[100]}$

Zanthoxylum acanthapodium, ${ }^{[92]}$ Zanthoxylum valens, ${ }^{[92]}$ Zanthoxylum setulosum $^{[92]}$

Zanthoxylum piperitum (Szechuanpfeffer) ${ }^{[92]}$

Forsythia koreana $\left(35 \%\right.$ ee), ${ }^{[91]}$ Linum flavum var. compactum $\left(70 \%\right.$ ee), ${ }^{[91]}$ Wikstroemia elliptica, ${ }^{[92]}$ Larix leptolepis, ${ }^{\left[{ }^{[2]}\right.}$ Abies sachalinensis (Sachalintanne), ${ }^{[92}$ Araucaria angustifolia ${ }^{[92]}$

Wikstroemia sikokiana (39\% ee), ${ }^{[92]}$ Daphne odora $(89 \%$ ee $),{ }^{[92]}$ Daphne genkwa $(88 \%$ ee $),{ }^{[92]}$ Wikstroemia elliptica, ${ }^{[93]}$ Daphne tangutica, ${ }^{[93]}$ Dirca occidentalis ${ }^{[93]}$

Arctium lappa (Große Klette, Stiel) $(81 \% e e),{ }^{[91]}$ Phyllanthus sp. $(98 \% e e),{ }^{[91]}$ Daphne odora (>99\% ee), ${ }^{\left[{ }^{[1]}\right.}$ Daphne genkwa $(97 \% \text { ee })^{[91]}$

\section{Antioxidans ${ }^{[103]}$}

Arctium lappa (Samen) $\left(65 \%\right.$ ee), ${ }^{[91]}$ Forsythia koreana $(>99 \%$ ee $),{ }^{[91]}$ Forsythia Antioxidans ${ }^{[103]}$ intermedia (>99\% ee), ${ }^{[91]}$ Wikstroemia sikokiana (45\% ee), ${ }^{\left[{ }^{[1]}\right.}$ Zanthoxylum ailanthoides, ${ }^{\left[{ }^{[2]}\right.}$ Larix leptolepis, ${ }^{\left[{ }^{[2]}\right.}$ Larix decidua (Europäische Lärche), ${ }^{[92]}$ Araucaria angustifolia, ${ }^{[92]}$ Podocarpus spicatus ${ }^{[92]}$

Wikstroemia indica, ${ }^{[92]}$ Daphne genkwa ${ }^{[100]}$

Antitumorwirkung ${ }^{[100]}$

(+)-Arctigenin

(-)-Arctigenin
Arctium lappa (Samen) $\left(>99 \%\right.$ ee),${ }^{[91]}$ Forsythia koreana $(>99 \% e e),{ }^{[91]}$ Forsy- tumorhemmend, ${ }^{[105]}$ Antioxidans ${ }^{[104]}$ thia intermedia $\left(>99 \%\right.$ ee), ${ }^{[9]]}$ Trachelospermum asiaticum var. intermedium (Gelber Sternjasmin), ${ }^{[92]}$ Centaurea pamphylica ${ }^{[104]}$ 
Tabelle 4: (Fortsetzung)

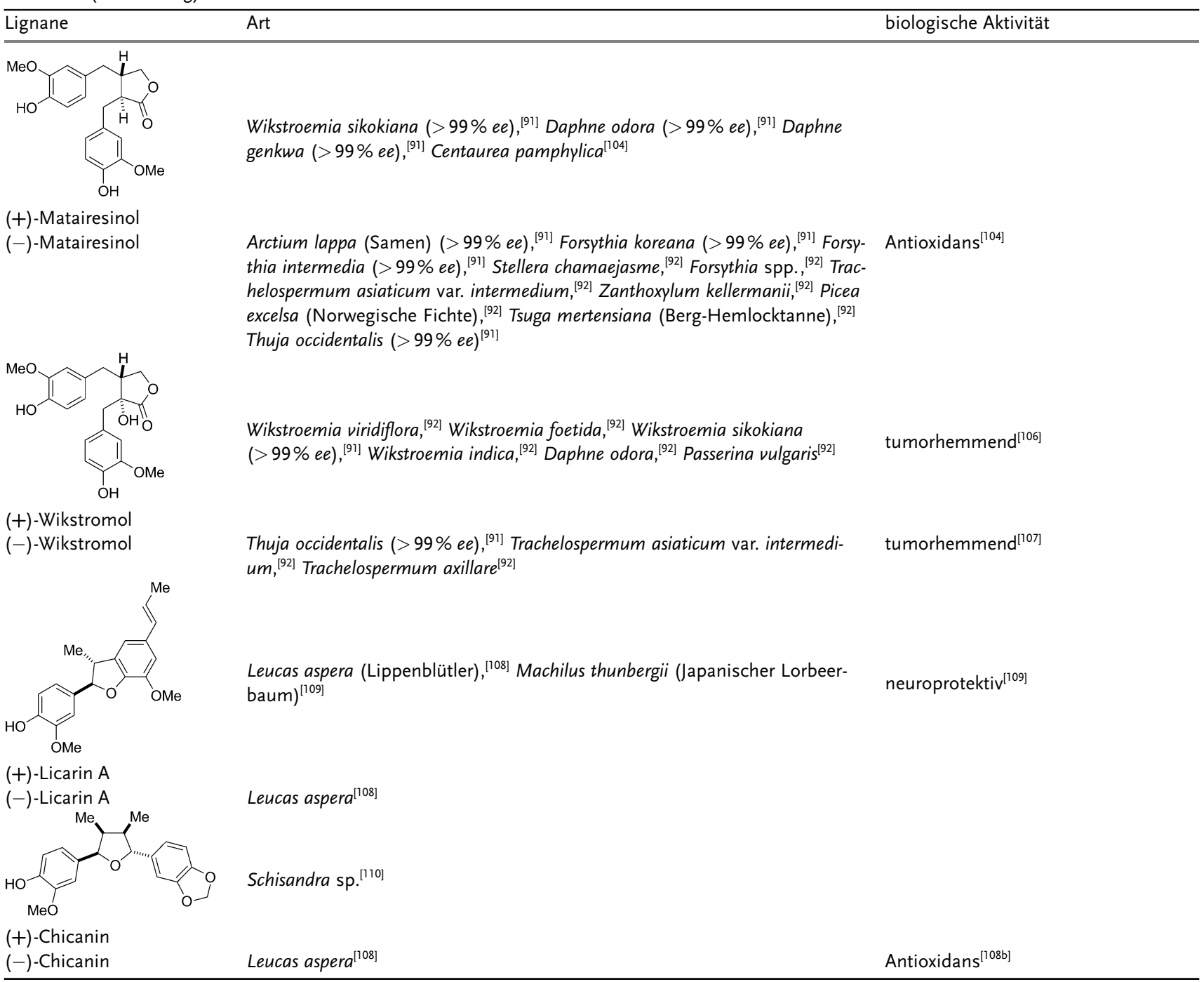

gesetzte Reduktase (-)-Pinoresinol in (+)-Secoisolariciresinol umwandelt. ${ }^{[95]}$

Die abschließende enzymatische Konversion von Secoisolariciresinol in enantiomerenreines Matairesinol ist noch nicht vollständig verstanden. (-)-Matairesinol wird in verschiedenen Pflanzenarten synthetisiert (z.B. in Forsythia intermedia, Arctium lappa, Thuja occidentalis). In Pflanzen aus der Gruppe der Thymelaeceae (Wikstroemia sikokiana und Daphne odora) wird das enantiomerenreine rechtsdrehende Enantiomer von Mataisoresinol gebildet. Aus Forsythia intermedia wurde eine Secoisolariciresinoldehydrogenase isoliert, die die enantioselektive Umsetzung von (-)-Secoisolariciresinol $\mathrm{zu}$ (-)-Matairesinol katalysiert (Schema 7). ${ }^{[6]}$ Eine Präparation von Secoisolariciresinoldehydrogenase gelang auch aus Daphne odora und Daphne genkwa, die beide das (+)-Enantiomer von Matairesinol bilden. In vitro dagegen entstand mit Enzympräparationen aus beiden DaphneArten bevorzugt (-)-Matairesinol. ${ }^{[97]}$ Bis heute ist nicht bekannt, wie (+)-Matairesonol gebildet wird.

\subsection{Flavonoide}

Flavonoide sind eine große und strukturell vielfältige Familie aromatischer Sekundärmetaboliten, die hauptsächlich wegen der roten, blauen und purpurnen Pigmente aus Pflanzen auffallen. ${ }^{[111]}$ Wegen der farbenfrohen Pigmente vermutet man bei Flavonoiden eine Funktion bei der Pflanzenvermehrung, indem bestäubende und Samen verbreitende Tiere angelockt werden. In jüngerer Zeit haben Flavonoide außerdem Interesse geweckt, da sie im Zusammenhang mit dem gesundheitlichen Nutzen von Wein, Schokolade, Früchten und Gemüsen stehen.

Wie in Tabelle 5 zusammengestellt, gehören die meisten Flavonoide einer von drei Strukturgruppen an: den Flavanolen, den Flavonolen oder den Isoflavonoiden. Die Aufklärung des Flavonoidbiosyntheseweges ist ein aufstrebendes Forschungsgebiet, wobei viel Aufmerksamkeit auf die molekulare Genetik des Stoffwechselweges gerichtet wurde. ${ }^{[11,86,111]}$ Viele der Biosyntheseenzyme der verschiede- 


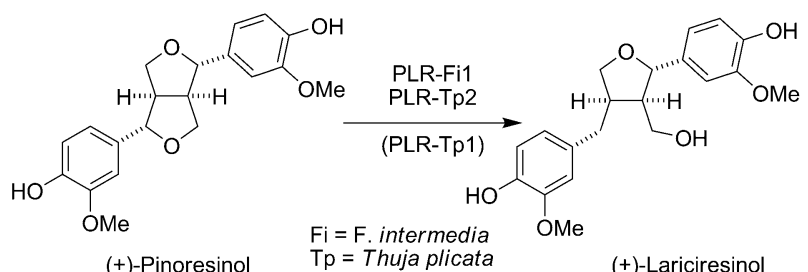

(+)-Pinoresinol $\quad \mathrm{Tp}=$ Thuja plicata

$(+)$-Lariciresinol

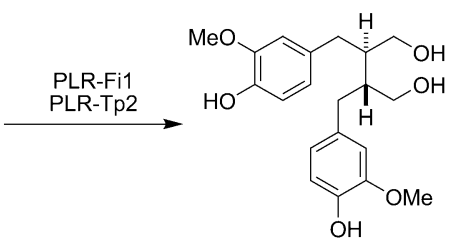

(-)-Secoisolariciresinol

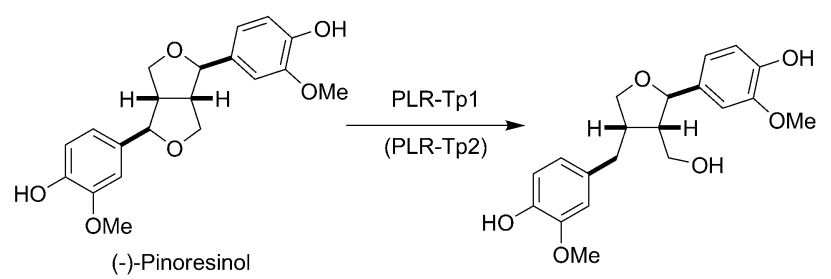

(-)-Pinoresinol

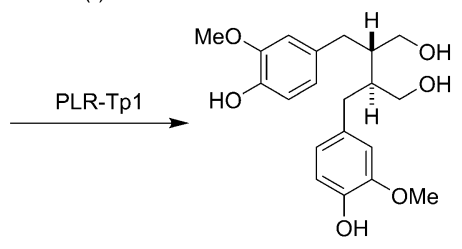

$(-)$-Lariciresinol

(+)-Secoisolariciresino

Schema 6. Enantioselektive Umwandlung von Pinoresinol in Secoisolariciresinol durch die Pinoresinol/Lariciresinolreduktase (PLR).<smiles>COc1cc(C[C@@H](CO)[C@H](CO)Cc2ccc(O)c(OC)c2)ccc1O</smiles>

(-)-Secoisolariciresinol<smiles>COc1cc(C[C@@H](CO)[C@H](CO)Cc2ccc(O)c(OC)c2)ccc1O</smiles>

(+)-Secoisolariciresinol

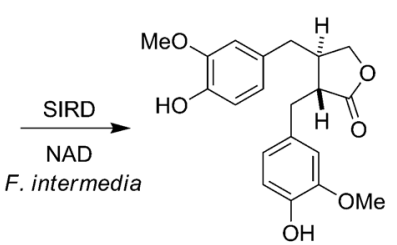

(-)-Matairesinol
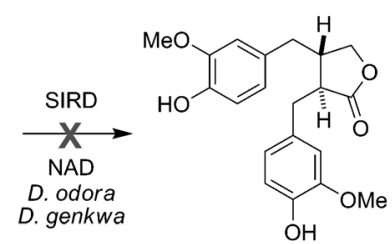

(+)-Matairesinol
Schema 7. (-)-Matairesinolbiosynthese durch die Secoisolariciresinoldehydrogenase (SIRD). NAD = Nicotinamid-Adenin-Dinucleotid.

nen Flavonoiduntergruppen wurden isoliert und charakterisiert; die Biosynthese der enantiomeren Flavonoide bleibt dagegen noch meist im Dunkeln.

Die Biosynthese von enantiomerem Medicarpin wurde in Medicago sativa L. (Alfalfa) und in Arachis hypogea (Erdnuss), die als Produzenten von (-)- und (+)-Medicarpin bekannt sind, untersucht. Der vollständige Biosyntheseweg von
(-)-Medicarpin wurde mit biochemischen Methoden bestimmt und durch Klonierung der Gene und Expressionsexperimente bestätigt. ${ }^{[12,113]}$ Schema 8 zeigt, wie die fortgeschrittene achirale Vorstufe 2'-Hydroxyformononetin von

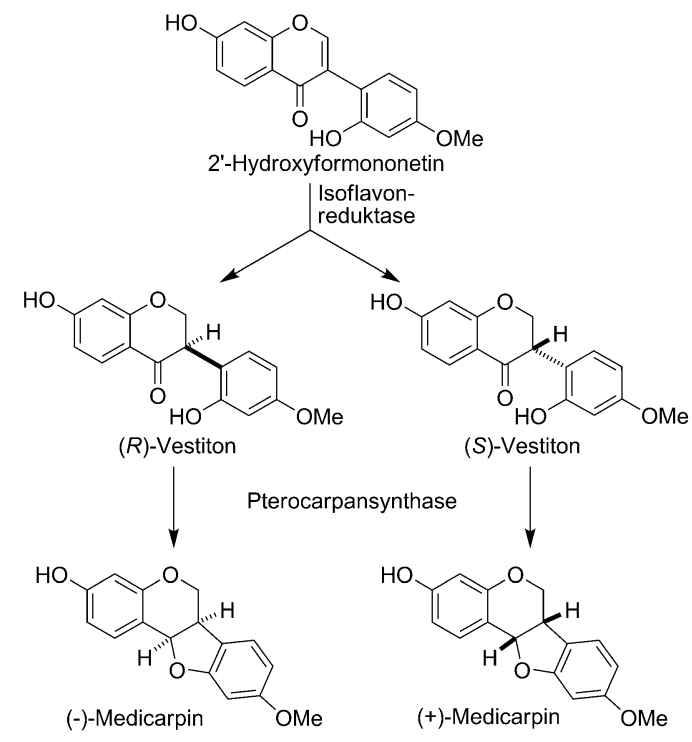

Schema 8. Biosynthese der Enantiomere von Medicarpin. ${ }^{[12]}$

einer Isoflavonreduktase $\mathrm{zu}(R)$-Vestiton umgesetzt wird, das anschließend in Alfalfa von der Pterocarpansynthase zu (-)Medicarpin umgewandelt wird. ${ }^{[112]}$ Über die (-)-Medicarpinsynthese weiß man damit deutlich mehr als über diejenige von (+)-Medicarpin in Erdnüssen. Überraschenderweise bildet die Isoflavonreduktase aus Erdnuss das gleiche $(R)$ Vestitonzwischenprodukt wie das Enzym aus Alfalfa. Die entstehende Verbindung hat allerdings die entgegengesetzten stereochemischen Eigenschaften wie die Substrate und Produkte der Pterocarpansynthase, was auf eine möglicherweise vorhandene Epimerase in der Erdnuss schließen lässt.

\subsection{Cumarine}

Cumarine werden allgemein von höheren Pflanzen gebildet und entstammen ebenfalls dem allgemeinen Phenylpropanoid-Stoffwechselweg. Cumarine spielen für Pflanzen eine wichtige Rolle als Verteidigung gegen Phytopathoge$n \mathrm{e}^{[124]}$ und weisen auch mannigfaltige biologische Aktivitäten für medizinische Anwendungen auf, darunter als Antibiotika, Gerinnungshemmer und Schmerzmittel. ${ }^{[125]}$ Die Bildung enantiomerer Cumarine (Tabelle 6) ist weniger verbreitet als bei Lignanen und Flavonoiden, weshalb die Biosynthese dieser enantiomeren Sekundärmetaboliten noch nicht untersucht wurde.

\subsection{Neoflavonoide}

Die Neoflavonoide sind eine Gruppe von Sekundärmetaboliten mit einem $\mathrm{C}_{6}-\mathrm{C}_{3}-\mathrm{C}_{6}$-Gerüst, die strukturell und 
Tabelle 5: Enantiomere Flavonoide.

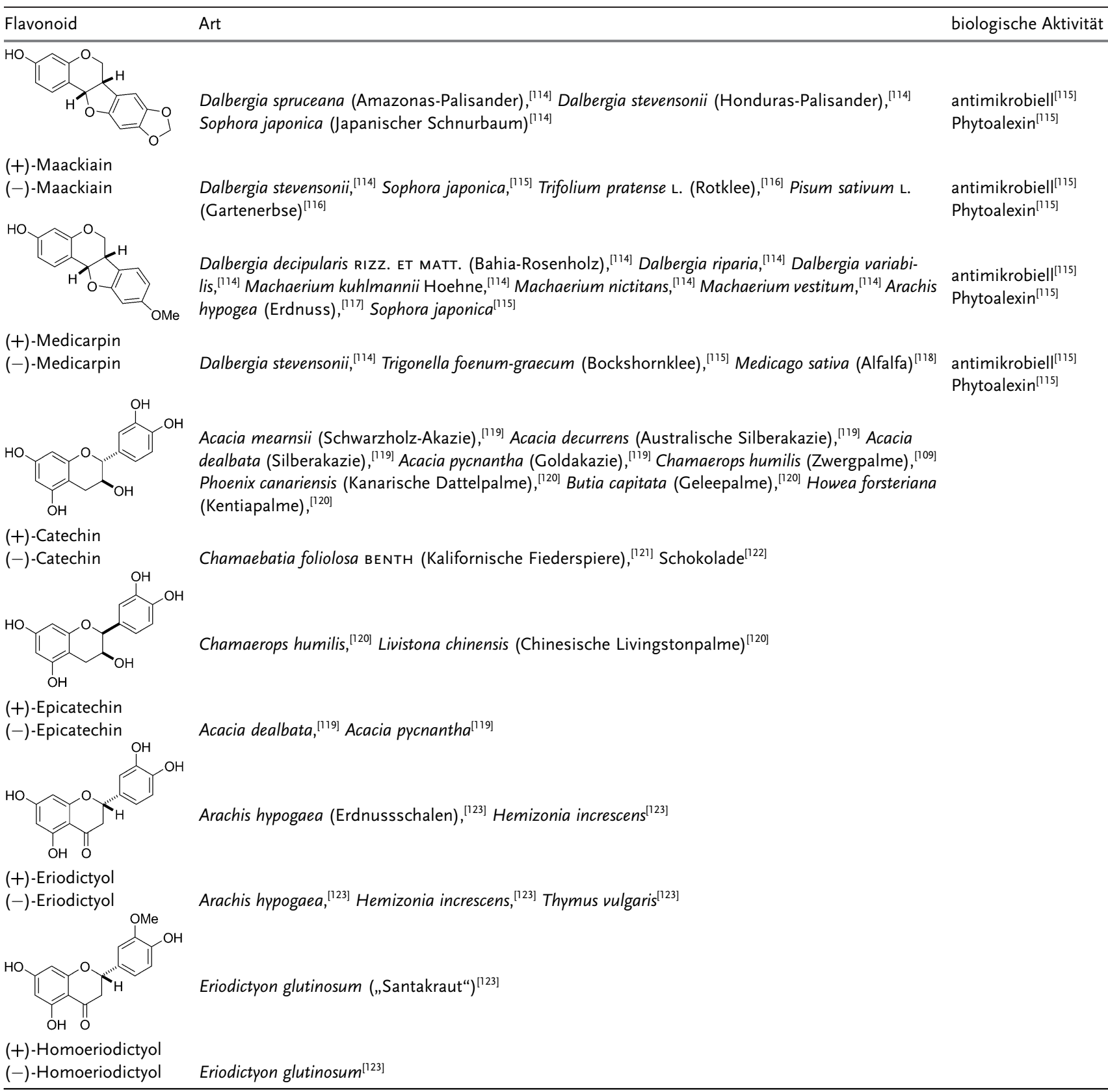

biogenetisch eng mit den Flavonoiden, Isoflavonoiden, $\mathrm{Cu}-$ marinen und Chinonen verwandt sind. ${ }^{[3,126]}$ Die Neoflavonoide finden sich in zahlreichen Pflanzenfamilien, darunter den Guttiferae, den Leguminosae, den Rubiaceae, den Passifloraceae, den Polypodiaceae und den Compositae.

4-Methoxydalbergion ist ein offenkettiges Neoflavonoid, das in der C7-Position ein stereogenes Zentrum aufweist und das von den verschiedenen Arten der Gattung Dalbergia in der $R$ - oder $S$-Isoform gebildet wird. ${ }^{[127]}$ Wie aus Tabelle 7 hervorgeht, kommen nur wenige enantiomere offenkettige Neoflavonoide in der Natur vor. Die Biogenese der enantiomeren Neoflavonoide ist daher unbekannt.

\subsection{Chinone}

Mit zahlreichen Fütterungsexperimenten wurde bestätigt, dass auch Chinone von Phenylalanin abgeleitet werden. Dieses wird zum bekannten Zwischenprodukt $p$-Hydroxybenzoesäure (PHB) umgesetzt. ${ }^{[151]}$ Durch die nachfolgende Prenylierung an der C3-Position entsteht $m$-Geranyl- $p$-hydroxybenzoesäure, die im Anschluss weiter in ein Schlüsselintermediat (Geranylhydrochinon) der Biosynthese von enantiomerem Shikonin und Alkannin umgewandelt wird (Schema 9). Gegenwärtig sind die frühen Stufen der Biosynthese von Shikonin und Alkannin viel besser verstanden als die späten. Wie in Tabelle 8 zu sehen, zeigen diese enantio- 
Tabelle 6: Enantiomere Cumarine.

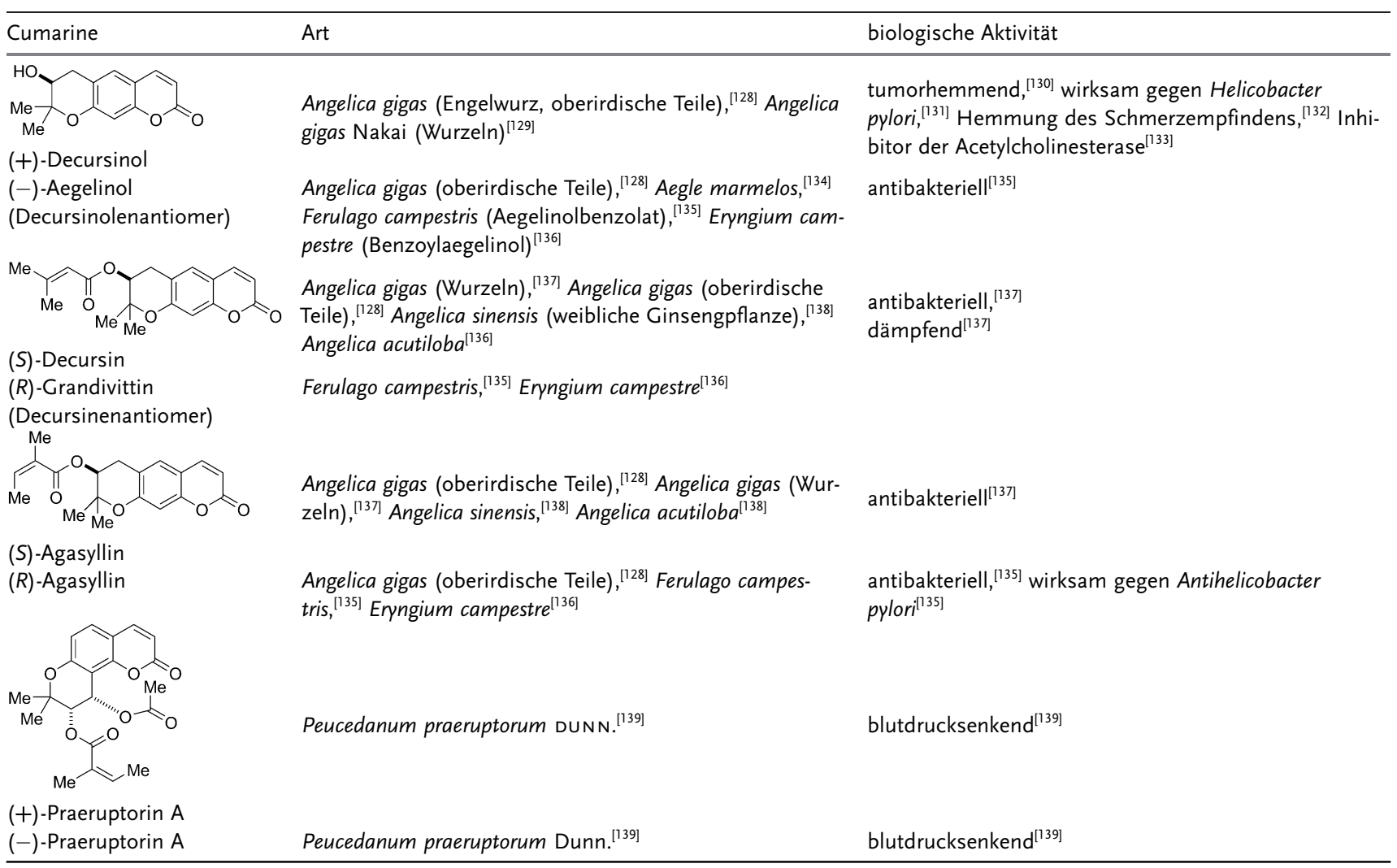

Tabelle 7: Neoflavonoidenantiomere.

\begin{tabular}{|c|c|c|}
\hline Neoflavonoid & Art & biologische Aktivität \\
\hline & 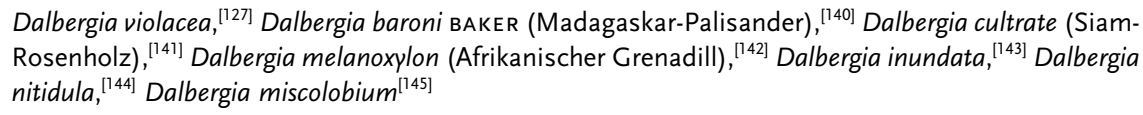 & \\
\hline \multicolumn{3}{|l|}{ (S)-Methoxydalbergion } \\
\hline (R)-Methoxydalbergion & $\begin{array}{l}\text { Dalbergia niger FR. ALLEM. (Brasilianischer Palisander) }{ }^{[127]} \text { Dalbergia latifolia ROXB. (Indischer Pa- } \\
\text { lisander) }{ }^{[127 c, 146]} \text { Dalbergia parviflora, }{ }^{[147]} \text { Dalbergia cochinchinensis (Thailändischer Palisander) }{ }^{[148]} \\
\text { Dalbergia retusa (Cocobolo) }{ }^{[149]}\end{array}$ & $\begin{array}{l}\text { wirksam gegen } \\
\text { Plasmodien }^{[150]}\end{array}$ \\
\hline
\end{tabular}

meren Chinone und ihre Derivate vielfältige biologische Aktivitäten, darunter entzündungshemmende, Antitumorund antibakterielle Wirkungen. Ein tiefergehender Einblick in die Chemie und Biologie von Alkannin, Shikonin und ihren Chinonderivaten findet sich in einem Aufsatz von Nicolaou et al. ${ }^{[151]}$

\section{Polyketide}

Die Polyketide, die sich vom Acetat ableiten, repräsentieren eine strukturell vielfältige Familie von Sekundärmetaboliten, die von einer Vielzahl von Pflanzen, Pilzen, Bakterien und Insekten gebildet werden. ${ }^{[3,154]}$ Die genaue Rolle der Polyketide in den Produzenten ist nicht bekannt, doch möglicherweise dienen manche der chemischen Verteidigung, der Unterstützung des Wachstums und der Entwicklung von
Pflanzen. Polyketide haben auch wichtige medizinische Eigenschaften wie antibiotische, Antitumor- und immunsuppressive Aktivität.

Es gibt mehrere Beispiele für enantiomere Polyketide, die im Pflanzenreich gebildet werden (Tabelle 9), doch ist über die enantioselektive Biosynthese vieler dieser Sekundärmetaboliten nur wenig bekannt. Bislang wurde auf enzymatischer Ebene intensiv an der Enantiomerenbildung von Makrotetrolid-Antibiotika (Nactine) und Benzylisochromanchinon-Antibiotika gearbeitet.

\subsection{Makrotetrolide}

Die Makrotetrolid-Antibiotika (Nactine) werden hauptsächlich von Streptomyces-Arten produziert und biosynthetisch aus vier Nonactinsäure(NA)-Monomeren oder ihren 

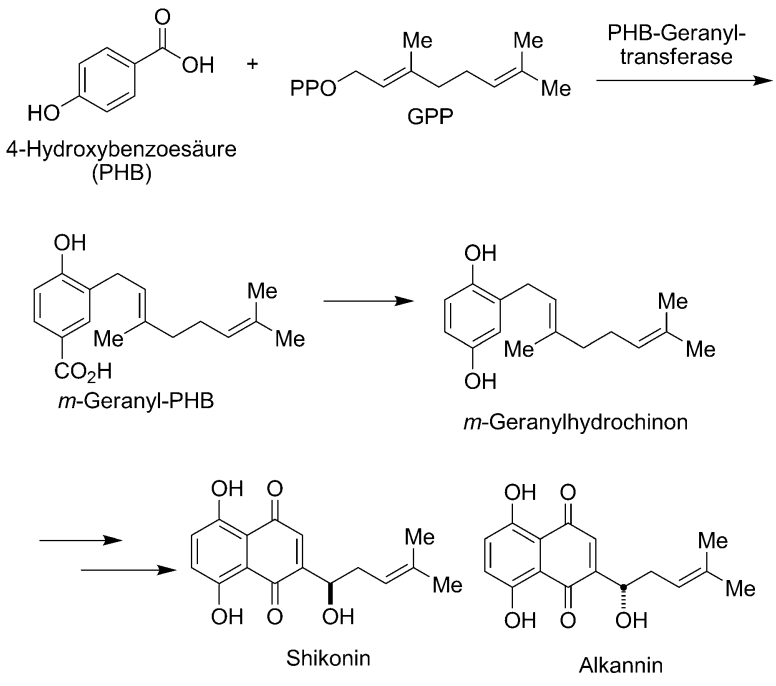

Schema 9. Vorschlag für die Biosynthese von Shikonin und Alkannin.

Homologen Homononactinsäure und/oder Bishomononactinsäure gebildet (Abbildung 2). ${ }^{[155,156]}$ Von den fünf bekannten Homologen (Nonactin, Monactin, Dinactin, Trinactin und Tetranactin) steht meistens Nonactin im Zentrum von Biosyntheseuntersuchungen. Nonactin ist ein 32-gliedriger Makrocyclus aus zwei alternierenden Einheiten $(+)$-Nonactinsäure und (-)-Nonactinsäure, wodurch Nonactin achiral wird. ${ }^{[155,156,173-175]}$

Die Biosynthese von Nonactin wurde ausgiebig über Invivo-Fütterungsexperimente mit ${ }^{13} \mathrm{C}$ - ${ }^{2} \mathrm{H}$ - und ${ }^{18} \mathrm{O}$-markierten Vorstufen $^{[173]}$ sowie durch Isolierung beider Nonactinenantiomere und ihrer Dimere untersucht. ${ }^{[156]}$ Zuletzt konzentrierte sich die Biosyntheseforschung an Nonactin auf die Isolierung und Charakterisierung der Gene und Enzyme, die an der Biosynthese beider Enantiomere von Nonactinsäure beteiligt sind. ${ }^{[155 i]}$ Die Biosynthese beider NA-Enantiomere mündete in die Vorstellung, dass die enantiomeren Polyketidzwischenstufen Ergebnis eines Paares enantiospezifischer Stoffwechselwege sind. Die vorgeschlagene Biogenese der Makrotetrolide wird durch Fütterungs- und enzymatische Untersuchungen gestützt, die unabhängig von den Gruppen um Robinson, Priesterley und Shen durchgeführt wurden. ${ }^{[155 i, 173-175]}$ Wie in Schema 10 gezeigt, entstehen die Nactine aus Malonyl-CoA, Succinyl-CoA und Acetyl-CoA, aus denen das vorgeschlagene Zwischenprodukt $\mathbf{1}$ hergestellt wird. Biosyntheseuntersuchungen von Robinson und Mitarbeitern mit ${ }^{14} \mathrm{C}$-markierten Verbindungen bestätigten, dass Propionat ebenfalls als primäre metabolische Vorstufe fungiert, aus der höchstwahrscheinlich das vermutete achirale Zwischenprodukt 2 entsteht. ${ }^{[173]}$ Da 2 achiral ist, kann es als gemeinsame Vorstufe beider enantiokomplementären Nonactinsäurestoffwechselwege wirken.

Entgegengesetzte stereospezifische Reduktionen von 2 würden die enantiomeren Vorstufen 3 und 4 ergeben. Robinson und Spavold bestätigten, dass die acyclischen Zwischenprodukte 3 und 4 ebenso wie $(6 R, 8 R)$ - und $(6 S, 8 S)$-2Methyl-6,8-dihydroxynon-( $2 E)$-ensäure enantioselektiv über die entsprechenden (+)- und (-)-Nonactatvorstufen in No-

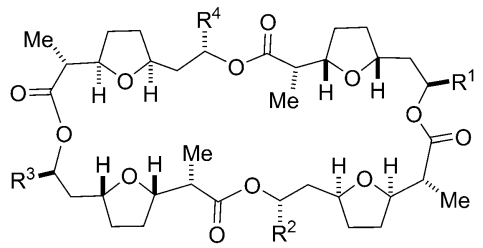

Nonactin (NON): $R^{1}=R^{2}=R^{3}=R^{4}=M e$

Monactin: $R^{1}=E t, R^{2}=R^{3}=R^{4}=M e$

Dinactin: $R^{1}=R^{3}=E t, R^{2}=R^{4}=M e$

Trinactin: $R^{1}=R^{2}=R^{3}=E t, R^{4}=M e$

Tetranactin: $R^{1}=R^{2}=R^{3}=R^{4}=E t$

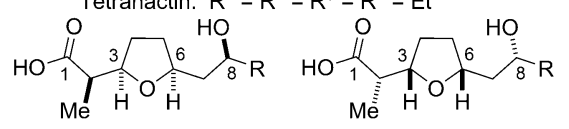

$(-)-(2 R, 3 R, 6 S, 8 S) \quad(+)-(2 S, 3 S, 6 R, 8 R)$

Nonactinsäure (NA): $\mathrm{R}=\mathrm{Me}$

Homononactinsäure (HNA): $R=E t$

Bishomonactinsäure (BNA): $\mathrm{R}=\mathrm{iPr}$

Abbildung 2. Nactine und die monomeren Einheiten, aus denen Makrotetrolidantibiotika bestehen.

nactin eingebaut wurden. ${ }^{[173 b]}$ Allerdings sind die Einzelheiten der Umwandlung der Primärmetaboliten in $\mathbf{3}$ und $\mathbf{4}$ noch weitgehend unbekannt. Durch enzymatische Untersuchungen mit NonS stützten Shen und Mitarbeiter die enantioselektiven Stoffwechselwege weiter. ${ }^{[155 i]}$ Die Autoren zeigten, dass nonS nur die enantioselektive Bildung von (-)-NA und seiner Homologen in S. griseus dirigiert; das Enzym für die Biosynthese von $(+)$-NA bleibt jedoch im Dunkeln.

\subsection{Benzoisochromanchinone}

Kalafungin, Actinorhodin, Medermycin, Dihydrogranaticin und Nanaomycin sind antimykotische und antimycoplasmatische Antibiotika mit einem Benzoisochromanchinon(BIQ)-Gerüst und werden von verschiedenen StreptomycesArten produziert. ${ }^{[176]}$ Strukturell haben die BIQs immer eine trans-Konfiguration an den Stereozentren von C3 und C15; daher können diese Metaboliten in eine von zwei Kategorien eingeordnet werden: Dihydrogranaticin (DHGRA) hat $(3 R, 15 S)$ - und Actinorhodin (ACT) $(3 S, 15 R)$-Konfiguration (Abbildung 3)..$^{177,178]}$

Ausgehend von enantiomer entgegengesetzten Stereozentren in den ACT- und AHGRA-Familien ließen sich auch enantiomere Zwischenprodukte aus frühen Synthesestadien aus verschiedenen Quellen isolieren. Bei der Analyse der zahlreichen identifizierten Gencluster (act, kal, nnm, gra usw.) wurden zwei enantioselektive Ketoreduktasen gefunden. In Schema 11 ist veranschaulicht, wie RED1/2 in einem bicyclischen Zwischenprodukt stereospezifisch die Carbonylfunktion reduziert und damit die C3-Konfiguration festlegt. ${ }^{[178]}$ Im Verlauf der ACT-Biosynthese wird die $S$-Konfiguration durch act-VI-ORF1 (RED1) bestimmt, ${ }^{[179]}$ während die $R$-Konfiguration im Dihydrogranaticin (DHGRA) durch die nicht verwandte gra-ORF6-Ketoreduktase RED2 eingeführt wird. ${ }^{[177,180]}$ Die beiden Enzyme unterscheiden sich bemerkenswert in ihrer Substratspezifität, ihrer dreidimensionalen Struktur und dem Katalysemechanismus. Dennoch er- 
Tabelle 8: Natürliche Chinonenantiomere. ${ }^{[a]}$

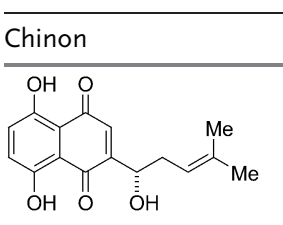

Alkannin

Shikonin

(Alkanninenantiomer)

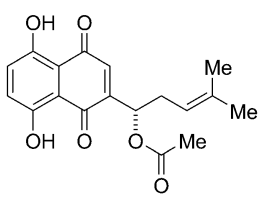

Acetylalkannin

Acetylshikonin

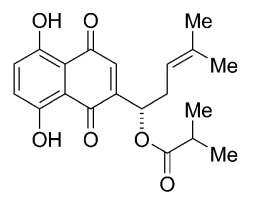

Isobutyrlalkannin

Isobutyrylshikonin

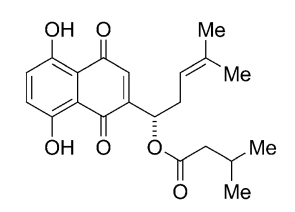

Isovalerylalkannin Isovalerylshikonin

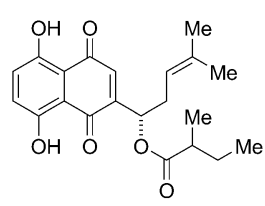

$\alpha$-Methylbutyrylalkannin $\alpha$-Methylbutyrylshikonin
Art biologische Aktivität

Alkanna tinctoria (Schminkwurz), Arnebia hispidissima, Arnebia nobilis, Arnebia tinctoria, Macrotomia cephalotes, Macrotomia euchroma (Syrische Alkanne), Onosma echioides, Onosma paniculata, Plagiobotrys arizonicus

Arnebia euchroma, Arnebia hispidissima, Arnebia guttata, Arnebia tibetiana, Cynoglossum officinale (Gewöhnliche Hundszunge), Echium lycopsis, Echium rubrum, Echium vulgare (Gewöhnlicher Natternkopf), Eritrichium incanum, Eritrichium sichotenze, Jatropha glandulifera, Lappula consanguinea, Lappula echinata (Gewöhnlicher Igelsame), Lithospermum erythrorhizon (Blauer Steinsame), Lithospermum officinale (Echter Steinsame), Macrotomia echioides, Macrotomia ugamensis, Macrotomia euchroma, Mertensia maritima (Austernpflanze), Onosma caucasicum, Onosma conferitum, Onosma hookeri, Onosma livanovii, Onosma polyphyllum, Onosma tauricum, Onosma sericium, Onosma setosum, Onosma visianii, Onosma zerizaminium

Alkanna tinctoria, Arnebia euchroma, Arnebia hispidissima, Arnebia nobilis, Macrotomia cephalotes

antimikrobiell, Hemmung der Topoisomerase I, thrombosehemmend, tumorhemmend

Arnebia decumbens, Arnebia euchroma, Arnebia guttata, Cynglossum officinale, Echium vulgare, Eritrichium incanum, Eritrichium sichotenze, Jatropha glandulifera, Lappula consanguinea, Lappul echinata, Lithospermum arvense (AckerSteinsame), Lithospermum erythrorhizon, Mertensia maritima, Onosma confertum, Onosma hookeri, Onosma paniculatum

Alkanna tinctoria

Cynoglossum officinale, Echium vulgare, Eritrichium sichotenze, Lappula consanguinea, Lappula echinata, Lithospermum arvense, Lithospermum erythrorhizon, Macrotomia euchroma, Mertensia maritima

Alkanna tinctoria, Arnebia hispidissima, Arnebia tinctoria, Macrotomia cephalotes, Onosma heterophylla

Hemmung der Topoisomerase I fördert die Wundheilung, entzündungshemmend, antibakteriell, Hemmung der Topoisomerase I, gerinnungshemmend

tumorhemmend, amöbenhemmend, fieber- und schmerzhemmend, antimykotisch, antibakteriell, fördert die Wundheilung, chemopräventiv, entzündungshemmend, Hemmung der Topoisomerase II, Hemmung der mikrosomalen Monooxygenase, Stimulation der Peroxidase, Schutz vor UV-Strahlung, Hemmung der Testosteron$\alpha$-Reduktase, Induktion und Sekretion von Nervenwachstumsfaktoren
Arnebia decumbens, Cynoglossum officinale, Echium vulgare, Lappula consanguinea, Lappula echinata, Lithospermum arvense, Lithospermum erythrorhizon, Macrotomia euchroma

Alkanna tinctoria, Macrotomia cephalotes

Cynoglossum officinale, Echium vulgare, Eritrichium incanum, Eritrichium sichotenze, Lappula consanguinea, Lappula echinata, Lappula erythrorhizon, Mertensia maritima 
Tabelle 8: (Fortsetzung)

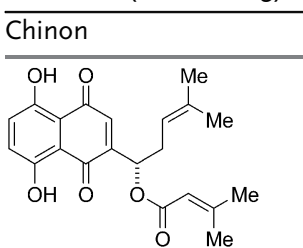

$\beta, \beta$-Dimethylacrylalkannin

$\beta, \beta$-Dimethylacrylshikonin

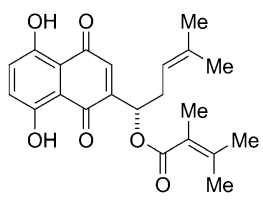

Teracrylalkannin

Teracrylshikonin<smiles>CC=C(C)C(=O)OC(CC=C(C)C)C1=CC(=O)c2c(O)ccc(O)c2C1=O</smiles>

Angelylalkannin

Angelylshikonin<smiles>CC(C)=CC[C@H](OC(=O)CC(C)(C)O)C1=CC(=O)c2c(O)ccc(O)c2C1=O</smiles>

$\beta$-Hydroxyisovalerylalkannin $\beta$-Hydroxyisovalerylshikonin<smiles>CC(C)=CC[C@H](OC(=O)CC(C)(C)OC(C)(C)C)C1=CC(=O)c2c(O)ccc(O)c2C1=O</smiles>

$\beta$-Acetoxyisovalerylalkannin $\beta$-Acetoxyisovalerylshikonin<smiles>CC1(C)OC([N+](=O)[O-])C2=C1c1ccccc1C(=O)C2=O</smiles>

(+)-Dunnione

(-)-Dunnione<smiles>CC1OC2=C(C(=O)c3ccccc3C2=O)C1(C)C</smiles>

Art

biologische Aktivität

Alkanna tinctoria, Arnebia euchroma, Arnebia gutatta, Arnebia nobilis, Lithospermum erythrorhizon, Macrotomia cephalotes, Onosma heterophylla, Onosma hookeri, Onosma paniculata

Alkanna hirsutissima, Arnebia euchroma, Arnebia guttata, Arnebia tibetiana, Cynoglossum officinale, Echium vulgare, Eritrichium incanum, Eritrichium sichotenze, Jatropha glandulifera, Lappula consanguinea, Lappula echinata, Echium spp., Lithospermum erythrorhizon, Macrotomia ugamensis, Mertensia maritima, Moltkiopsis ciliata, Onosma confertum, Onosma paniculatum, Onosma hookeri, Onosma zerizaminum

Arnebia densiflora

antimikrobiell

Arnebia euchroma, Arnebia guttata, Lithospermum erythro- antimikrobiell rhizon, Lithospermum euchromum

Alkanna tinctoria

Alkanna hirsutissima

Arnebia euchroma, Arnebia hispidissima, Macrotomia cephalotes

antimikrobiell

Arnebia euchroma, Arnebia guttata, Lithospermum arvense, antimikrobiell Lithospermum erythrorhizon, Lithospermum euchromum

Alkanna tinctoria, Arnebia euchroma, Moltkiopsis ciliata, Onosma heterophylla

antimikrobiell

Macrotomia euchroma

Streptocarpus dunnii (Kap-Primel), ${ }^{[152]}$ Calceolaria integrifo$\operatorname{lia}^{[153]}$

Streptocarpus dunnii, ${ }^{[152]}$ Calceolaria integrifolia ${ }^{[153]}$

Streptocarpus dunni $i^{[152]}$

(+)- $\alpha$-Dunnione

(-)- $\alpha$-Dunnione

Streptocarpus dunni ${ }^{[152]}$ 
Tabelle 8: (Fortsetzung)

Streptocarpus dunni ${ }^{[152]}$

[a] Arten und biologische Aktivität ohne Literaturangabe sind dem Aufsatz von Nicolaou et al. ([Lit.] [151]) entnommen.

Tabelle 9: Enantiomere Polyketide.

Polyketid Art biologische Aktivität<smiles>CC(O)CC1CCC(C(C)C(=O)O)O1</smiles>

(+)-Nonactinsäure

(und Homologe)

(-)-Nonactinsäure

(und Homologe)<smiles>C[C@H]1OC2CC(=O)OC2C2=C(C(=O)c3c(O)cccc3C2=O)C1O</smiles>

Kalafungin

Nanaomycin D

(Kalafunginenantiomer)<smiles>COc1cccc2c1C(=O)C1=C(CC(CC(=O)O)OC1[14C](=O)O)C2=O</smiles>

(+)-Nanaomycin A

(-)-Nanaomycin A

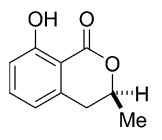

$(+)$-Mellein

$(-)$-Mellein<smiles>COc1cc(O)c2c(c1)C(=O)c1cc3c(c(O)c1C2=O)C(=O)OC(=[W])C3</smiles>

(+)-Dermolacton

$(-)$-Dermolacton<smiles>O=C1CC(O)Cc2cc(O)cc(O)c21</smiles>

(+)-Scytalon

(-)-Scytalon<smiles>COc1cc(O)c2c(c1)C(=O)C1CC(C2=O)C(C)CC1O</smiles>

$(1 S, 3 S)$-Austrocortilutein $(1 R, 3 R)$-Austrocortilutein
Streptomyces griseus (Bakterien) ${ }^{[155]}$ Streptomyces spec. |A 5909- ${ }^{[156]}$

Streptomyces griseus, ${ }^{[155]}$ Streptomyces spec. JA 5909- ${ }^{[156]}$

Streptomyces tanashiensis Stamm Kala, ${ }^{[157]}$ Streptomyces coelicolor A3 (2) ${ }^{[158]}$ antibiotisch ${ }^{[159]}$

Streptomyces rosa var. notoensis OS3966 $6^{[160]}$

antibiotisch $^{[160]}$

Nocardia sp. (Bakterien) ${ }^{[161]}$

antibiotisch $^{[161]}$

Streptomyces rosa var. notoensis OS3966 $6^{[162]}$

antibiotisch, ${ }^{[162]}$ antimykotisch, ${ }^{[162]}$ gegen Mycoplasmen wirksam ${ }^{[162]}$

Cercospora taiwanensis, ${ }^{[163]}$ Fusarium larvarum, ${ }^{[163]}$ Grignardia laricina, ${ }^{[163]}$ Gyrostroma missouriense (Pilz), ${ }^{[163]}$ Helicascus kanaloanus (mariner Pilz), ${ }^{\left[{ }^{164]}\right.}$ nicht identifizierter Pilz ${ }^{[163]}$

Aspergillus melleus (Pilz), ${ }^{[163]}$ Aspergillus ochraceus (Pilz), ${ }^{[163]}$ Aspergillus oniki (Pilz), ${ }^{[163]}$ Camponotus spp.,${ }^{[163]}$ Cornitermes spp., ${ }^{[163]}$ Grapholithia molesta (Pfirsichtriebbohrer), ${ }^{[163]}$ Hypoxylon spp., ${ }^{[163]}$ Lasiodiplodia theobromae (Pilz), ${ }^{[163]}$ Marasmiellus ramealis (Ästchen-Schwindling), ${ }^{[163]}$ Pestalotia ramulosa (Pilz), ${ }^{[163]}$ Rhytidoponera metallica (grünköpfige Ameise), ${ }^{[163]}$ Septoria nodorum (Pilz) ${ }^{[163]}$

Dermocybe kula (Pilz) ${ }^{[166]}$

Dermocybe kula ${ }^{[166]}$

Verticillium dahliae (Pilz) ${ }^{[167]}$ Phialophora lagerbergii (Pilz), ${ }^{[168]}$ Scytalidium sp. ${ }^{[169]}$

Phialophora lagerbergii, ${ }^{[168]}$ Scytalidium sp. ${ }^{[169]}$

Dermocybe splendida (Hautkopf-Art, Pilz) ${ }^{[170]}$

antibiotisch, $^{[171]}$ Pilzpigment (gelb) ${ }^{[172]}$ 
Tabelle 9: (Fortsetzung)

\begin{tabular}{|c|c|c|}
\hline Polyketid & Art & biologische Aktivität \\
\hline & $\begin{array}{l}\text { Dermocybe splendida, }{ }^{[170]} \text { Dermocybe sp. WAT } 20934,{ }^{[172]} \text { Dermocybe sp. WAT } \\
21568^{[172]}\end{array}$ & $\begin{array}{l}\text { antibiotisch, }{ }^{[171]} \text { Pilzpigment (gelb- } D \text {. } \\
\text { splendida) }{ }^{[172]}\end{array}$ \\
\hline $\begin{array}{l}(1 S, 3 R) \text { - Austrocortilutein } \\
(1 R, 3 S) \text {-Austrocortilutein }\end{array}$ & Dermocybe sp. WAT 21567, ${ }^{[172]}$ Dermocybe sp. WAT $20934^{[172]}$ & \\
\hline
\end{tabular}

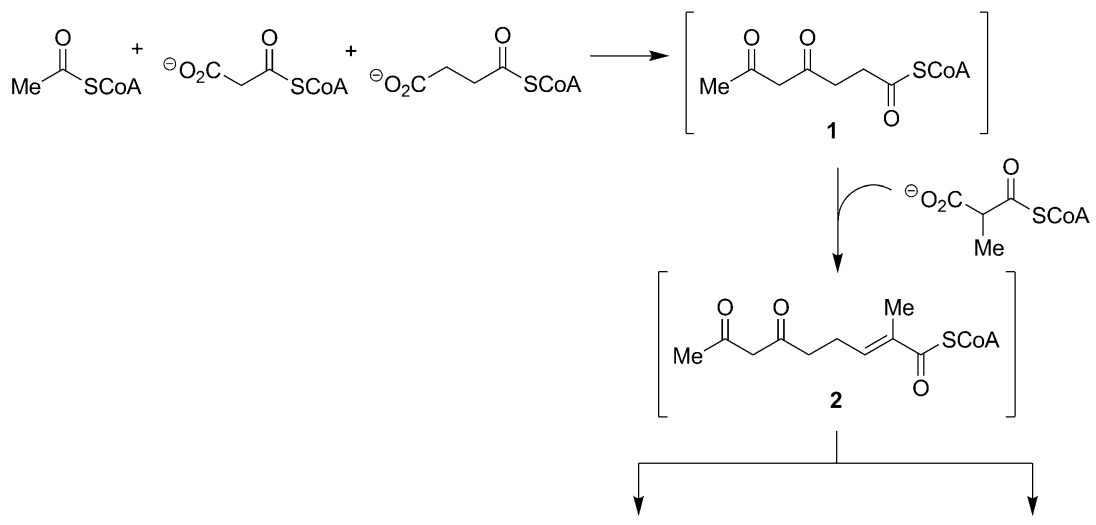

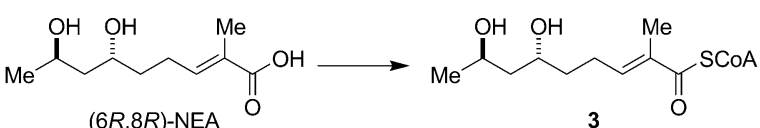

$(6 R, 8 R)-\mathrm{NEA}$<smiles>CC(O)C[C@H]1CC[C@@H](C(C)C(=O)O)O1</smiles>

(+)-Nonactinsäure

5<smiles>CC(CCCC(O)CC(C)O)=C(C)C(=O)O</smiles>
Nons

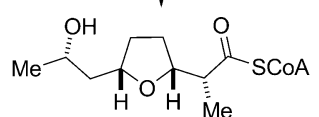

6<smiles>CCCCCC(O)CC(O)CCCCC(C)C(=O)O</smiles>

$(6 S, 8 S)-N E A$

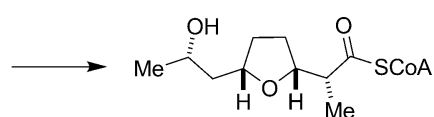

(-)-Nonactinsäure
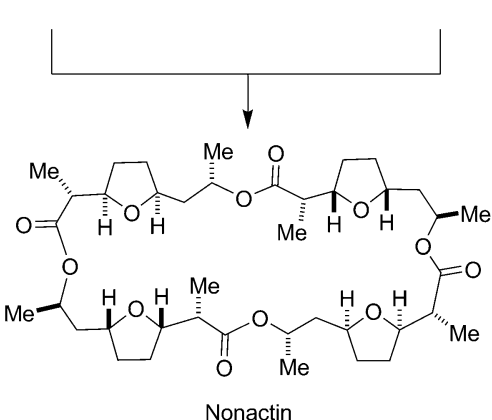

Schema 10. Vorschlag für stereochemisch komplementäre Biogenesewege für (+)- und (-)-Nonactinsäure.$^{[155]}$ NEA $=2-$ Methyl-6,8-dihydroxynon(2E)-ensäure.

kennen beide dasselbe Substratmotiv des bicyclischen Zwischenprodukts. ${ }^{[178 a]}$ Aus diesem Zwischenprodukt entstehen durch nachfolgende Cyclisierung und Reduktion die jeweiligen enantiomeren Intermediate $(S)$ - und $(R)$-DNPA. Aus diesen chiralen Verbindungen leiten sich die höheren BIQNaturstoffe wie Actinorhodin und DHGRA ab.

\section{Alkaloide}

Alkaloide sind eine riesige und strukturell sehr vielfältige Gruppe stickstoffhaltiger Metaboliten, die aus Pflanzen,
Bakterien, Pilzen und Tieren isoliert werden können. ${ }^{[3]}$ Diese Naturstoff-Familie kann weiter in Untergruppen eingeteilt werden, die auf den wenigen $\alpha$-Aminosäuren beruhen, von denen Alkaloide abgeleitet werden, im Wesentlichen Lysin, Ornithin, Phenylalanin, Tyrosin und Tryptophan. Zusätzlich zu diesen primären Bausteinen sind auch Mevalonat und Acetat wichtige Ausgangsverbindungen für die Alkaloidbiosynthese.

Alkaloide haben umfangreiche pharmakologische Aktivitäten und werden oft als Medikamente, als Aufputschmittel oder in spirituellen Ritualen verwendet. ${ }^{[181]}$ Morphin, Coffein und Psilocin (ein Pilzhalluzinogen) sind verbreitete und gut 


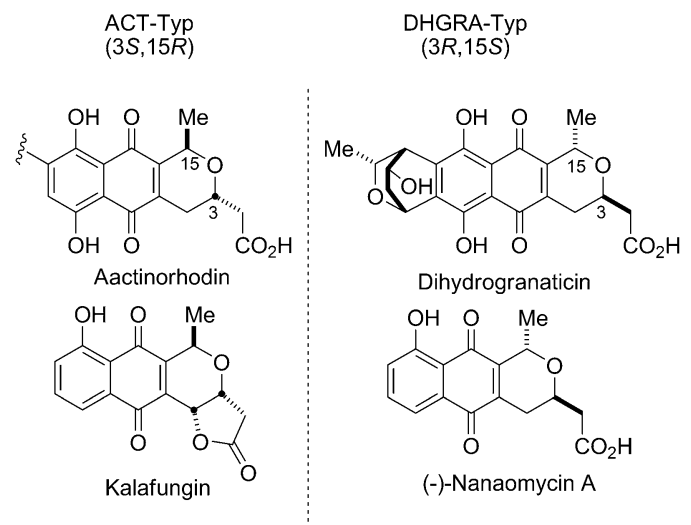

Abbildung 3. Strukturelle Diversität der BIQ-Antibiotika.

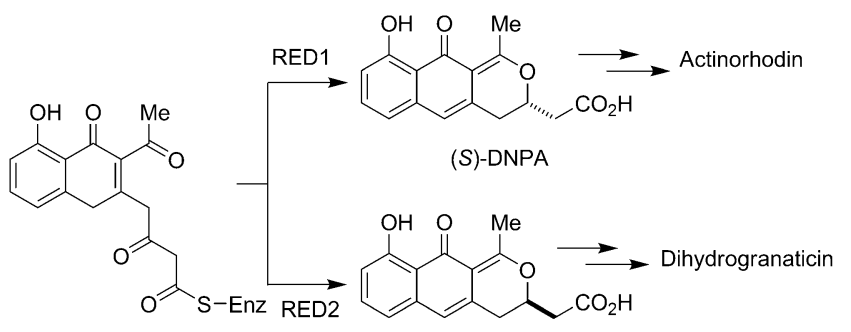

bicyclisches Intermediat

(R)-DNPA

Schema 11. Vorschlag für enantioselektive Biosynthesewege von Actinorhodin und Dihydrogranaticin. (RED1/2= stereospezifische C3-Reduktase).

bekannte bioaktive Mitglieder der Alkaloide. Verschiedene weniger bekannte Alkaloide sind ebenfalls biologisch aktiv und zeigen Antitumor-, antibakterielle, antihelmintische oder entzündungshemmende Aktivitäten. ${ }^{[182]}$

Enantiomere Alkaloide kommen in der Natur vor, doch im Allgemeinen werden sie als racemische Gemische oder mit einem Enantiomerenüberschuss produziert und isoliert. Wie bei den Lignanen beobachtet, werden viele der späteren Alkaloidmetabolite in enantiomerenreiner Form synthetisiert, doch die Metaboliten aus den frühen Synthesestufen kommen oft als Enantiomerengemische vor. Ausgewählte Beispiele dieser enantiomeren Alkaloide werden in den folgenden Unterabschnitten besprochen.

\subsection{Manzaminalkaloide}

Manzamine sind eine wachsende Klasse $\beta$-Carbolin-haltiger cytotoxischer Alkaloide mariner Schwämme, die ein ungewöhnliches polycyclisches Diaminsystem enthalten. ${ }^{[183]}$ Diese Naturstoffe wurden erstmals in den späten 1980er Jahren gefunden und zeichnen sich durch vielfältige biologische Aktivitäten aus, zu denen unter anderem Antitumor-, entzündungshemmende, insektizide und antiparasitische Wirkungen gehören. Einige dieser Naturstoffe zeigen auch vielversprechende antiinfektive Aktivität gegen Malaria und Mtb. ${ }^{[183]}$
Die Vielfalt der Gebiete (Okinawa, Philippinen, Indonesien, Rotes Meer, Italien, Südafrika und Papua-Neuguinea) und der Gattungen (Amphimedon sp. und Acantho strongylophora) der Schwämme, die die Manzaminalkaloide synthetisieren, rührt nach allgemeiner Auffassung von der symbiotischen Beziehung zwischen diesen Schwämmen mit gemeinsamen oder eng miteinander verwandten Mikroorganismen her, die für die Bildung der Manzaminenantiomere sorgen. ${ }^{[183]}$ Bislang wurden nur wenige enantiomerenreine Manzamine isoliert (Tabelle 10), und die Biosynthese dieser Metaboliten wird gegenwärtig untersucht.

Aus dieser Alkaloidklasse wurden die beiden Enantiomere von 8-Hydroxymanzamin A, Manzamin F und Keramaphidin B isoliert, außerdem die enantiomeren Nebenprodukte Ircinal A und B sowie Ircinol A und B. ${ }^{[183]}$ Interessanterweise sind Ircinol A und B enantiomere Nebenkomponenten von Ircinal A und B, und sie sind die ersten Manzaminalkaloide, die die exakt gegensätzliche absolute Konfiguration zu den Manzaminen A und B aufweisen. ${ }^{[184]}$ Wie man Abbildung 4 entnehmen kann, gehören ein Enantiomer von Keramaphidin B, die Ircinale A und B und die Manzamine A und B alle zu einer Konfigurationsserie, während das andere Enantiomer von Keramaphidin B, die Ircinole A und B, Ingenamin und Ingamin A die umgekehrte absolute Konfiguration aufweisen und so eine zweite Enantiomerenserie bilden.

Weil wahrscheinlich schwammassoziierte Mikroorganismen die Manzamine produzieren, gibt es nur wenig Arbeiten zur Aufklärung des Biosyntheseweges dieser einzigartigen Verbindungen. ${ }^{[183]}$ Die Identifizierung der Bakterienisolate aus einem Manzamin produzierenden Schwamm und die Kultivierung der Bakterien, die diese Transformationen durchführen, sind die begrenzenden Faktoren für ein umfassendes Verständnis der Biosynthese der Manzamine. Nach Identifizierung, Isolierung und Durchmusterung vieler Mikroorganismen aus Manzamin produzierenden Schwämmen konnte die Biotransformation von 8-Hydroxymanzamin A zu Manzamin $\mathrm{A}^{[185]}$ und von ent-8-Hydroxymanzamin A zu dem bekannten Zwischenprodukt ent-12,34-Oxamanzamin $\mathrm{F}^{[186]}$ durchgeführt werden (Schema 12).

\subsection{Indolalkaloide}

Indolalkaloide sind Naturstoffe, die von Tryptophan abgeleitet sind und eine der größten Gruppen von AlkaloidSekundärmetaboliten darstellen. ${ }^{[193]}$ Biogenetisch lässt sich diese Alkaloidklasse in zwei Strukturkategorien einteilen: die isoprenoidhaltigen Naturstoffe und die isoprenfreien Alkaloide. Die zweite Gruppe besteht aus einfachen Indolderivaten, einfachen $\beta$-Carbolinderivaten und Pyrroloindolalkaloiden. ${ }^{[194]}$ Die Isoprenoidalkaloide enthalten terpenoide Strukturelemente, die sich von DMAPP und/oder IPP ableiten. ${ }^{[195]}$ Die Bildung enantiomerer Indolalkaloide wird bei den verschiedenen Untergruppen der komplexeren Isoprenoidalkaloide beschrieben, die in den Abschnitten 5.2.1 und 5.2.2 abgehandelt werden. 
Tabelle 10: Enantiomere Manzaminalkaloide.

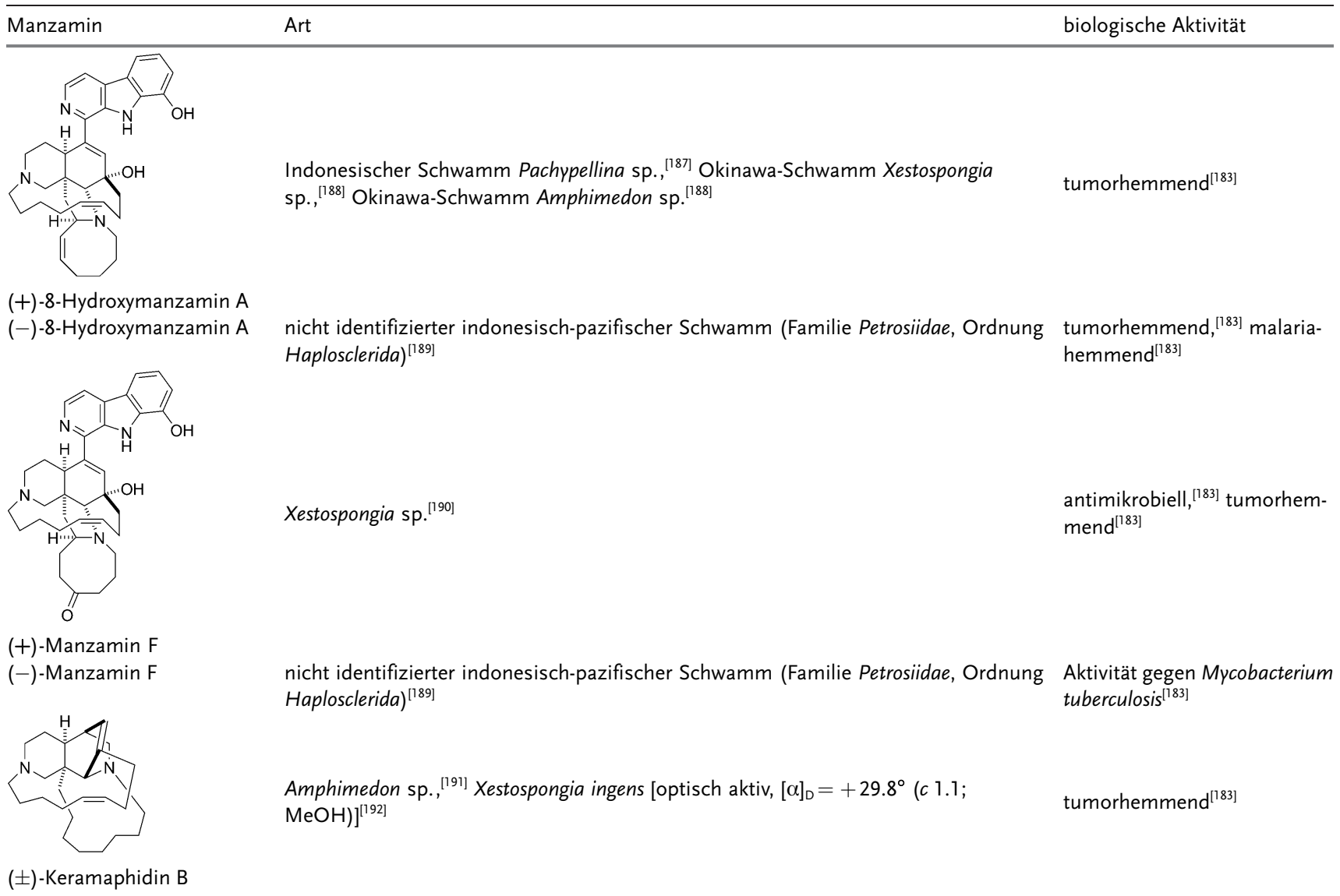

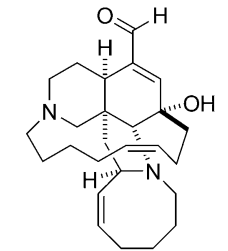

Ircinal A

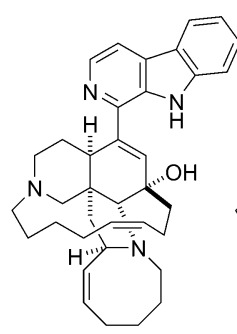

Manzamin A

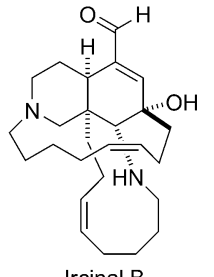

Ircinal B

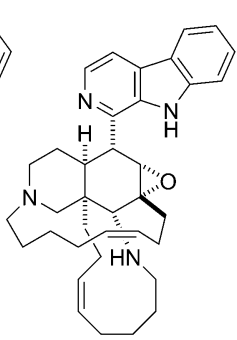

Manzamin B

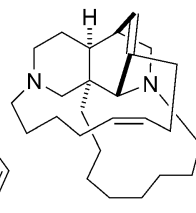

Keramaphidin B

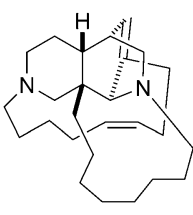

Keramaphidin B

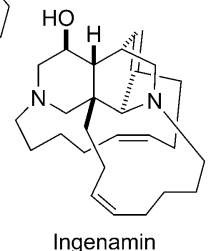

Ingenamin

Ircinol A
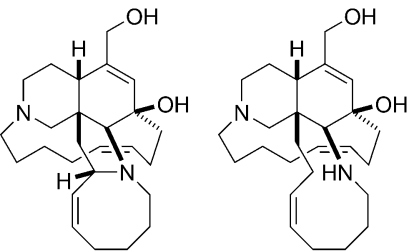

Ircinol B

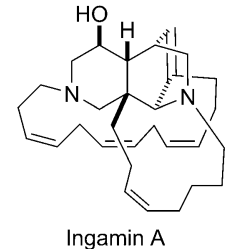

der Apocynaceae bildet über hundert strukturell unterschiedliche Terpenoidindolalkaloide. Die Aufklärung des zugehörigen Biosyntheseweges in Catharanthus roseus wurde intensiv bearbeitet. Mehr als zwanzig enzymatische Stufen in diesem komplizierten Biosyntheseweg wurden identifiziert; sie führen von den primären Metaboliten zum strukturell komplexen antineoplastischen Agens Vinblastin. Wie bei vielen Sekundärmetaboliten werden auch hier die Zwischenprodukte in den späten Synthesestadien, wie Vinblastin und Vincristin, als einzelnes Enantiomer gebildet und isoliert, während die frühen Metaboliten öfter als Enantiomerengemische synthetisiert werden. Wie in Tabelle $11 \mathrm{zu}$ sehen, kommen diese enantiomeren Metaboliten oft in unterschiedlichen Arten als einzelne Enantiomere vor. 


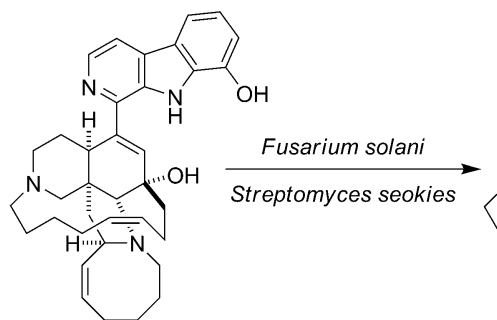

(+)-8-Hydroxymanzamin A

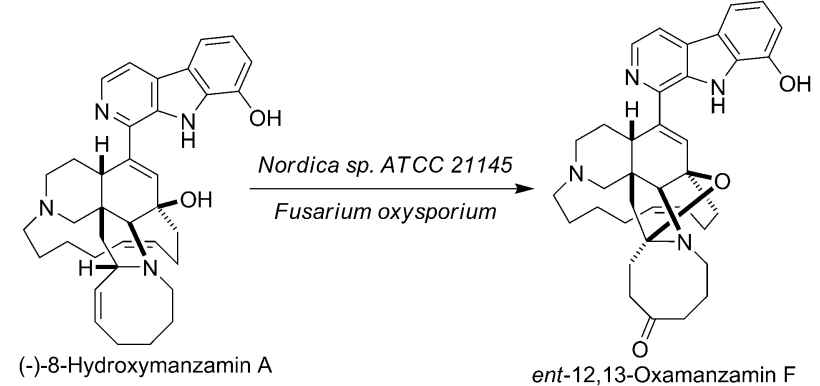

Schema 12. Biokatalytische Umwandlung des enantiomeren 8-Hydroxymanzamins $A$.
Während die Gesamtbiosynthese von Terpenoidindolalkaloiden weitgehend geklärt ist, ist die Biogenese enantiomerer Metaboliten gegenwärtig noch unbekannt.

\subsubsection{Revers prenylierte Indolalkaloide}

Die einzigartige und vielfältige Familie der revers prenylierten Indolalkaloide mit ihrem Bicyclo[2.2.2]diazaoctanRingsystem wurde wegen ihrer komplexen Molekülstruktur und der weitreichenden biologischen Aktivitäten intensiv untersucht. ${ }^{[203]}$ Mitglieder dieser Familie wurden aus marinen und terrestrischen Quellen isoliert, hauptsächlich aus den Gattungen Aspergillus und Penicillium, und es wurden insektizide, antihelmintische, calmodulinhemmende, antibakterielle und Antitumorwirkungen nachgewiesen. Die jüngst erfolgte Identifizierung enantiomerer Verbindungen aus verwandten Aspergillus-Arten hat das Interesse am Biosyntheseweg der Stephacidin- und Notoamidfamilie der revers prenylierten Indolalkaloide geweckt.

2009 isolierten Tsukamoto und Mitarbeiter den bekannten Naturstoff (+)-Stephacidin $\mathrm{A}^{[204]}$ aus der marinen Aspergillus sp. MF297-2 zusammen mit einigen neuen Verbindungen, die später als Notoamide bezeichnet wurden. ${ }^{[205]}$ Kurz

Tabelle 11: Enantiomere Indolalkaloid-Metabolite. ${ }^{[a]}$

Amsonia tabernaemontana (Blausternbusch), ${ }^{[197]}$ Amsonia angustifolia, Rhazya stricta, Taber-
naemontana riedelii, Vinca difformis (Mittleres Immergrün), Macoubea guianensis ${ }^{[198]}$

(+)-Vincadifformin

(-)-Vincadifformin

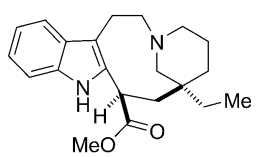

$(+)$-Vincadin

(-)-Vincadin

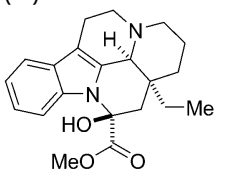

(+)-Vincamin

$(-)$-Vincamin

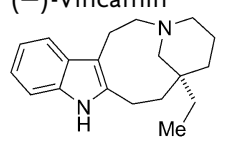

(+)-Quebrachamin

(-)-Quebrachamin

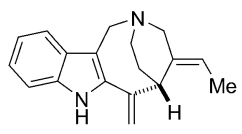

$(+)$-Apparicin

(-)-Apparicin
Vinca minor (Kleines Immergrün), Vinca difformis, Rhazya stricta, Tabernaemontana riedelii, Macoubea guianensis ${ }^{[198]}$

Vinca minor, Amsonia tabernaemontana, Amsonia angustifolia, Macoubea guianensis ${ }^{[198]}$

Amsonia tabernaemontana, Amsonia angustifolia, Macoubea guianensis

Vinca minor, Vinca major (Großes Immergrün), Vinca erecta, Vinca difformis, Tabernaemontana rigida

blutdrucksenkend

Tabernaemontana rigida

Vinca erecta, Pleiocarpa tubicina, Pleiocarpa pycnantha var. pycnantha, Stemmadenia donnellsmithii

Aspidosperma quebracho-blanco (Quebrachobaum, Südamerika), Aspidosperma chakensis, andere Aspidosperma spp., Gonioma kamassi, Hunteria elliotii, Rhazya stricta

Aspidosperma dasycarpon

Aspidosperma olivaceum und andere Aspidosperma spp., Catharanthus ovalis (Rosa Immergrün), Catharanthus roseus (Madagaskar-Immergrün), Pandaca ochrascens, Pandaca eusepala, Ervatamia heyneana, Tabernaemontana cumminsii, Schizzygia caffaeoides tumorhemmend, antibakteriell, antiviral 


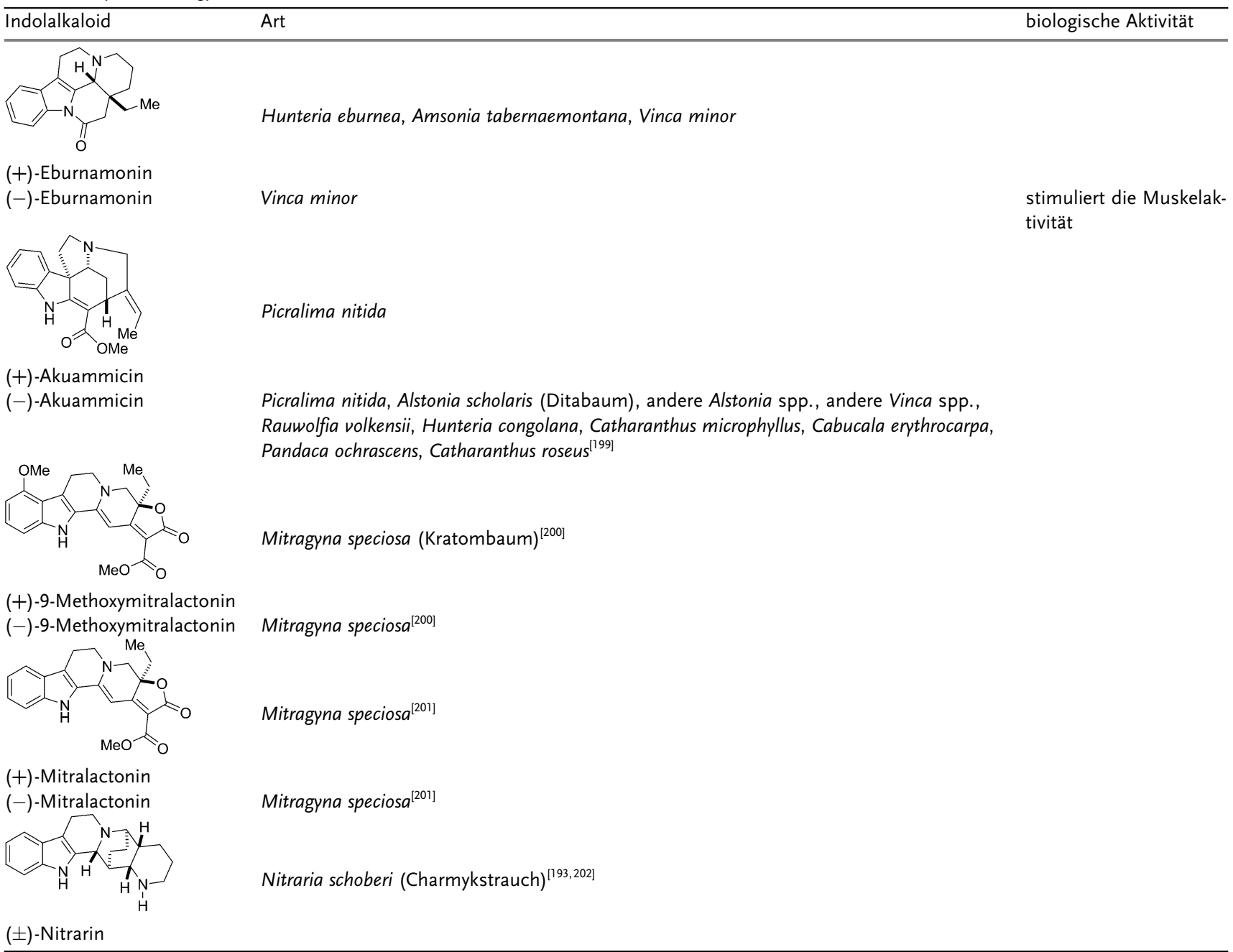

[a] Arten und biologische Aktivität ohne Literaturangabe sind dem Dictionary of Alkaloids ([Lit.] [193]) entnommen.

danach isolierten Gloer et al. die entsprechenden Enantiomere aus dem terrestrischen Pilz Aspergillus versicolor NRRL 35600. ${ }^{[206]}$ Diese enantiomeren Alkaloide (Tabelle 12) entstehen einer Hypothese zufolge über eine biosynthetische Diels-Alder-Reaktion, was voraussetzt, dass die AspergillusArten enantiomer unterschiedliche Diels-Alderasen enthalten. Außerdem müssen die Pilzkulturen auch enantiomer unterschiedliche Oxidasen aufweisen, die die seitenspezifische Pinakolumlagerung zum Spirooxindolrest katalysieren, der in Notoamid B und Versicolamid B vorkommt. Daher schlugen Williams und Mitarbeiter vor, dass die Familien der Stephacidine und Notoamide einen gemeinsamen Biosyntheseweg aufweisen und dass die Bildung verschiedener Enantiomere dieser Alkaloide auf einen enantioselektiven Schlüsselschritt in einem ansonsten gemeinsamen biogenetischen Stoffwechselweg zurückgehe. ${ }^{[203]}$ Diese Arbeit wurde außerdem durch die Identifizierung und Charakterisierung der Gencluster aus Aspergillus sp. MF297-2 und Aspergillus versicolor NRRL35600 ${ }^{[207]}$ und durch parallele Einbaustudien von Vorstufen in beiden Kulturen gestützt. ${ }^{[208]}$

Aufbauend auf vergleichenden Genomuntersuchungen und Fütterungsversuchen wurde ein Biosyntheseweg vorge- schlagen. ${ }^{[207,208]}$ Wie in Schema 13 dargestellt, beginnt der Weg mit dem vermutlich zentralen Zwischenprodukt Notoamid $S,{ }^{[209]}$ von dem aus er sich in mindestens zwei mögliche Richtungen verzweigt. Die Bildung des Pyranoindols mit Notoamid E als Produkt mündet in die Biosynthese von Notoamid C, 3-epi-Notoamid C und Notoamid $\mathrm{D}^{[208 \mathrm{a}, \mathrm{b}]}$ unter Beteiligung des Enzyms NotB. Notoamid S kann aber auch eine Zwei-Elektronen-Oxidation in Gegenwart von NotD oder NotH durchlaufen. Dabei entsteht das achirale Azadien, das als Verzweigungspunkt für die verschiedenen Enantiomere wirkt. Es kann eine stereoselektive [4+2]-Cycloaddition zum (+)-Notoamid T in Aspergillus sp. MF297-2 oder zum (-)-Notoamid T in Aspergillus versicolor durchlaufen. In diesen möglichen Zwischenprodukten kann durch Cyclisierung das Pyranoindolringsystem gebildet werden, aus dem anschließend das Enantiomerenpaar von Stephacidin A hervorgeht. Durch Einbaustudien mit ${ }^{13} \mathrm{C}$-markiertem $( \pm)$ Stephacidin A mit A. versicolor und Aspergillus sp. MF297-2 wurde sichergestellt, dass die seitenspezifischen Oxidationsenzyme (gegenwärtig geht man von Flavoenyzmen aus) in beiden Pilzkulturen vorhanden sind, wie sich aus der enantioselektiven Umwandlung von Stephacidin A in Notoamid B 
Tabelle 12: Enantiomere revers prenylierte Indolalkaloide.

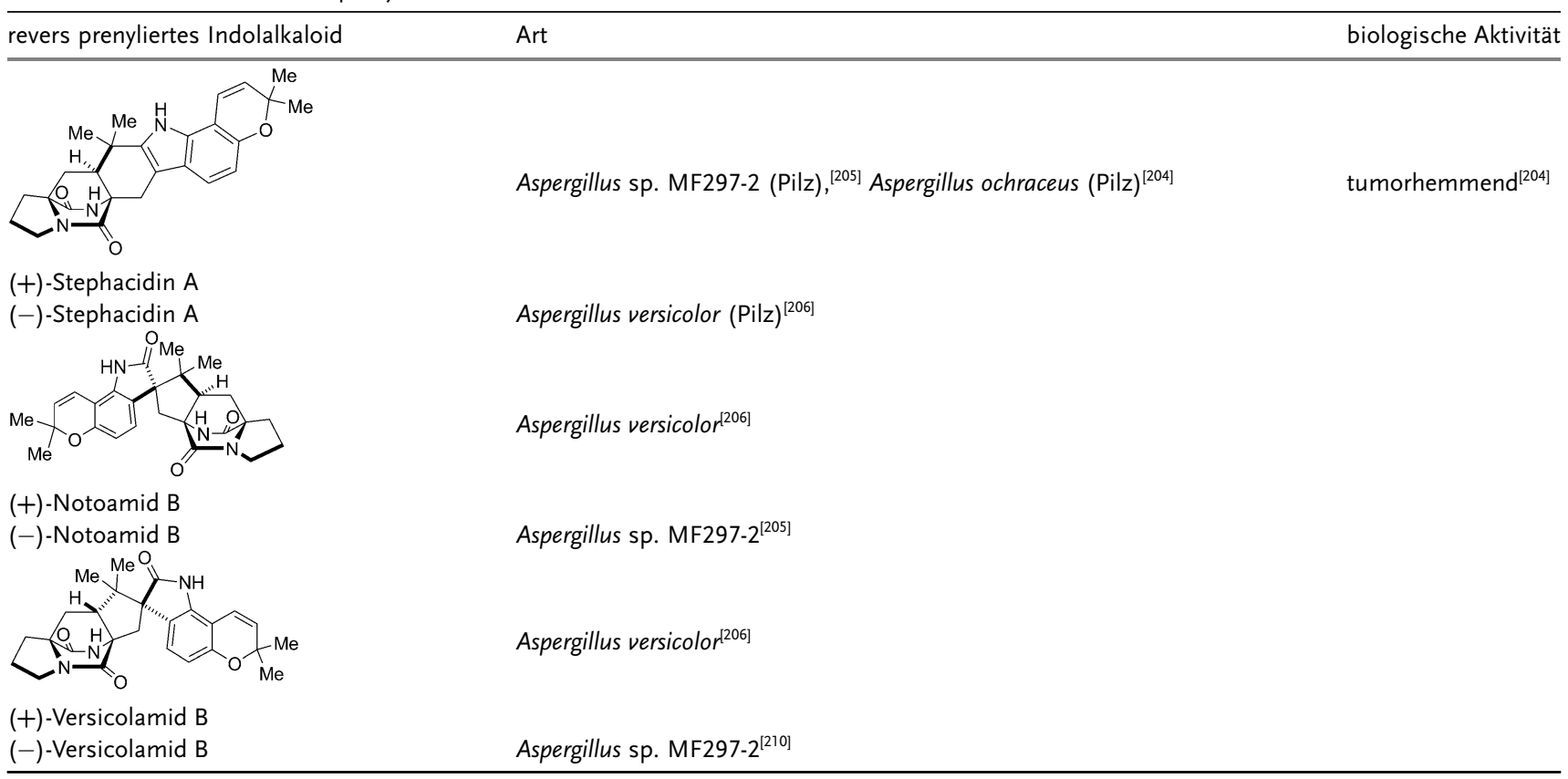

schließen lässt. ${ }^{[208 c]}$ Die Oxidase in A. versicolor NRRL 35600 ist spezifisch für die Umwandlung von (-)-Stephacidin A in (+)-Notoamid B, während eine stereochemisch komplementäre Oxidase aus der marinen Aspergillus sp. MF297-2 (+)-Stephacidin A zu (-)-Notoamid B umsetzt.

Bei jeder dieser Oxidationsreaktionen des 2,3-disubstituierten Indolrestes von Stephacidin A muss die Oxidation von einer definierten Seite der enantiotopen Flächen des Indolringsystems her eingeleitet werden, und wir bezweifeln derzeit, dass dies durch identische Enzyme geschieht. So muss die Oxidation von (+)-Stephacidin A zu (-)-Notoamid B ausschließlich von der pro- $R$-Seite des Indols in Aspergillus sp. MF297-2 erfolgen, die Oxidation von (-)-Stephacidin A zu (+)-Notoamid B in Aspergillus versicolor hingegen ausschließlich von der pro-S-Seite. Bis heute sind keine diastereomeren Oxindole nachgewiesen worden, die bei einer möglichen nichtseitenspezifischen Oxidation entstehen würden. Von Interesse war auch die Beobachtung, dass $A s$ pergillus sp. MF297-2 (-)-Versicolamid B bildet und dass Aspergillus versicolor dessen Enantiomer (+)-Versicolamid B produziert. Die mutmaßliche Vorstufe von Versicolamid B, C6-epi-Stephacidin A, ist als natürlicher Metabolit noch nicht entdeckt worden, doch seine Existenz in jedem Pilz wird erwartet. Synthetische Proben dieser Substanz wurden hergestellt und werden derzeit untersucht.

Bei Versuchen zur Aufklärung der enzymatischen Basis der Biosynthese enantiomerer Alkaloide haben wir eine Sequenzierung und ein Mining des vollständigen Genoms für die Stephacidin/Notoamid-Stoffwechselwege zweier Pilzstämme durchgeführt. Der marine Aspergillus-sp.-MF297-2Stamm bildet (-)-Notoamid B und der terrestrische Aspergillus-versicolor-Stamm das enantiomere (+)-Notoamid B. Als Schlüsselelement für die Bestimmung der Chiralität wird die intramolekulare Diels-Alderase angesehen. Wir fanden heraus, dass die molekulare Architektur (z. B. die Position der Gene und die Transkriptionsrichtung) dieser Stoffwechselwege die auffällige Ähnlichkeit von $>70 \%$ Identität der Nucleotidsequenzen innerhalb des $35 \mathrm{~kb}$ großen Genclusters aufweist. Der entsprechend hohe Grad an Übereinstimmung der Aminosäuresequenz lässt erwarten, dass feine Sequenzunterschiede im aktiven Zentrum eine entscheidende Rolle bei der Kontrolle der Chiralität und der Aufnahme der jeweiligen enantiomeren Substrate für die nachfolgenden Aufbau- und Umwandlungsreaktionen spielen.

\subsection{Chinolizidin(Lupinen)-Alkaloide}

Chinolizidinalkaloide, oft auch Lupinenalkaloide genannt, sind Sekundärmetaboliten, die in vielen Leguminosen und Baumarten vorkommen. ${ }^{[211]}$ Es gibt über 550 bekannte Chinolizidinalkaloide, von denen viele in der Unterfamilie Papilionoideae der Fabaceae vorkommen. Sie sind besonders in den Familien Genisteae, Sophoreae und Thermopsideae verbreitet. Man vermutet bei ihnen eine Rolle bei der Auseinandersetzung der Pflanzen mit Herbivoren, denn viele dieser Alkaloide haben toxische und/oder teratogene Eigenschaften auf Tiere. ${ }^{[212]}$

Die ersten Isolierungen von Lupinenalkaloiden ergaben, dass in vielen Fällen beide Enantiomere eines Alkaloids in der Natur vorkommen;;213] nach vertiefter Untersuchung stellten sich jedoch viele der scheinbaren Racemate als enantiomerenreine Isoformen heraus. ${ }^{[14]}$ In diesem Aufsatz werden wir uns auf ausgewählte wichtige enantiomere Lupinenmetaboliten beschränken, die in der Natur vorkommen; eine Auswahl ist in Tabelle 13 zusammen mit einigen der biologischen Quellen für die Isolierung zusammengestellt. 


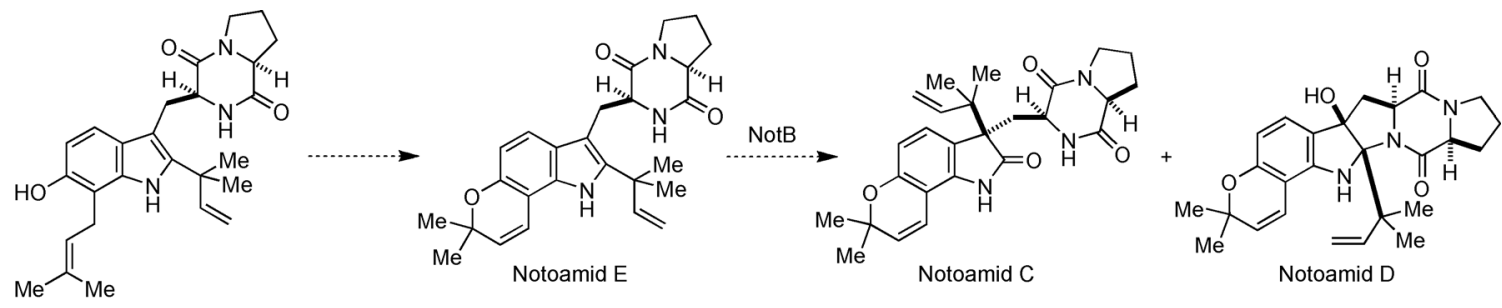

Notoamid S
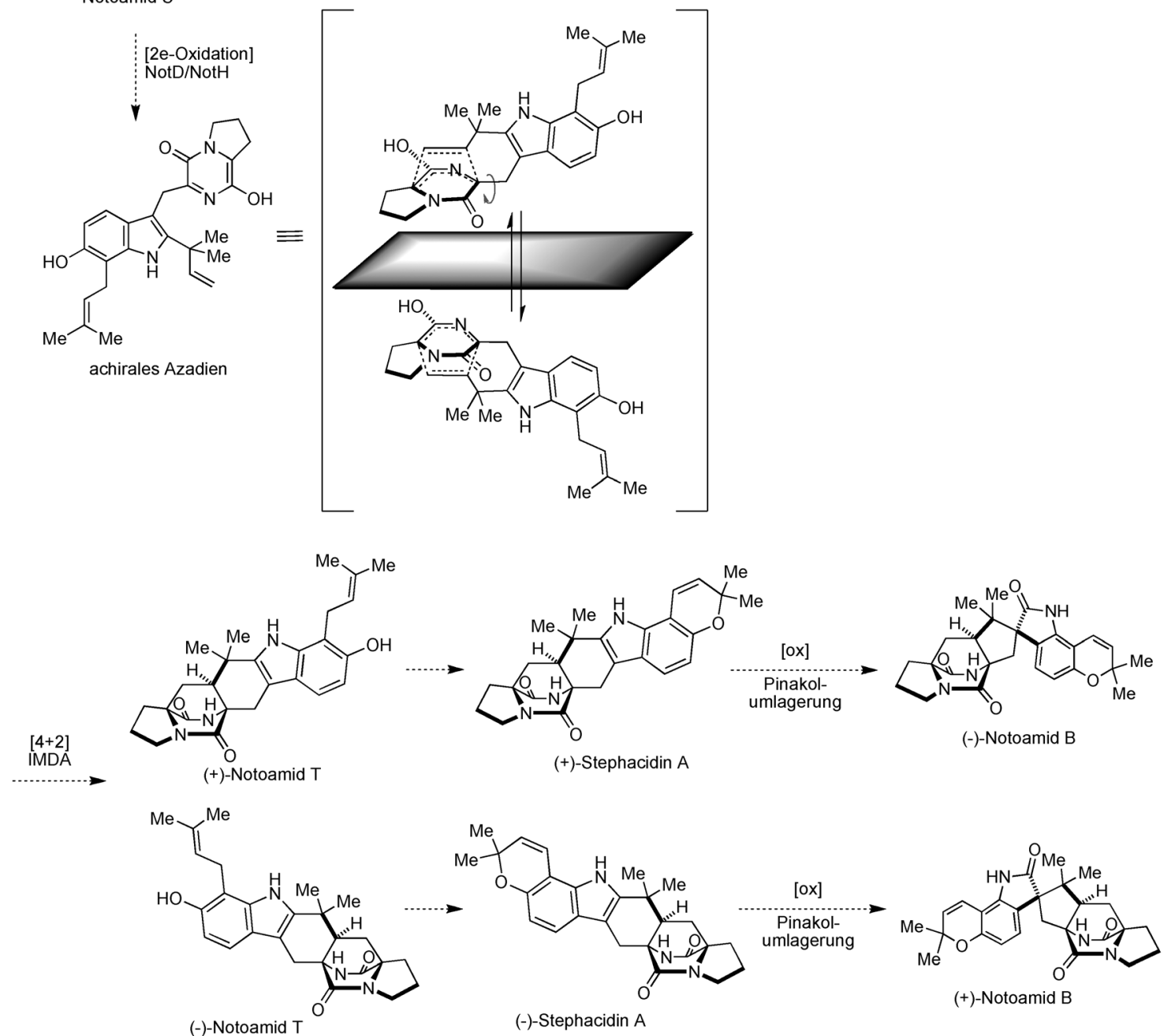

Schema 13. Mögliche stereochemische Aufspaltung der Biosynthese von Stephacidin A und den Notoamiden. IMDA=intramolekulare Diels-AlderReaktion.

Biosyntheseuntersuchungen an enantiomeren Lupinenalkaloiden sind relativ selten. Unabhängig voneinander wiesen die Gruppen um Spenser, Robins und Wink nach, dass die Chinolizidinalkaloide aus Lysin über ein symmetrisches Cadaverinzwischenprodukt entstehen. Eine Lysindecarboxylase, die Lysin in Cadaverin umwandelt, konnte aus Lupinenzellkulturen und aus ganzen Pflanzen isoliert werden. Die späteren biosynthetischen Reaktionen sind allerdings schwer fassbar. ${ }^{[222]}$ Durch Fütterungsversuche mit markierten Vorstufen konnte nachgewiesen werden, dass Lysin und Cadaverin in (-)-Spartein, (+)-Spartein und (+)-Lupanin eingebaut werden (Schema 14). ${ }^{[223]}$

\subsection{Piperidin- und Pyridinalkaloide}

Piperidin- und Pyridinalkaloide sind sekundäre Naturstoffe, die einen stickstoffhaltigen Sechsring enthalten, der bei Piperidinalkaloiden gesättigt, bei Pyridinalkaloiden ungesättigt ist. Einfache Piperidine und Pyridine finden sich meist in toxischen Alkaloiden, zu deren bekanntesten Mitgliedern das Pyridinalkaloid Nicotin zählt. ${ }^{[8]}$ Auch einige Piperidinalkaloide sind bekannte, von Conicum maculatum, dem Schierling, produzierte Gifte. ${ }^{[224]}$ Viele der Piperidin- und Pyridinalkaloide wirken teratogen,${ }^{[225]}$ und die Aufnahme von Pflanzen, die diese Naturstoffe bilden, durch trächtiges Vieh kann bei den Jungtieren Mißbildungen wie Gelenkverwachsungen und/oder Gaumenspalten verursachen. ${ }^{[226]}$ Wie in 
Tabelle 13: Lupinenalkaloidenantiomere. ${ }^{[a]}$

Lupinalkaloide Art biologische Akti-

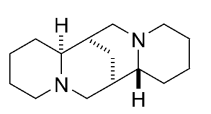

(+)-Spartein

(-)-Spartein<smiles>O=C1CCC[C@@H]2C[C@@H]1C[C@@H]1CCCCN1C2</smiles>

(+)-Lupanin

(-)-Lupanin<smiles>C1CCN2CC3CC(CN4CCCCC34)C2C1</smiles>

(+)- $\beta$-Isospartein

(-)- $\beta$-Isospartein

$\overbrace{O}^{N} N_{H}^{N}$

(+)-Thermopsin

(-)-Thermopsin<smiles>CC[C@H](N)C12CC(C[C@H]3CCCNC31)C1CCCCN12</smiles><smiles>C1CCNCC1</smiles>

(-)-Ormosanin

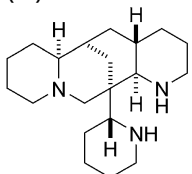

(+)-Ormosanin

Cytisus caucasicus, Lupinus pusillus (rostrote Lupine), Genista monosperma (Ginster), Pelargonium acutifolia, Pelargonium longifolia, Sophora pachycarpa, Ammodendron spp., Baptisia spp. Chamaecytisus proliferus, Adenocarpus hispanicus, Hovea linearis (Vogelaugen-Hovea), ${ }^{[214]}$ Lygos raetam var. sarcocarpa, ${ }^{[215]}$ Lupinus albus (weiße Lupine), ${ }^{[216]}$ Genista lydia (Steinginster) ${ }^{[217]}$

Cytisus scoparius (Besenginster), Lupinus spp., Adenocarpus spp., Piptanthus nanus, Sarothamnus spp., Chamaecytisus proliferus, Corothamnus rectipilosus, ${ }^{[215]}$ Chamaecytisus austriacus, ${ }^{[216]}$ Genista lydia ${ }^{[217]}$

Lupinus albus, Lupinus termis, Podalyria buxifolia, Virgilia capensis, Cytisus scoparius, andere Cytisus spp., Cadia purpurea, Ammopiptanthus mongolicus, Thermopsis chinensis (chinesische Scheinlupine), Leontice spp., Genista spp., Templetonia spp., Chamaespartium sagittale, ${ }^{[215]}$ Corothamnus rectipilosus, ${ }^{[215]}$ Genista rumelica, ${ }^{[215]}$ Genista sessilifolia, ${ }^{[215]}$ Chamaecytisus austriacus, ${ }^{[216]}$ Genista lydia ${ }^{[217]}$

Lupinus albus, Lupinus termis, Podalyria buxifolia, Virgilia capensis, Lupinus pusillus, Lupinus macounii, Baptisia versicolor, Podalyria calyptrata (Wasserblumenerbse), Ammodendron spp., Leontice smirnovii, Leontice eversmannii, Lygos raetam var. sarcocarpa, ${ }^{[215]}$ Genista lydia, ${ }^{[217]}$ Clathrotropis glaucophylla ${ }^{[218]}$

Lupinus spp., ${ }^{[211 a]}$ Lupinus pusillus ${ }^{[219]}$

Lupinus pusillus, ${ }^{[211 a, 220]}$ Lupinus sericeus (Seidenlupine), ${ }^{[221]}$ Lupinus argenteus stenophyllus (Silberlupine), Lupinus solosericeus, Sophora secundiflora (Meskalbohne)

Lupinus caudatus (Bitterlupine), Lupinus corymbosus

Thermopsis lanceolata (Goldlupine), Thermopsis rhombifolia (Büffelbohne), Sophora secundiflora

Ormosia panamensis (Coronil), Piptanthus nanus

Podopetalum ormondii, Ormosia semicastrata, Ormosia jamaicensis, Piptanthus nanus

Hovea linearis, Templetonia retusa (Hahnenzunge), Ormosia semicastrata, Ammopiptanthus mongolicus

(+)-Piptanthin

(-)-Piptanthin

Hovea linearis, Templetonia retusa, Ormosia semicastrata, Ammopiptanthus mongolicus, Piptanthus nanus hochgiftig

wehenfördernd, antiarrhythmisch

giftig für Vieh

giftig für Vieh

[a] Arten und biologische Aktivität ohne Literaturangabe sind dem Dictionary of Alkaloids ([Lit.] [193]) entnommen.

Tabelle 14 zusammengestellt, sind enantiomere Metaboliten dieser Alkaloide besonders selten, doch die bekannten Verbindungen werden von verschiedenen Pflanzen gebildet. Einige dieser Metaboliten wie Ammodendrin werden als fast racemisches Gemisch von einer einzelnen Art gebildet,

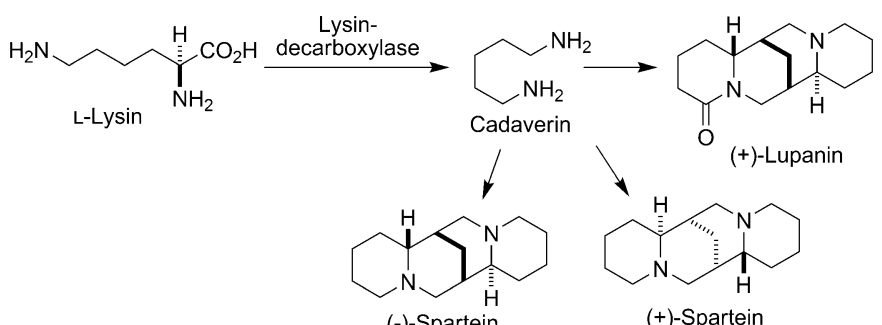

Schema 14. Biogenese von (-)-Spartein. während andere Metaboliten als partielle Racemate vorkommen. ${ }^{[6 b]}$ So macht die $S$ - oder (-)-Isoform von Nicotin meist mehr als $95 \%$ des von Tabak produzierten Naturstoffs aus. ${ }^{[8]}$

Während viel Arbeit in die Aufklärung der Biosynthesewege dieser Metaboliten gesteckt wurde ${ }^{[8,227]}$ wurde die enantiomere Biogenese der Piperidin- und Pyridinalkaloide noch nicht untersucht. Wie bei Nicotin haben sich die meisten Biosynthese-Untersuchungen auf das Hauptenantiomer, in diesem Fall (-)-Nicotin, konzentriert, und von daher gibt es keine Erklärungen für die Bildung von $(+)$-Nicotin. Außerdem deckte die Charakterisierung von Enzymen für die Biosynthese von Piperidin- und Pyridinalkaloiden wie Coniin eine hohe Substrat- und Stereospezifität auf, sodass nur die Biosynthese eines Enantiomers bekannt ist. ${ }^{[182]}$ Bisher wurden noch keine Enzyme für die Synthese von Piperidin- 
Tabelle 14: Enantiomere Piperidin- und Pyridinalkaloide. ${ }^{[a]}$

\begin{tabular}{|c|c|c|}
\hline $\begin{array}{l}\text { Piperidin- oder } \\
\text { Pyridinalkaloid }\end{array}$ & Art & biologische Aktivität \\
\hline & $\begin{array}{l}\text { Genista sphaerocarpa, Ammodendron conollyi, Ammodendron spp., Sophora franchetiana, } \\
\text { Sophora tomentosa (Silberbusch), }{ }^{[228]} \text { Coelidium fourcadei, Lupinus formosus (Sommerlu- } \\
\text { pine), }{ }^{[225 a, b]} \text { Lupinus varius, }{ }^{[225 a]} \text { Lupinus hirsutus }{ }^{[225]}\end{array}$ & teratogen ${ }^{[225]}$ \\
\hline $\begin{array}{l}(+) \text {-Ammodendrin } \\
(-) \text {-Ammodendrin }\end{array}$ & $\begin{array}{l}\text { Ammodendron conollyi, Ammodendron spp., Sophora franchetiana, Sophora tomentosa, }{ }^{[228]} \\
\text { Coelidium fourcadei, Lupinus formosus, }{ }^{[225 a, b]} \text { Castilleja miniata (Roter Indianerpinsel) }{ }^{[225 a]}\end{array}$ & teratogen $^{[225]}$ \\
\hline & $\begin{array}{l}\text { Nicotiana glauca (Strauchtabak), }{ }^{[225 \mathrm{~d}]} \text { Aphaenogaster subterranea (Ameise), }{ }^{\left[{ }^{[29]}\right.} \text { Aphaeno- } \\
\text { gaster miamiana (Ameise) }{ }^{[229]}\end{array}$ & teratogen ${ }^{[225 d]}$ \\
\hline $\begin{array}{l}(+) \text {-Anabasin } \\
(-) \text {-Anabasin }\end{array}$ & $\begin{array}{l}\text { Nicotiana glauca, }{ }^{[225 \mathrm{~d}]} \text { Anabasis aphylla, }{ }^{[230]} \text { Aphaenogaster subterranea, }{ }^{[229]} \text { Aphaenogaster } \\
\text { miamiana, }{ }^{[229]} \text { Messor sanctus (Ameise) }{ }^{[229]}\end{array}$ & teratogen $^{[225 \mathrm{~d}]}$ \\
\hline $\mathrm{Me}$ & Conium maculatum (Gefleckter Schierling) ${ }^{[225 c]}$ & giftig für Vieh ${ }^{[225 c]}$ \\
\hline $\begin{array}{l}\text { niin } \\
\text { niin }\end{array}$ & Conium maculatum ${ }^{[225]}$ & giftig für Vieh ${ }^{[225 c]}$ \\
\hline$\stackrel{N}{\mathrm{Me}}$ & Nicotiana tabacum (Zuchttabak) & $\begin{array}{l}\text { bindet schwach an nicotinische Ace- } \\
\text { tylcholinrezeptoren }{ }^{[8]}\end{array}$ \\
\hline $\begin{array}{l}(+) \text {-Nicotin } \\
(-) \text {-Nicotin }\end{array}$ & $\begin{array}{l}\text { Nicotiana tabacum, andere Nicotiana spp., Asclepias syriaca (Gewöhnliche Seidenpflanze), } \\
\text { Lycopodium spp., Equisetum arvense (Ackerschachtelhalm), Sedum acre (Scharfe Fett- } \\
\text { henne) }\end{array}$ & $\begin{array}{l}\text { sehr reaktiv gegenüber nicotinischen } \\
\text { Acetylcholinrezeptoren }^{[8]}\end{array}$ \\
\hline
\end{tabular}

[a] Arten und biologische Aktivität ohne Literaturangabe sind dem Dictionary of Alkaloids ([Lit.] [193]) entnommen.

oder Pyridinalkaloiden mit entgegengesetzter Stereospezifität identifiziert.

\subsection{Benzylisochinolinalkaloide}

Benzylisochinolinalkaloide (BIA) sind eine strukturell vielfältige Gruppe stickstoffhaltiger sekundärer Pflanzeninhaltsstoffe mit mehr als 2500 definierten Mitgliedern, die überwiegend in fünf Pflanzenfamilien gebildet werden: Papaveraceae, Fumariaceae, Ranunculaceae, Berberidaceae und Menispermaceae. ${ }^{[196 c, 231]}$ Auf der Basis ihrer Struktur können die Substanzen in zahlreiche Untergruppen eingeteilt werden, so die Aporphine, die Phthalidisochinoline, die Morphinane, die Protoberberine und die Pavine. ${ }^{[232]}$ Benzylisochinolinalkaloide werden bekanntermaßen von Schlafmohn (Papaver somniferum) gebildet und haben vielfältige biologische Wirkungen, oft von pharmakologischer Bedeutung. Dazu gehören Morphin und Codein, zwei bekannte Analgetika, Papaverin, ein Muskelrelaxans, Noscapin, ein Antitumorwirkstoff, und Sanguinarin, ein Antibiotikum. ${ }^{[231 b, 233]}$ Die Biosynthese der Benzylisochinolinalkaloide wurde sorgfältig untersucht, und der größte Teil der Biogenese ist auf enyzmatischer Ebene aufgeklärt. ${ }^{[196 c, 231-233]} \mathrm{Au}-$ Berdem sind, wie aus Tabelle 15 hervorgeht, auch enantiomere Benzylisochinoline bekannt, doch ist die Biosynthese aller Enantiomere noch nicht in Gänze verstanden.
Die Biosynthese aller Benzylisochinolinalkaloide geht vom L-Tyrosin aus und verläuft nach dem grundlegenden Benzylisochinolin-Stoffwechselweg. ${ }^{[232,233]}$ Wie in Schema 15 dargestellt, ist die erste beteiligte Reaktion der BIA-Synthese die asymmetrische Pictet-Spengler-Kondensation von Dopamin (aus Tyrosin) und p-Hydroxyphenylacetaldehyd (4HPAA) zu enantiomerenreinem $(S)$-Norcoclaurin, katalysiert von der Norcoclaurinsynthase (NCS) ${ }^{[221]}$ In vier enzymatischen Stufen wird $(S)$-Norcoclaurin in enantiomerenreines $(S)$-Reticulin umgewandelt. Dieses fungiert als zentraler Verzweigungspunkt zu den verschiedenen Benzylisochinolinalkaloiden, von denen viele die gleiche Konfiguration wie $(S)$-Reticulin aufweisen. Demgegenüber sind die Promorphinan- und die Morphinanuntergruppe der BIA $R$-konfiguriert. ${ }^{[232]}$ Diese Alkaloide stammen von $(R)$-Reticulin ab, das durch Konfigurationsumkehr aus $(S)$-Reticulin entsteht. Dazu wird die Verbindung durch die 1,2-Dehydroreticulinsynthase (DRS) oxidiert und anschließend durch die 1,2Dehydroreticulinreduktase (DRR) wieder reduziert. ${ }^{[235]}$

Ursprünglich wurde vermutet, dass die Biosynthese einiger $R$-konfigurierter Benzylisochinolinalkaloide über $(R)$ Reticulin verlaufen würde; dies wurde jedoch durch Einbauversuche mit markierten Vorstufen widerlegt. ${ }^{[236]}$ Weil $(R)$-Reticulin nicht in die komplexeren $R$-konfigurierten BIA eingebaut wird, vermutete man, dass die Bildung der $R$-Serie auf die stereochemische Inversion des $S$-Enantiomers über eine enzymatische Oxidation und Reduktion zurückgeht. Ähnlich wie enantiomeres Reticulin werden auch andere 
Tabelle 15: Enantiomere sekundäre Benzylisochinolin-Alkaloid-Metaboliten. ${ }^{[a]}$

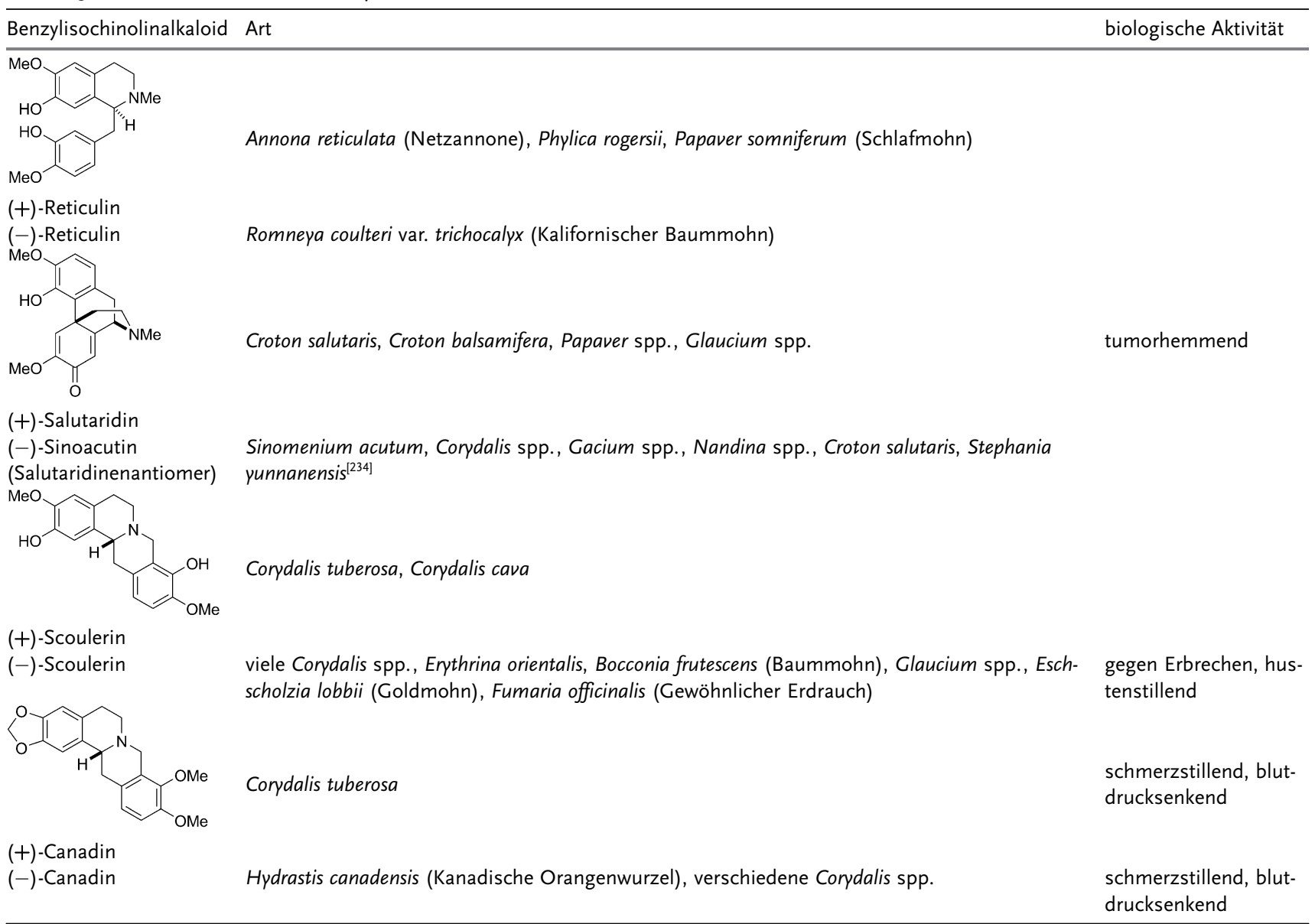

[a] Arten und biologische Aktivität ohne Literaturangabe sind dem Dictionary of Alkaloids ([Lit.] [193]) entnommen.

BIA-Enantiomere wie $(R)$ - und $(S)$-Canadin durch eine Konfigurationsumkehr gebildet. Im Falle des enantiomeren Canadins wird $(S)$-Canadin zunächst von der $(S)$-Tetrahy-

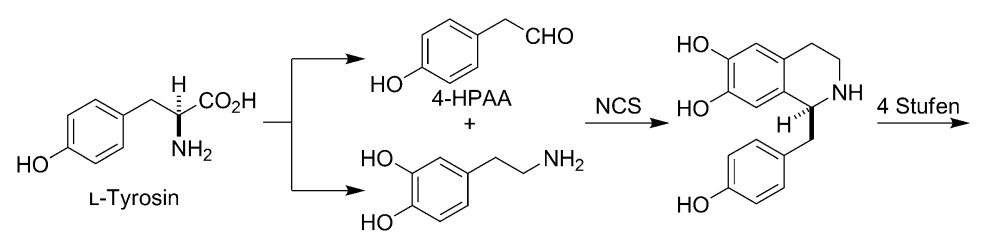

(S)-Norcoclaurin<smiles>CCCCCCCCCN1CCc2cc(O)c(O)cc2C1Cc1ccc(OC)cc1</smiles>

(S)-Reticulin

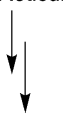

Aporphines Protoberberines Phthalideisoquinolines Rhoeadines/Papaverrubines Benzophenanthridines

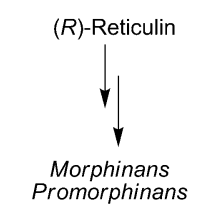

droxyprotoberberinoxidase (STOX) zu Berberin oxidiert, das anschließend von der Berberinreduktase zu $(R)$-Canadin umgesetzt wird (Schema 16). ${ }^{[236,237]}$

Leider fehlen wichtige Informationen zur Biosynthese aller enantiomeren BIA. Wie man bei der Aufklärung der Stoffwechselwege für enantiomeres Nicotin sehen konnte, ist nur die Synthese von einem Enantiomer der BIA-Naturstoffe bekannt; Gleiches gilt auch für $(S)$-Scoulerin und (+)-Salutaridin. ${ }^{[233]}$ Bis heute wurde noch kein enantiomer entgegengesetzt ausgerichtetes Enzym für die Biosynthese von Benzylisochinolinalkaloiden isoliert.

\section{Zusammenfassung und Ausblick}

Wie in diesem Aufsatz gezeigt wurde, ist die Bildung enantiomerer Naturstoffe in der Natur nicht so ungewöhnlich, wie man ursprünglich erwartet hatte. Während die Zahl der bislang entdeckten Verbindungen nur einen kleinen Bruchteil $(<1 \%)$ des Metaboloms der Biosphäre ausmacht, ist klar, dass biogenetische Mechanismen zur Erzeugung von Enantiomeren weit verbreitet sind. Viele Rätsel und stereochemische Anomalien sind

Schema 15. Frühe Stufen der Benzylisochinolinalkaloid-Biogenese. 

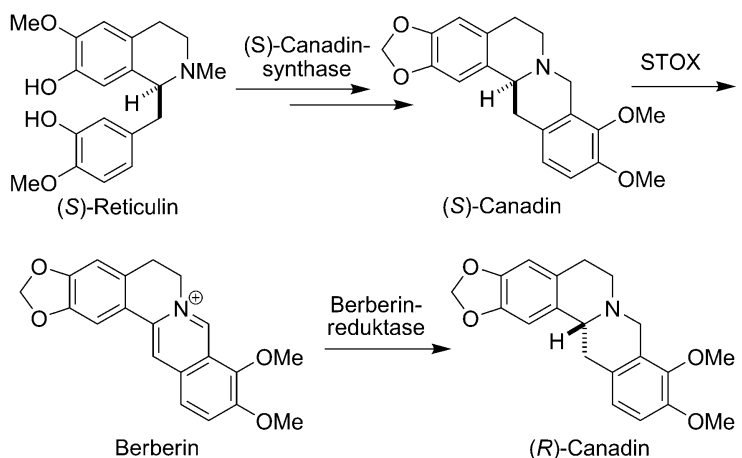

Schema 16. Biosynthese von enantiomerem Canadin.

und bleiben ein herausforderndes Gebiet für zukünftige Forschungen und Entdeckungen. Umfangreiche Forschungen dokumentieren über die Jahre den Versuch, die Biogenese einiger enantiomerer Metaboliten zu verstehen, doch reicht unser Wissen noch nicht sehr tief.

Die Stellen, an denen sich die Biosynthesewege zu den jeweiligen Enantiomeren aufspalten, wechseln. So kann bei den Terpencyclasen (Pinen, Limonen; siehe Schema 2) eine einfache Vorstufe wie Geranyldiphosphat in der ersten enzymatischen Stufe der Biosynthese Ausgangspunkt für zwei enantiomere Formen sein. In anderen Fällen geschieht die Verzweigung später im Stoffwechselweg, wie bei den Stephacidinen und Notoamiden. Dank der aktuellen Fortschritte bei der Sequenzierung ganzer Genome, bei Proteom- und Metabolomforschung und dem bioinformatischen Vergleich von Genomen kann erwartet werden, dass die Aufklärung dieser komplexen Stoffwechselwege nunmehr rascher vorankommt. Oft entstehen enantiomere Metaboliten durch das Zusammenwirken zweier getrennter Enzyme mit unterschiedlichen Mechanismen, die enantiodivergent wirken, wie im Fall der (+)- und (-)-Limonensynthasen. Andererseits kann das Entstehen beider Enantiomere in einer Enzymreaktion teilweise durch einen Mangel an Substrat- und Stereospezifität des Enzyms zustandekommen, wie dies bei der Synthese von (+)-Carvon, katalysiert von der (+)-Limonen-6-hydroxylase und der (+)-trans-Carveoldehydrogenase, beobachtet wurde. Es gibt Beispiele, bei denen die Bildung eines Enantiomers auf Enzymebene verstanden ist, während die Biogenese der enantiomeren Nebenkomponente unbekannt ist. Außerdem bleibt der enantioselektive Abbau eines zunächst gebildeten racemischen Metaboliten eine weitere Möglichkeit, die noch wenig untersucht ist. Mit der Entdeckung immer weiterer Naturstoffe werden mit Sicherheit trotz der aktuellen Kürzung der Forschungsförderung für die Isolierung und Strukturaufklärung von Naturstoffen weitere Familien enantiomerer Naturstoffe gefunden werden. Die unüberschaubar vielen genetischen und biochemischen Mechanismen für Kontrolle und phänotypische Ausprägung enantiomerer Naturstoffe werden auch weiterhin die Phantasie anregen. Das Next-Generation-Sequencing und die bioinformatischen Möglichkeiten, Biosynthesegene für Naturstoffe aufzufinden und daraus Stoffwechselwege aus verschiedenen Mikrobenund Pflanzenarten zusammenzufügen, werden die künftige Forschung erheblich beinflussen. Die ständige Weiterent- wicklung von molekularen Verfahren zur gezielten Ausschaltung von Genfunktionen wird neue Einblicke in die Einzelheiten des Naturstoffaufbaus und die Rolle funktioneller Gruppen ermöglichen. Außerdem werden durch Klonierung, Überexpression und Reinigung von Biosyntheseenzymen aus verschiedenen Mikroorganismen- und Pflanzenarten In-vitro-Untersuchungen einzelner Bestandteile des Metabolismus mit natürlichen und nichtnatürlichen Substraten ermöglicht. Diese leistungsfähigen Ansätze werden den Zugang zu weiterer chemischer Vielfalt eröffnen, mit deren Hilfe interessante biologische Aktivitäten und potenzielle Leitstrukturen identifiziert werden können.

Schließlich muss der genetische Mechanismus der Bildung enantiomerer Naturstoffe auch noch aus Sicht der evolutionären Molekulargenetik analysiert werden. ${ }^{[238]}$ Unter diesem Blickwinkel ist die entscheidende Frage die, weshalb ein Enzym, das eine enantiomere Form einer Verbindung synthetisiert, sich so weiterentwickelt, dass es nun das enantiomere Gegenstück bildet. Ist dazu z. B. eine Genduplikation erforderlich, durch die eines der Paralogen von Selektionszwängen befreit wird und sich so durch genetische Drift infolge verschiedener Basensubstitutionen entwickelt? Oder kann alternativ ein einzelnes Orthologes diese Eigenschaft unabhängig von verschiedenen Vorstufenformen einer enzymatischen Funktion entwickeln? Die Beispiele aus dem Aufsatz lassen beide Möglichkeiten zu. Eine verwandte Frage in Fällen, in denen sich zwei stereoselektive Enzyme aus einem gemeinsamen Vorfahren entwickelt haben, ist, welche Funktion dieser Vorfahr hatte - produzierte er ein (teilweise) racemisches Gemisch oder ein reines Enantiomer? Es gibt Beispiele, in denen ein Enzym beide Enantiomere bildet, und auch solche, in denen ein Gemisch mit einem großen Enantiomerenüberschuss entsteht. Kann man sich den zweiten Fall als Beispiel eines Zwischenzustandes in der Evolution eines Enzyms von einer nichtselektiven zu einer rein selektiven Form vorstellen? Dieser provokativen Frage sollte man nachgehen, denn wenn die Evolution von einer Form des Enzyms zur anderen fortschreitet (also von einer (-)-produzierenden $\mathrm{zu}$ einer (+)-produzierenden Form) und dies nicht in einem Schritt geschieht (also durch den Austausch einer einzelnen Aminosäure im aktiven Zentrum), sondern durch den sukzessiven Austausch mehrerer Aminosäuren, dann müssen alle Zwischenzustände noch funktionell sein und dürfen auch den produzierenden Organismus nicht schädigen. Der funktionale Zustand des Vorstufenproteins und die Zahl der Veränderungen, die in einem Protein notwendig sind, um von einem Enantiomer als Reaktionsprodukt zum anderen zu gelangen, sind grundlegende Fragen, die bislang kaum oder gar nicht untersucht wurden. Eine ebenso interessante Frage betrifft die adaptive Bedeutung dieser stereoselektiven Übergänge, ein Gebiet, das wahrscheinlich zahlreiche Forschungsmöglichkeiten bereithält. Die phylogenetische und bioinformatische Analyse von enantiomeren Enzymen verspricht, mechanistische Signaturen ihrer funktionellen Evolution aufzudecken, darunter die Bedeutung von Genverdopplung, Exon-Shuffling, natürlicher Selektion und genetischer Drift. Besonders faszinierend an Enzymen, die entgegengesetzte Enantiomere einer bestimmten Struktur bilden, ist die Möglichkeit, viele unabhängige Momente 
dieses evolutionären Vorgangs zu untersuchen - eine seltene Gelegenheit in der molekularen Evolution. Eine solche Untersuchung könnte es uns ermöglichen, allgemeine Prinzipien der Evolution von Proteinstruktur und -funktion bei der subtilsten aller möglichen Änderungen in der Naturstoffchemie aufzudecken.

Diese Arbeiten wurden von den National Institutes of Health gefördert (RO1CA070375 an RMW \& DHS).

Eingegangen am 11. Oktober 2011

Übersetzt von Dr. Burkard Neuß, Jülich

[1] K. A. Miller, S. Tsukamoto, R. M. Williams, Nat. Chem. 2009, 1, $63-68$.

[2] G. L. Challis, D. A. Hopwood, Proc. Natl. Acad. Sci. USA 2003, $100,14555-14561$.

[3] R. B. Herbert, The Biosynthesis of Secondary Metabolites, 2. Aufl., Chapman and Hall, New York, 1989

[4] J. Clardy, C. Walsh, Nature 2004, 432, 829-837.

[5] A. A. L. Gunatilaka, J. Nat. Prod. 2006, 69, 509-526.

[6] a) S. M. Colegate, R. J. Molyneux, Bioactive Natural Products: Detection, Isolation, and Structural Determination, 2. Aufl., Taylor and Francis, Boca Raton, 2008, S. 209-219; b) S. T. Lee, D. R. Gardner, C.-W. T. Chang, K. E. Panter, R. J. Molyneux, Phytochem. Anal. 2008, 19, 395-402.

[7] A. Somogyi, F. Bochner, D. Foster, Aust. Prescr. 2004, 27, $47-$ 49.

[8] a) J. W. Gorrod, P. Jacob, Analytical Determination of Nicotine and Related Compounds and Their Metabolites, Elsevier, Amsterdam, 1999; b) D. Pogocki, T. Ruman, M. Danilczuk, M. Danilczuk, M. Celuch, E. Walajtys-Rode, Eur. J. Pharmacol. 2007, 563, 18-39.

[9] J. D. Connolly, R. A. Hill, Dictionary of Terpenoids, Chapman and Hall, London, 1991.

[10] E. M. Davis, R. Croteau, Top. Curr. Chem. 2000, 209, 53-95.

[11] a) R. P. Gregson, D. Ouvrier, J. Nat. Prod. 1982, 45, 412-414; b) A. Fontana, I. Fakhr, E. Mollo, G. Cimino, Tetrahedron: Asymmetry 1999, 10, 3869-3872.

[12] M. L. Wise, Phycologia 2003, 42, 370-377.

[13] a) R. Croteau, Chem. Rev. 1987, 87, 929-954; b) B. M. Lange, T. Rujan, W. Martin, R. Croteau, Proc. Natl. Acad. Sci. USA 2000, 97, 13172-13177;c) D. J. McGarvey, R. Croteau, Plant Cell 1995, 7, 1015-1026.

[14] D. C. Hyatt, B. Youn, Y. Zhao, B. Santhamma, R. M. Coates, R. B. Croteau, C. Kang, Proc. Natl. Acad. Sci. USA 2007, 104, 5360-5365, zit. Lit.

[15] a) R. Croteau, D. E. Cane, Methods Enzymol. 1985, 110, $352-$ 405; b) D. E. Cane, Acc. Chem. Res. 1985, 18, 220-226; c) C. J. Wheeler, R. Croteau, J. Biol. Chem. 1987, 262, 8213-8219; d) W. Schwab, D. C. Williams, E. M. Davis, R. Croteau, Arch. Biochem. Biophys. 2001, 392, 123-136.

[16] a) M. Laska, P. Teubner, Chem. Senses 1999, 24, 161-170; b) R. Bentley, Chem. Rev. 2006, 106, 4099-4112.

[17] a) R. Kjonaas, R. Croteau, Arch. Biochem. Biophys. 1983, 220, 79-89; b) W. R. Alonso, J. I. M. Rajaonarivony, J. Gershenzon, R. Croteau, J. Biol. Chem. 1992, 267, 7582-7587; c) S. M. Colby, W. R. Alonso, E. J. Katahira, D. J. McGarvey, R. Croteau, J. Biol. Chem. 1993, 268, 23016-23024.

[18] H.-J. Pyun, R. M. Coates, K. C. Wagschal, P. McGeady, R. B. Croteau, J. Org. Chem. 1993, 58, 3998-4009.

[19] A. Yuba, K. Yazaki, M. Tabata, G. Honda, R. Croteau, Arch. Biochem. Biophys. 1996, 332, 280-287.
[20] J. Bohlmann, C. L. Steele, R. Croteau, J. Biol. Chem. 1997, 272, $21784-21792$.

[21] K. Rani, A. Akhila, Fitoterapia 1998, 69, 337-348.

[22] T. Maruyama, M. Ito, F. Kiuchi, G. Honda, Biol. Pharm. Bull. 2001, 24, 373-377.

[23] H. J. Bouwmeester, J. Gerschenzon, M. C. J. M. Konings, R. Croteau, Plant Physiol. 1998, 117, 901-912.

[24] J. Lücker, M. K. El Tamer, W. Schwab, F. W. A. Verstappen, L. H. W. van der Plas, H. J. Bouwmeester, H. A. Verhoeven, Eur. J. Biochem. 2002, 269, 3160-3171.

[25] J. Gershenzon, M. Maffei, R. Croteau, Plant Physiol. 1989, 89, $1351-1357$.

[26] M. Ito, F. Kiuchi, L. L. Yang, G. Honda, Biol. Pharm. Bull. 2000, 23, 359-362.

[27] a) H. J. Bouwmeester, J. A. R. Davies, H. Toxopeus, J. Agric. Food Chem. 1995, 43, 3057-3064; b) B. Faber, K. Bangert, A. Mosandl, Flavour Fragrance J. 1997, 12, 305-314.

[28] A. B. Attygalle, X. Wu, D. R. Maddison, K. W. Will, Naturwissenschaften 2009, 96, 1443-1449.

[29] K. Sjödin, M. Persson, J. Fäldt, I. Ekberg, A. K. Borg-Karlson, J. Chem. Ecol. 2000, 26, 1701-1720.

[30] A. Tsokou, K. Georgopoulou, E. Melliou, P. Magiatis, E. Tsitsa, Molecules 2007, 12, 1233-1239.

[31] Y. Holm, P. Vuorela, R. Hiltunen, Flavour Fragrance J. 1997, 12, $397-400$.

[32] A. Akhila, D. V. Banthorpe, M. G. Rowan, Phytochemistry 1980, $19,1433-1437$.

[33] T. J. Savage, H. Ichii, S. D. Hume, D. B. Little, R. Croteau, Arch. Biochem. Biophys. 1995, 320, 257-265.

[34] M. A. Phillips, M. R. Wildung, D. C. Williams, D. C. Hyatt, R. Croteau, Arch. Biochem. Biophys. 2003, 411, 267-276.

[35] H. Gambliel, R. Croteau, J. Biol. Chem. 1982, 257, 2335-2342.

[36] K. Wagschal, T. J. Savage, R. Croteau, Tetrahedron 1991, 47, $5933-5944$.

[37] R. Croteau, J. Gershenzon, C. J. Wheeler, D. M. Satterwhite, Arch. Biochem. Biophys. 1990, 277, 374-381.

[38] A. R. Battersby, D. G. Laing, R. Ramage, J. Chem. Soc. Perkin Trans. 1 1972, 2743-2748.

[39] R. Croteau, J. Shaskus, Arch. Biochem. Biophys. 1985, 236, $535-543$.

[40] D. V. Banthorpe, D. Baxendale, J. Chem. Soc. 1970, 2694-2696.

[41] M. L. Wise, T. J. Savage, E. Katahira, R. Croteau, J. Biol. Chem. 1998, 273, $14891-14899$.

[42] H. Gambliel, R. Croteau, J. Biol. Chem. 1984, 259, 740-748.

[43] a) R. Croteau, D. M. Satterwhite, C. J. Wheeler, N. M. Felton, J. Biol. Chem. 1989, 264, 2075-2080; b) R. Croteau, D. M. Satterwhite, J. Biol. Chem. 1989, 264, 15309-15315; c) P. McGeady, H.-J. Pyun, R. M. Coates, R. Croteau, Arch. Biochem. Biophys. 1992, 299, 63-72.

[44] I. Prosser, I. G. Altug, A. L. Phillips, W. A. König, H. J. Bouwmeester, M. H. Beale, Arch. Biochem. Biophys. 2004, 432, $136-144$.

[45] C. O. Schmidt, H. J. Bouwmeester, S. Franke, W. A. König, Chirality 1999, 11, 353-362.

[46] C. M. Starks, K. Back, J. Chappell, J. P. Noel, Science 1997, 277, $1815-1820$.

[47] D. E. Cane, M. Tandon, P. C. Prabhakaran, J. Am. Chem. Soc. 1993, $115,8103-8106$.

[48] D. E. Cane, J. S. Oliver, P. M. H. Harrison, C. Abell, B. R. Hubbard, C. T. Kane, R. Lattman, J. Am. Chem. Soc. 1990, 112, $4513-4524$.

[49] S. M. Colby, J. Crock, B. Dowdle-Rizzo, P. G. Lemaux, R. Croteau, Proc. Natl. Acad. Sci. USA 1998, 95, 2216-2221.

[50] C. L. Steele, J. Crock, J. Bohlmann, R. Croteau, J. Biol. Chem. 1998, 273, 2078-2089.

[51] D. E. Cane, Chem. Rev. 1990, 90, 1089-1103. 
[52] M. Niwa, M. Iguchi, S. Yamamura, Chem. Pharm. Bull. 1980, 28, $997-999$.

[53] P. A. Searle, N. M. Jamal, G. M. Lee, T. F. Molinski, Tetrahedron 1994, 50, 3879-3888.

[54] P. Horton, W. D. Inman, P. Crews, J. Nat. Prod. 1990, 53, $143-$ 151.

[55] C. M. Beechan, C. Djerassi, H. Eggert, Tetrahedron 1978, 34, 2503-2508.

[56] K. W. L. Yong, A. Jankam, J. N. A. Hooper, A. Suksamrarn, M. J. Garson, Tetrahedron 2008, 64, 6341-6348.

[57] Y. Naya, F. Miyamoto, T. Takemoto, Experientia 1978, 34, $984-$ 986.

[58] K. Yoshihara, Y. Hirose, Proceedings of the 21st Symposium on the Chemistry of Terpenes, Essential Oils and Aromatics. The Chemical Society of Japan, Okayama, 1973, Abstract no. 1 E704.

[59] W. A. König, N. Bülow, C. Fricke, S. Melching, A. Rieck, H. Muhle, Phytochemistry 1996, 43, 629-633.

[60] J. Degenhardt, T. G. Köllner, J. Gershenzon, Phytochemistry 2009, 70, $1621-1637$

[61] S. D. Lorimer, R. T. Weavers, Phytochemistry 1987, 26, 3207 3215.

[62] F. Deguerry, L. Pastore, S. Wu, A. Clark, J. Chappell, M. Schalk, Arch. Biochem. Biophys. 2006, 454, 123-136.

[63] M. Pietsch, W. A. König, Phytochem. Anal. 2000, 11, 99-105.

[64] M. Bordoloi, V. S. Shukla, S. C. Nath, R. P. Sharma, Phytochemistry 1989, 28, 2007-2037.

[65] a) K. Nabeta, N. Katayama, S. Nakagawara, K. Katoh, Phytochemistry 1993, 32, 117-122; b) K. Nabeta, M. Fujita, K. Komuro, K. Katayama, T. Takasawa, J. Chem. Soc. Perkin Trans. 1 1997, 2065-2070.

[66] D. E. Cane, M. Tandon, J. Am. Chem. Soc. 1995, 117, 56025603.

[67] B. Tomita, Y. Hirose, Phytochemistry 1972, 11, 3355-3357.

[68] N. N. Gerber, Phytochemistry 1971, 10, 185-189.

[69] Y. Ohta, Y. Hirose, Tetrahedron Lett. 1967, 8, 2073-2075.

[70] S. Melching, N. Bülow, K. Wihstutz, S. Jung, W. A. König, Phytochemistry 1997, 44, 1291-1296.

[71] E. Grotewold, The Science of Flavonoids, Springer, New York, 2006.

[72] R. Kazlauskas, P. T. Murphy, R. J. Wells, Tetrahedron Lett. 1978 19, $4951-4954$

[73] G. Guella, I. Mancini, A. Guerriero, F. Pietra, Helv. Chim. Acta 1985, 68, 1276-1282

[74] E. Mollo, M. Gavagnin, M. Carbone, Y.-W. Guo, G. Cimino, Chemoecology 2005, 15, 31-36.

[75] G. Cimino, S. De Stefano, L. Minale, Experientia 1975, 31 $1117-1118$

[76] W. Fenical, O. McConnell, Experientia 1975, 31, 1004-1005.

[77] M. E. S. Koker, J. Pharm. Bioresour. 2010, 7, 77-92.

[78] W. Fenical, J. J. Sims, D. Squatrito, R. M. Wing, R. Radlick, J. Org. Chem. 1973, 38, 2383-2386.

[79] G. Cimino, S. De Stefano, A. Guerriero, L. Minale, Tetrahedron Lett. 1975, 16, 1425-1428.

[80] A. Spinella, L. A. Alvarez, C. Avila, G. Cimino, Tetrahedron Lett. 1994, 35, 8665-8668.

[81] H. Weenen, M. H. H. Nkunya, A. A. El-Fadl, S. Harkema, B. Zwanenburg, J. Org. Chem. 1990, 55, 5107-5109.

[82] N. B. Perry, R. T. Weavers, Phytochemistry 1985, 24, $2899-$ 2904.

[83] V. De Santis, J. D. Medina, J. Nat. Prod. 1981, 44, 370-372.

[84] a) C. W. L. Bevan, D. E. U. Ekong, J. I. Okogun, J. Chem. Soc. C 1968, 1067-1070; b) D. E. U. Ekong, J. I. Okogun, Chem. Commun. 1967, 72-73.

[85] B. Weisshaar, G. I. Jenkins, Curr. Opin. Plant Biol. 1998, 1, 251 257.

[86] T. Vogt, Mol. Plant 2010, 3, 2-20.
[87] S. Suzuki, T. Umezawa, M. Shimada, J. Chem. Soc. Perkin Trans. 1 2001, 3252-3257.

[88] S. Suzuki, T. Umezawa, J. Wood Sci. 2007, 53, 273-284.

[89] L. B. Davin, N. G. Lewis, Curr. Opin. Plant Biol. 2005, 16, 398 406.

[90] P. Meresse, E. Dechaux, C. Monneret, E. Bertounesque, Curr. Med. Chem. 2004, 11, 2443-2466.

[91] T. Umezawa, Photochem. Rev. 2003, 2, 371-390, zit. Lit.

[92] T. Umezawa, T. Okunishi, M. Shimada, Wood Res. 1997, 84, 62 75, zit. Lit.

[93] L. D. Davin, H.-B. Wang, A. L. Crowell, D. L. Bedgar, D. M. Martin, S. Sarkanen, N. G. Lewis, Science 1997, 275, 362-366.

[94] A. T. Dinkova-Kostova, D. R. Gang, L. B. Davin, D. L. Bedgar, A. Chu, N. G. Lewis, J. Biol. Chem. 1996, 271, 29473-29482.

[95] M. Fujita, D. R. Gang, L. B. Davin, N. G. Lewis, J. Biol. Chem. 1999, 274, 618-627.

[96] Z.-Q. Xia, M. A. Costa, H. C. Pélissier, L. B. Davin, N. G. Lewis, J. Biol. Chem. 2001, 276, 12614-12623.

[97] T. Okunishi, N. Sakakibara, S. Suzuki, T. Umezawa, M. Shimada, J. Wood Sci. 2004, 50, 77-81.

[98] F. A. Macías, A. López, R. M. Varela, A. Torres, J. M. G. Molinillo, J. Agric. Food Chem. 2004, 52, 6443-6447.

[99] Y.-L. Leu, C.-L. Lin, P.-C. Kuo, Arch. Pharmacal. Res. 2011, 34, $377-382$.

[100] B.-Y. Park, S.-R. Oh, K.-S. Ahn, O.-K. Kwon, H.-K. Lee, Int. Immunopharmacol. 2008, 8, 967-973.

[101] X. Kong, J.-R. Yang, L.-Q. Guo, Y. Xiong, X.-Q. Wu, K. Huang, Y. Zhou, Eur. J. Pharmacol. 2009, 620, 84-89.

[102] H. Nishiwaki, M. Kumamoto, Y. Shuto, S. Yamauchi, J. Agric. Food Chem. 2011, 59, 13089-13095.

[103] T. Masuda, J. Akiyama, A. Fujimoto, S. Yamauchi, T. Maekawa, Y. Sone, Food Chem. 2010, 123, 442-450.

[104] M. Shoeb, S. M. Macmanus, P. Kong-Thoo-Lin, S. Celik, M. Jaspars, L. Nahar, S. D. Sarker, Daru J. Pharm. Sci. 2007, 15, $118-122$.

[105] S. Zhang, Y.-K. Won, C.-N. Ong, H.-M. Shen, Curr. Med. Chem. Anticancer Agents 2005, 5, 239-249.

[106] K.-H. Lee, ACS Symp. Ser. 1992, 507, 367-379.

[107] A. G. Desai, G. N. Qazi, R. K. Ganju, M. El-Tamer, J. Singh, A. K. Saxena, Y. S. Bedi, S. C. Taneja, H. K. Bhat, Curr. Drug Metab. 2008, 9, 581-591.

[108] a) S. K. Sadhu, E. Okuyama, H. Fujimoto, M. Ishibashi, Chem. Pharm. Bull. 2003, 51, 595-598; b) F. Ahmed, S. K. Sadhu, M. Ishibashi, J. Nat. Med. 2010, 64, 393-401.

[109] C. J. Ma, S. H. Sung, Y. C. Kim, Planta Med. 2004, 70, 79-80.

[110] J.-S. Liu, M.-F. Huang, Y.-L. Gao, J. A. Findlay, Can. J. Chem. 1981, 59, 1680-1684.

[111] B. Winkel-Shirley, Plant Physiol. 2001, 126, $485-493$.

[112] D. J. Allen, J. C. Gray, N. L. Paiva, J. T. Smith, Electrophoresis 2000, 21, 2051-2057, zit. Lit.

[113] a) L. Guo, R. A. Dixon, N. L. Paiva, J. Biol. Chem. 1994, 269 , $22372-22378$; b) R. A. Dixon, A. D. Dalkin, R. Edwards, T. Fahrendorf, G. Gowri, M. J. Harison, C. J. Lamb, G. J. Loake, C. A. Maxwell, J. D. Orr, N. L. Paiva in Phenolic Metabolism in Plants (Hrsg.: H. A. Stafford, R. K. Ibrahim), Plenum, New York, 1992, S. $91-138$; c) N. L. Paiva, R. Edwards, Y. Sun, G. Hrazdina, R. A. Dixon, Plant Mol. Biol. 1991, 17, 653-667.

[114] J. T. Cook, W. D. Ollis, I. O. Sutherland, O. R. Gottlieb, Phytochemistry 1978, 17, 1419-1422, zit. Lit.

[115] H. D. VanEtten, P. S. Matthews, E. H. Mercer, Phytochemistry 1983, 22, 2291-2295, zit. Lit.

[116] a) J. L. Ingham in Phytoalexins (Hrsg.: J. A. Bailey, J. W. Mansfield), Blackie \& Son Ltd., Glasgow, 1982, S. 21; b) L. M. Delserone, D. E. Matthews, H. D. VanEtten, Phytochemistry 1992, 31, 3813-3819. 
[117] R. N. Strange, J. R. Ingham, D. L. Cole, M. E. Cavill, C. Edwards, C. J. Cooksey, P. Garratt, Z. Naturforsch. C 1985, 40, $313-316$.

[118] Siehe Lit. [113c].

[119] D. G. Roux, E. A. Maihs, E. Paulus, Biochem. J. 1961, 78, $834-$ 839.

[120] F. Delle Monache, F. Ferrari, A. Poce-Tucci, G. B. Marini-Bettolo, Phytochemistry 1972, 11, 2333-2335.

[121] A. Nahrstedt, P. Proksch, E. E. Conn, Phytochemistry 1987, 26, $1546-1547$

[122] J. L. Donovan, V. Crespy, M. Oliveira, K. A. Cooper, B. B. Gibson, G. Williamson, Free Radical Res. 2006, 40, 1029-1034.

[123] M. Krause, R. Galensa, Chromatographia 1991, 32, 69-72.

[124] E. Bourgaud, A. Hehn, R. Larbat, S. Doerper, E. Gontier, S. Kellner, U. Matern, Phytochem. Rev. 2006, 5, 293-308.

[125] R. L. Mueller, Best Pract. Res. Clin. Haematol. 2004, 17, 23 -53.

[126] D. M. X. Donnelly, G. Boland, The Flavonoids: Advances in Research Since 1986, Chapman and Hall, London, S. 239, 1986.

[127] a) W. D. Ollis, H. J. P. E. M. Landgraf, O. R. Gottlieb, M. Taveira Magalhaes, Anais Acad. Bras. Cienc. 1964, 36, 31-32; b) W. D. Ollis, Experientia 1966, 22, 777-783; c) W. B. Eyton, W. D. Ollis, I. O. Sutherland, O. R. Gottlieb, M. Taveira Magalhaes, L. M. Jackman, Tetrahedron 1966, 21, 2683-2696.

[128] D. J. Jung, A. Porzel, S. Huneck, Phytochemistry 1991, 30, 710712 .

[129] K. Hata, K. Sano, Tetrahedron Lett. 1966, 7, 1461-1465.

[130] K.-S. Ahn, W.-S. Sim, I.-H. Kim, Planta Med. 1996, 62, 7-9.

[131] E.-A. Bae, M. J. Han, N.-J. Kim, D.-H. Kim, Bio. Pharm. Bull. 1998, 21, 990-992.

[132] S.-S. Choi, K.-J. Han, J.-K. Lee, H.-K. Lee, E.-J. Han, D.-H. Kim, H. W. Suh, Life Sci. 2003, 73, 471-485.

[133] S. Y. Kang, K. Y. Lee, S. H. Sung, M. J. Park, Y. C. Kim, J. Nat. Prod. 2001, 64, 683-685.

[134] A. Chatterjee, R. Sen, D. Ganguly, Phytochemistry 1978, 17, $328-329$

[135] A. Basile, S. Sorbo, V. Spadaro, M. Bruno, A. Maggio, N. Faraone, S. Rosselli, Molecules 2009, 14, 939-952.

[136] C. A. J. Erdelmeier, O. Sticher, Planta Med. 1985, 51, 407-409.

[137] S. Lee, D.-S. Shin, J. S. Kim, K.-B. Oh, S. S. Kang, Arch. Pharmacal Res. 2003, 26, 449-452.

[138] S.-K. Cho, A. M. A. El-Aty, J.-H. Choi, M. R. Kim, J. H. Shim, J. Pharm. Biomed. Anal. 2007, 44, 1154-1158.

[139] Z. Xu, X. Wang, Y. Dai, L. Kong, F. Wang, H. Xu, D. Lu, J. Song, Z. Hou, Chem.-Biol. Interact. 2010, 186, 239-246, zit. Lit.

[140] B. J. Donnelly, D. M. X. Donnelly, C. B. Sharkey, Phytochemistry 1965, 4, 337-340.

[141] D. M. X. Donnelly, J. O'Reilly, J. Thompson, Phytochemistry 1972, 11, 823-826.

[142] D. M. X. Donnelly, J. O'Reilly, W. B. Whalley, Phytochemistry 1975, 14, 2287-2290.

[143] M. E. Leite de Almeida, O. R. Gottlieb, Phytochemistry 1974, $13,751-752$.

[144] R. M. Letcher, I. M. Shirley, Phytochemistry 1976, 15, 353-354.

[145] M. Gregson, W. D. Ollis, I. O. Sutherland, O. R. Gottlieb, M. T. Magalhaes, Phytochemistry 1978, 17, 1375-1377.

[146] a) C. B. Dempsey, D. M. X. Donnelly, R. A. Laidlaw, Chem. Ind. 1963, 491-492; b) M. M. Rao, T. R. Seshadri, Tetrahedron Lett. 1963, 4, 211-215.

[147] N. Muangnoicharoen, A. W. Frahm, Phytochemistry 1982, 21, $767-772$.

[148] V. Pathak, O. Shirota, S. Sekita, Y. Hirayama, Y. Hakamata, T. Hayashi, T. Yanagawa, M. Satake, Phytochemistry 1997, 46, $1219-1223$

[149] a) L. Jurd, K. Stevens, G. Manners, Phytochemistry 1972, 11, 3287-3292; b) M. Gregson, W. D. Ollis, B. T. Redman, I. O. Sutherland, H. H. Dietrichs, O. R. Gottlieb, Phytochemistry 1978, 17, $1395-1400$.
[150] N. Beldjoudi, L. Mambu, M. Labaïd, P. Grellier, D. Ramanitrahasimbola, P. Rasoanaivo, M. T. Martin, F. Frappier, J. Nat. Prod. 2003, 66, 1447-1450.

[151] V. P. Papageorgiou, A. N. Assimopoulou, E. A. Couladouros, D. Hepworth, K. C. Nicolaou, Angew. Chem. 1999, 111, $280-$ 311; Angew. Chem. Int. Ed. 1999, 38, 270-300.

[152] K. Inoue, S. Ueda, H. Nayeshiro, H. Inouye, Phytochemistry 1983, 22, 737-741.

[153] P. Rüedi, C. H. Eugster, Helv. Chim. Acta 1977, 60, 945-947.

[154] S. R. Baerson, A. M. Rimando, ACS Symp. Ser. 2005, 995, $2-$ 14.

[155] Nonactin und seine Homologen leiten sich von repetitiven monomeren (+)- und (-)-Vorstufen ab, daher beziehen sich viele der folgenden Zitate auf die Isolierung des MakrotetrolidNaturproduktes im Unterschied zur Isolierung der einzelnen Monomervorstufen; a) R. E. Bennett, S. A. Brindle, N. A. Giuffre, P. W. Jackson, J. Kowald, F. E. Pansy, D. Perlman, W. H. Trejo, Antimicrob. Agents Chemother. 1961, 169-172; b) R. Corbaz, L. Ettinger, E. Gaumann, W. Keller-Schlierlein, F. Kradolfer, L. Neipp, V. Prelog, H. Zähner, Helv. Chim. Acta 1955, 38, 1445-1448; c) M. Dobler, Helv. Chim. Acta 1972, 55, 1371-1384; d) J. D. Dutcher, Antimicrob. Agents Chemother. 1961, 173 -177; e) H. Gerlach, R. Hutter, W. Keller-Schlierlein, J. Seibl, H. Zähner, Helv. Chim. Acta 1967, 50, 1782-1793; f) W. Keller-Schierlein, H. Gerlach, Fortschr. Chem. Org. Naturst. 1968, 26, 161-189; g) G. P. Menshikov, M. M. Rubinsthein, J. Gen. Chem. USSR 1956, 26, 2267; h) E. Meyers, F. E. Pansy, D. Perlman, D. A. Smith, F. L. Weisenborn, J. Antibiot. 1965, 18, 128-129; i) W. C. Smith, L. Xiang, B. Shen, Antimicrob. Agents Chemother. 2000, 44, 1809-1817, zit. Lit.

[156] W. F. Fleck, M. Ritzau, S. Heinze, U. Gräfe, J. Basic Microbiol. 1996, 36, 235-238.

[157] a) M. E. Bergy, J. Antibiot. 1968, 21, 454-457; b) H. Hoeksema, W. C. Krueger, J. Antibiot. 1976, 29, 704-709.

[158] S. P. Cole, B. A. M. Rudd, D. A. Hopwood, C. Chang, H. G. Floss, J. Antibiot. 1987, 40, 340-347.

[159] M. E. Bergy, J. Antibiot. 1968, 21, 454-457.

[160] S. Omura, H. Tanaka, Y. Okada, H. Marumo, J. Chem. Soc. Chem. Commun. 1976, 320-321.

[161] H. Imai, K. Suzuki, S. Kadota, M. Iwanami, T. Saito, J. Antibiot. 1989, $42,1186-1188$.

[162] a) S. Omura, H. Tanaka, Y. Koyama, R. Oiwa, M. Katagiri, J. Awaya, T. Nagai, T. Hata, J. Antibiot. 1974, 27, 363-365; b) H. Tanaka, Y. Koyama, J. Awaya, H. Marumo, R. Oiwa, M. Katagiri, T. Nagai, S. Omura, J. Antibiot. 1975, 28, 860-867; c) H. Tanaka, Y. Koyama, T. Nagai, H. Marumo, S. Omura, J. Antibiot. 1975, 28, 868-875.

[163] R. A. Hill, Prog. Chem. Org. Nat. Prod. 1986, 49, $1-78$.

[164] G. K. Poch, J. B. Gloer, J. Nat. Prod. 1989, 52, 257-260.

[165] a) J.-R. Dai, B. K. Carté, P. J. Sidebottom, A. L. S. Yew, S.-B. Ng, Y. Huang, M. S. Butler, J. Nat. Prod. 2001, 64, 125-126; b) siehe Lit. [5].

[166] a) M. Gill, A. Giménez, J. Chem. Soc. Perkin Trans. 11990, 2585-2591; b) C. D. Donner, M. Gill, L. M. Tewierik, Molecules 2004, 9, 498-512.

[167] A. A. Bell, R. D. Stipanovic, J. E. Puhalla, Tetrahedron 1976, $32,1353-1356$.

[168] D. C. Aldridge, A. B. Davies, M. R. Jackson, W. B. Turner, J. Chem. Soc. Perkin Trans. 1 1974, 1540-1541.

[169] J. A. Findlay, D. Kwan, Can. J. Chem. 1973, 51, 1617-1619.

[170] M. Gill, A. F. Smrdel, R. J. Strauch, M. J. Begley, J. Chem. Soc. Perkin Trans. 1 1990, $1583-1592$.

[171] K. D. Beattie, R. Rouf, L. Gander, T. W. May, D. Ratkowsky, C. D. Donner, M. Gill, I. D. Grice, E. Tiralongo, Phytochemistry 2010, 71, $948-955$.

[172] M. Gill, A. Giménez, A. G. Jhingran, A. Qureshi, Phytochemistry 1992, 31, 947-951. 
[173] a) D. M. Ashworth, C. A. Clark, J. A. Robinson, J. Chem. Soc. Perkin Trans. 1 1989, 1461-1467; b) Z. M. Spavold, J. A. Robinson, J. Chem. Soc. Chem. Commun. 1988, 4-6; c) D. M. Ashworth, J. A. Robinson, D. L. Turner, J. Chem. Soc. Perkin Trans. 1 1988, 1719-1727.

[174] a) A. J. Woo, W. R. Strohl, N. D. Priestley, Antimicrob. Agents Chemother. 1999, 1662-1668; b) M. E. Nelson, N. D. Priestley, J. Am. Chem. Soc. 2002, 124, 2894-2902; c) J. E. Cox, N. D. Priestley, J. Am. Chem. Soc. 2005, 127, 7976-7977; d) R. J. Walczak, M. E. Nelson, N. D. Priestley, J. Am. Chem. Soc. 2001 , 123, $10415-10416$.

[175] H.-J. Kwon, W. C. Smith, L. Xiang, B. Shen, J. Am. Chem. Soc. 2001, 123, 3385-3386

[176] S. Kakinuma, H. Ikeda, S. Omura, Tetrahedron 1991, 47, 60596068.

[177] a) T. Taguchi, Y. Ebizuka, D. A. Hopwood, K. Ichinose, J. Am. Chem. Soc. 2001, 123, 11376-11380; b) K. Ichinose, Actinomycetologica 2003, 17, 71-75; c) K. Ichinose, T. Taguchi, Y. Ebizuka, D. A. Hopwood, Actinomycetologica 1998, 12, 99 109

[178] a) T. Taguchi, K. Kunieda, M. Takeda-Shitaka, D. Takaya, N. Kawano, M. R. Kimberley, K. I. Booker-Milburn, G. R. Stephenson, H. Umeyama, Y. Ebizuka, K. Ichinose, Bioorg. Med. Chem. 2004, 12, 5917-5927; b) A. Li, T. Itoh, T. Taguchi, T. Xiang, Y. Ebizuka, K. Ichinose, Bioorg. Med. Chem. 2005, 13, $6856-6863$

[179] a) M. A. Fernández-Moreno, E. Martinez, J. L. Caballero, K. Ichinose, D. A. Hopwood, F. Malpartida, J. Biol. Chem. 1994, 269, 24854-24863; b) K. Ichinose, C. Surti, T. Taguchi, F. Malpartida, K. I. Booker-Milburn, G. R. Stephenson, Y. Ebizuka, D. A. Hopwood, Bioorg. Med. Chem. Lett. 1999, 9, $395-$ 400 ; c) T. Taguchi, K. Itou, Y. Ebizuka, F. Malpartida, D. A. Hopwood, C. M. Surti, K. I. Booker-Milburn, G. R. Stephenson, K. Ichinose, J. Antibiot. 2000, 53, 144-152.

[180] K. Ichinose, T. Taguchi, D. J. Bedford, Y. Ebizuka, D. A. Hopwood, J. Bacteriol. 2001, 183, 3247-3250.

[181] E. Freye, J. V. Levy, Pharmacology and Abuse of Cocaine, Amphetamines, Ecstasy and Related Designer Drugs, Springer, London, 2009.

[182] M. F. Roberts, M. Wink, Alkaloids: Biochemistry Ecology, and Medicinal Applications, Plenum, New York, 1998.

[183] J.-F. Hu, M. T. Hamann, R. Hill, M. Kelly, Alkaloids Chem. Biol. 2003, 60, 207-285, zit. Lit.

[184] a) M. Tsuda, N. Kawasaki, J. Kobayashi, Tetrahedron 1994, 50, 7957-7960; b) K. Kondo, H. Shigemori, Y. Kikuchi, M. Ishibashi, T. Sasaki, J. Kobayashi, J. Org. Chem. 1992, 57, 24802483.

[185] N. Kasanah, K. V. Rao, M. Yousaf, D. E. Wedge, M. T. Hamann, Tetrahedron Lett. 2003, 44, 1291 - 1293.

[186] M. Yousaf, K. A. El Sayed, K. V. Rao, C. W. Lim, J.-F. Hu, M. Kelly, S. G. Franzblau, F. Zhang, O. Peraud, R. T. Hill, M. T. Hamann, Tetrahedron 2002, 58, 7397-7402.

[187] T. Ichiba, J. M. Corgiat, P. J. Scheuer, M. Kelly-Borges, J. Nat. Prod. 1994, 57, 168-170.

[188] M. Tsuda, J. Kobayashi, Heterocycles 1997, 46, 765-794.

[189] K. A. El Sayed, M. Kelly, U. A. K. Kara, K. K. H. Ang, I. Katsuyama, D. C. Dunbar, A. A. Khan, M. T. Hamann, J. Am. Chem. Soc. 2001, 123, 1804-1808.

[190] T. Ichiba, R. Sakai, S. Kohmoto, G. Saucy, T. Higa, Tetrahedron Lett. 1988, 29, 3083-3086.

[191] a) J. Kobayashi, M. Tsuda, N. Kawasaki, K. Matsumoto, T. Adachi, Tetrahedron Lett. 1994, 35, 4383-4386; b) M. Tsuda, K. Inaba, N. Kawasaki, K. Honma, J. Kobayashi, Tetrahedron 1996, 52, 2319-2324.

[192] F. Kong, R. J. Andersen, Tetrahedron 1995, 51, 2895-2906
[193] G. A. Cordell, J. E. Saxton, M. Shamma, G. F. Smith, I. W. Southon, J. Buckingham, Dictionary of Alkaloids, Chapman and Hall, London, 1989.

[194] M. Ishikura, K. Yamada, T. Abe, Nat. Prod. Rep. 2010, 27, $1630-1680$.

[195] a) A. I. Scott, Acc. Chem. Res. 1970, 3, 151-157; b) A. C. Ramos-Valdivia, R. van der Heijden, R. Verpoorte, Nat. Prod. Rep. 1997, 14, 591-603.

[196] a) M. El-Sayed, R. Verpoorte, Phytochem. Rev. 2007, 6, 277 305; b) S. E. O'Connor, J. J. Maresh, Nat. Prod. Rep. 2006, 23, 532 -547; c) P. J. Facchini, V. De Luca, Plant J. 2008, 54, 763 784.

[197] B. Zsadon, P. Kaposi, Tetrahedron Lett. 1970, 11, 4615-4616.

[198] L. A. Anderson, N. G. Bisset, J. D. Phillipson, J. L. Zarucchi, J. Ethnopharmacol. 1985, 14, 187-192.

[199] F. Constabel, S. Rambold, K. B. Chatson, W. G. M. Kurz, J. P. Kutney, Plant Cell Rep. 1981, 1, 3-5.

[200] H. Takayama, M. Kurihara, M. Kitajima, I. M. Said, N. Aimi, Tetrahedron 2000, 56, 3145-3151.

[201] H. Takayama, M. Kurihara, M. Kitajima, I. M. Said, N. Aimi, J. Org. Chem. 1999, 64, 1772-1773.

[202] M. Normatov, S. Y. Yunusov, Khim. Prir. Soedin. 1968, 4, 139.

[203] a) E. M. Stocking, R. M. Williams, Angew. Chem. 2003, 115, 3186-3223; Angew. Chem. Int. Ed. 2003, 42, 3078-3115; b) R. M. Williams, R. J. Cox, Acc. Chem. Res. 2003, 36, $127-$ 139 ; c) J. D. Sunderhaus, D. H. Sherman, R. M. Williams, Isr. J. Chem. 2011, 51, 442-452; d) R. M. Williams, J. Org. Chem. 2011, 76, 4221-4259; e) R. M. Williams, Chem. Pharm. Bull. 2002, 50, 711 -740; f) K. A. Miller, R. M. Williams, Chem. Soc. Rev. 2009, 38, 3160-3174.

[204] J. Qian-Cutrone, K. D. Krampitz, Y. Z. Shu, L. P. Chang, U.S. Patent 6,291,461, 2000.

[205] H. Kato, T. Yoshida, T. Tokue, Y. Nojiri, H. Hirota, T. Ohta, R. M. Williams, S. Tsukamoto, Angew. Chem. 2007, 119, $2304-$ 2306; Angew. Chem. Int. Ed. 2007, 46, 2254-2256.

[206] T. J. Greshock, A. W. Grubbs, P. Jiao, D. T. Wicklow, J. B. Gloer, R. M. Williams, Angew. Chem. 2008, 120, 3629-3633; Angew. Chem. Int. Ed. 2008, 47, 3573-3577.

[207] a) Genomcluster von Aspergillus sp. MF297-2: Y. Ding, J. R. de Wet, J. Cavalcoli, S. Li, T. J. Greshock, K. A. Miller, J. M. Finefield, J. D. Sunderhaus, T. J. McAfoos, S. Tsukamoto, R. M. Williams, D. H. Sherman, J. Am. Chem. Soc. 2010, 132, 1273312740; b) Genomcluster von A. versicolor NRRL 35600: S. Li, J. M. Finefield, S. Tsukamoto, R. M. Williams, D. H. Sherman, unveröffentlichte Ergebnisse.

[208] a) S. Tsukamoto, H. Kato, T. J. Greshock, H. Hirota, T. Ohta, R. M. Williams, J. Am. Chem. Soc. 2009, 131, 3834-3835; b) J. M. Finefield, T. J. Greshock, D. H. Sherman, S. Tsukamoto, R. M. Williams, Tetrahedron Lett. 2011, 52, 1987-1989; c) J. M. Finefield, H. Kato, T. J. Greshock, D. H. Sherman, S. Tsukamoto, R. M. Williams, Org. Lett. 2011, 13, 3802-3805; d) J. M. Finefield, D. H. Sherman, S. Tsukamoto, R. M. Williams, J. Org. Chem. 2011, 76, 5954-5958; e) H. Kato, Y. Nakamura, J. M. Finefield, H. Umaoka, T. Nakahara, R. M. Williams, Tetrahedron Lett. 2011, 52, 6923-6926.

[209] T. J. McAfoos, S. Li, S. Tsukamoto, D. H. Sherman, R. M. Williams, Heterocycles 2010, 82, 461-472.

[210] S. Tsukamoto, T. Kawabata, H. Kato, T. J. Greshock, H. Hirota, T. Ohta, R. M. Williams, Org. Lett. 2009, 11, 1297-1300.

[211] a) N. R. Norcross, J. P. Melbardis, M. F. Solera, M. A. Sephton, C. Kilner, L. N. Zakharov, P. C. Astles, S. L. Warriner, P. R. Blakemore, J. Org. Chem. 2008, 73, 7939-3951; b) B.-E. Van Wyk, G. H. Verdoorn, Plant Syst. Evol. 1995, 198, $267-$ 274; c) M. Wink, C. Meibner, L. Witte, Phytochemistry 1995, 38, $139-153$. 
[212] D. Cook, S. T. Lee, D. R. Gardner, J. A. Pfister, K. D. Welch, B. T. Green, T. Z. Davis, K. E. Panter, J. Agric. Food Chem. 2009, $57,1646-1653$.

[213] W. M. Golebiewski, I. D. Spenser, J. Am. Chem. Soc. 1976, 98 , $6726-6728$.

[214] a) M. F. Grundon, Nat. Prod. Rep. 1984, 1, 349-353; b) J. A. Lamberton, T. C. Morton, H. Suares, Aust. J. Chem. 1982, 35, $2577-2582$.

[215] J. P. Michael, Nat. Prod. Rep. 1994, 11, 639-657.

[216] J. P. Michael, Nat. Prod. Rep. 1997, 14, 619-636.

[217] J. P. Michael, Nat. Prod. Rep. 2002, 19, 719-741.

[218] J. P. Michael, Nat. Prod. Rep. 2004, 21, 625-649.

[219] D. W. Van Wyk, R. Greinwald, L. Witte, Biochem. Syst. Ecol. 1995, 23, $533-537$.

[220] L. Marion, S. W. Fenton, J. Org. Chem. 1948, 13, 780-781.

[221] M. Carmack, B. Douglas, E. W. Martin, H. Suss, J. Am. Chem. Soc. 1955, 77, 4435.

[222] a) M. Wink, T. Hartmann, Plant Physiol. 1982, 70, 74-77, zit. Lit.; b) M. Wink, Planta Med. 1987, 53, 509-514, zit. Lit.

[223] a) W. M. Golebiewski, I. D. Spenser, Can. J. Chem. 1985, 63, 2707-2718; b) I. D. Spenser, Pure Appl. Chem. 1985, 57, 453 470; c) W. M. Golebiewski, I. D. Spenser, Can. J. Chem. 1988 , 66, 1734-1748; d) A. M. Fraser, D. J. Robins, J. Chem. Soc. Chem. Commun. 1986, 545-547; e) A. M. Fraser, D. J. Robins, J. Chem. Soc. Perkin Trans. 1 1987, 105-109.

[224] a) J. Vetter, Food Chem. Toxicol. 2004, 42, 1373-1382; b) T. Reynolds, Phytochemistry 2005, 66, 1399-1406.

[225] a) S. T. Lee, K. E. Panter, R. J. Molyneux, C.-W. T. Chang, D. R. Gardern, J. A. Pfister in Poisonous Plants: Global Research and Solutions (Hrsg.:K. E. Panter, T. L. Wierenga, J. A. Pfister), CABI Pub., Wallingford, Großbritannien, 2007, S. 469; b) S. T. Lee, R. J. Molyneux, K. E. Panter, C.-W. T. Chang, D. R. Gardner, J. A. Pfister, M. Garrossian, J. Nat. Prod. 2005, $68,681-685$; c) S. T. Lee, B. T. Green, K. D. Welch, J. A. Pfister, K. E. Panter, Chem. Res. Toxicol. 2008, 21, 2061-2064; d) S. T. Lee, K. Wildeboer, K. E. Panter, W. R. Kem, D. R. Gardner, R. J. Molyneux, C.-W. T. Chang, F. Soti, J. A. Pfister, Neurotoxicol. Teratol. 2006, 28, 220-228.

[226] a) R. F. Keeler, J. L. Shupe, M. W. Crowe, A. Olson, L. D. Balls, Am. J. Vet. Res. 1981, 42, 1231-1234; b) R. F. Keeler, M. W. Crowe, E. A. Lambert, Teratology 1984, 30, 61-69; c) R. F. Keeler, M. W. Crowe, Cornell Vet. 1984, 74, 50-59; d) K. E.
Panter, T. D. Bunch, R. F. Keeler, D. V. Sisson, R. J. Callan, J. Toxicol. Clin. Toxicol. 1990, 28, 69-83.

[227] a) K. Mothes, H. R. Schütte, Angew. Chem. 1963, 75, 265-281; Angew. Chem. Int. Ed. Engl. 1963, 2, 341-357; b) E. Leete, Annu. Rev. Plant Physiol. 1967, 18, 179-196; c) E. Leete, J. Am. Chem. Soc. 1964, 86, 2509-2513; d) E. Leete, Acc. Chem. Res. 1971, 4, 100-107; e) W. L. Alworth, H. Rapoport, Arch. Biochem. Biophys. 1965, 112, 45-53; f) M. L. Solt, R. F. Dawson, D. R. Christman, Plant Physiol. 1960, 35, 887-894; g) E. Leete, E. G. Gros, T. J. Gilbertson, J. Am. Chem. Soc. 1964, 86, 3907-3908; h) E. Leete, J. Nat. Prod. 1982, 45, $197-$ 205 ; i) K. D. DeBoer, J. C. Lye, C. D. Aitken, A. K.-K. Su, J. D. Hamill, Plant Mol. Biol. 2009, 69, 299-312; j) A. Katoh, H. Ohki, K. Inai, T. Hashimoto, Plant Biotechnol. 2005, 22, 389392.

[228] I. Murakoshi, E. Kidoguchi, M. Nakamura, J. Haginiwa, S. Ohmiya, K. Higashiyama, H. Otomasu, Phytochemistry 1981, 20, $1725-1730$.

[229] S. Leclercq, S. Charles, D. Daloze, J.-C. Braekman, S. Aron, J. M. Pasteels, J. Chem. Ecol. 2001, 27, 945-952.

[230] R. Lukes, A. A. Arojan, J. Kovar, K. Blaha, Collect. Czech. Chem. Commun. 1962, 27, 751-756.

[231] a) A. Bonamore, M. Barba, B. Botta, A. Boffi, A. Macone, Molecules 2010, 15, 2070-2078; b) N. Samanani, P. J. Facchini, Planta 2001, 213, 898-906.

[232] J. Ziegler, P. J. Facchini, R. Geibler, J. Schmidt, C. Ammer, R. Kramell, S. Voigtländer, A. Gesell, S. Pienkny, W. Brandt, Phytochemistry 2009, 70, 1696-1707.

[233] I. Desgagné-Penix, P. J. Facchini in Plant Metabolism and Biotechnology (Hrsg.: H. Ashihara, A. Crozier, A. Komamine), Wiley, Chichester, 2011, S. 241.

[234] L.-B. Zhang, G.-X. Rao, Biochem. Syst. Ecol. 2009, 37, 622625.

[235] a) W. De-Eknamkul, M. H. Zenk, Phytochemistry 1992, 31, 813-821; b) K. Hirata, C. Poeaknapo, J. Schmidt, M. H. Zenk, Phytochemistry 2004, 65, 1039-1046.

[236] W. Bauer, M. H. Zenk, Tetrahedron Lett. 1991, 32, 487-490.

[237] L. M. Mascavage, S. Jasmin, P. E. Sonnet, M. Wilson, D. R. Dalton in Ullmann's Encyclopedia of Industrial Chemistry, Wiley-VCH, Weinheim, 2011.

[238] a) J. T. Bridgham, S. M. Carroll, J. W. Thornton, Science 2006, 312, 97-101; b) A. M. Dean, J. W. Thornton, Nat. Rev. Genet. 2007, 8, 675-688. 